Cochrane Database of Systematic Reviews

\title{
Sound therapy (using amplification devices and/or sound generators) for tinnitus (Review)
}

Sereda M, Xia J, El Refaie A, Hall DA, Hoare DJ

Sereda M, Xia J, El Refaie A, Hall DA, Hoare DJ.

Sound therapy (using amplification devices and/or sound generators) for tinnitus.

Cochrane Database of Systematic Reviews 2018, Issue 12. Art. No.: CD013094.

DOI: 10.1002/14651858.CD013094.pub2.

www.cochranelibrary.com 
TABLE OF CONTENTS

HEADER 1

ABSTRACT

PLAIN LANGUAGE SUMMARY

SUMMARY OF FINDINGS

BACKGROUND

OBJECTIVES

METHODS

RESULTS

Figure 1.

Figure 2.

Figure 3.

Figure 4.

DISCUSSION

AUTHORS' CONCLUSIONS

ACKNOWLEDGEMENTS

REFERENCES

CHARACTERISTICS OF STUDIES

DATA AND ANALYSES

Analysis 1.1. Comparison 1 Hearing aid only compared to sound generator only for tinnitus, Outcome 1 Tinnitus symptom severity at 3 months.

Analysis 1.2. Comparison 1 Hearing aid only compared to sound generator only for tinnitus, Outcome 2 Tinnitus symptom severity at 6 months.

Analysis 1.3. Comparison 1 Hearing aid only compared to sound generator only for tinnitus, Outcome 3 Tinnitus symptom severity at 12 months.

Analysis 2.1. Comparison 2 Combination hearing aids compared to hearing aids for tinnitus, Outcome 1 Tinnitus symptom severity at 3 to 5 months.

ADDITIONAL TABLES

APPENDICES

CONTRIBUTIONS OF AUTHORS

DECLARATIONS OF INTEREST

SOURCES OF SUPPORT

DIFFERENCES BETWEEN PROTOCOL AND REVIEW

INDEX TERMS 
[Intervention Review]

\section{Sound therapy (using amplification devices and/or sound generators) for tinnitus}

Magdalena Sereda ${ }^{1}$, Jun Xia², Amr El Refaie ${ }^{3}$, Deborah A Hall ${ }^{1}$, Derek J Hoare ${ }^{1}$

1NIHR Nottingham Biomedical Research Centre, Division of Clinical Neuroscience, School of Medicine, University of Nottingham, Nottingham, UK. ${ }^{2}$ Cochrane Schizophrenia Group, The University of Nottingham, Nottingham, UK. ${ }^{3}$ Department of Speech and Hearing Sciences, University College Cork, Cork, Ireland

Contact address: Magdalena Sereda, NIHR Nottingham Biomedical Research Centre, Division of Clinical Neuroscience, School of Medicine, University of Nottingham, Ropewalk House, 113 The Ropewalk, Nottingham, NG1 5DU, UK. magdalena.sereda@nottingham.ac.uk.

Editorial group: Cochrane ENT Group.

Publication status and date: New, published in Issue 12, 2018.

Citation: Sereda M, Xia J, El Refaie A, Hall DA, Hoare DJ. Sound therapy (using amplification devices and/or sound generators) for tinnitus. Cochrane Database of Systematic Reviews 2018, Issue 12. Art. No.: CD013094. DOI: 10.1002/14651858.CD013094.pub2.

Copyright ( 2018 The Cochrane Collaboration. Published by John Wiley \& Sons, Ltd.

\section{A B S T R A C T}

\section{Background}

Tinnitus affects $10 \%$ to $15 \%$ of the adult population, with about $20 \%$ of these experiencing symptoms that negatively affect quality of life. In England alone there are an estimated $3 / 4$ million general practice consultations every year where the primary complaint is tinnitus, equating to a major burden on healthcare services. Clinical management strategies include education and advice, relaxation therapy, tinnitus retraining therapy (TRT), cognitive behavioural therapy (CBT), sound enrichment using ear-level sound generators or hearing aids, and drug therapies to manage co-morbid symptoms such as insomnia, anxiety or depression. Hearing aids, sound generators and combination devices (amplification and sound generation within one device) are a component of many tinnitus management programmes and together with information and advice are a first line of management in audiology departments for someone who has tinnitus.

\section{Objectives}

To assess the effects of sound therapy (using amplification devices and/or sound generators) for tinnitus in adults.

\section{Search methods}

The Cochrane ENT Information Specialist searched the Cochrane ENT Register; Central Register of Controlled Trials (CENTRAL, via the Cochrane Register of Studies); Ovid MEDLINE; Ovid Embase; CINAHL; Web of Science; ClinicalTrials.gov; ICTRP and additional sources for published and unpublished trials. The date of the search was 23 July 2018.

\section{Selection criteria}

Randomised controlled trials (RCTs) recruiting adults with acute or chronic subjective idiopathic tinnitus. We included studies where the intervention involved hearing aids, sound generators or combination hearing aids and compared them to waiting list control, placebo or education/information only with no device. We also included studies comparing hearing aids to sound generators, combination hearing aids to hearing aids, and combination hearing aids to sound generators.

\section{Data collection and analysis}

We used the standard methodological procedures expected by Cochrane. Our primary outcomes were tinnitus symptom severity as measured as a global score on multi-item tinnitus questionnaire and significant adverse effects as indicated by an increase in self-reported tinnitus loudness. Our secondary outcomes were depressive symptoms, symptoms of generalised anxiety, health-related quality of life 
and adverse effects associated with wearing the device such as pain, discomfort, tenderness or skin irritation, or ear infections. We used GRADE to assess the quality of evidence for each outcome; this is indicated in italics.

\section{Main results}

This review included eight studies (with a total of 590 participants). Seven studies investigated the effects of hearing aids, four combination hearing aids and three sound generators. Seven studies were parallel-group RCTs and one had a cross-over design. In general, risk of bias was unclear due to lack of detail about sequence generation and allocation concealment. There was also little or no use of blinding.

No data for our outcomes were available for any of our three main comparisons (comparing hearing aids, sound generators and combination devices with a waiting list control group, placebo or education/information only). Data for our additional comparisons (comparing these devices with each other) were also few, with limited potential for data pooling.

\section{Hearing aid only versus sound generator device only}

One study compared patients fitted with sound generators versus those fitted with hearing aids and found no difference between them in their effects on our primary outcome, tinnitus symptom severity measured with the Tinnitus Handicap Inventory (THI) at 3, 6 or 12 months (low-quality evidence). The use of both types of device was associated with a clinically significant reduction in tinnitus symptom severity.

\section{Combination hearing aid versus hearing aid only}

Three studies compared combination hearing aids with hearing aids and measured tinnitus symptom severity using the THI or Tinnitus Functional Index. When we pooled the data we found no difference between them (standardised mean difference -0.15 , 95\% confidence interval -0.52 to 0.22 ; three studies; 114 participants) (low-quality evidence). The use of both types of device was again associated with a clinically significant reduction in tinnitus symptom severity.

Adverse effects were not assessed in any of the included studies.

None of the studies measured the secondary outcomes of depressive symptoms or depression, anxiety symptoms or generalised anxiety, or health-related quality of life as measured by a validated instrument, nor the newly developed core outcomes tinnitus intrusiveness, ability to ignore, concentration, quality of sleep and sense of control.

\section{Authors' conclusions}

There is no evidence to support the superiority of sound therapy for tinnitus over waiting list control, placebo or education/information with no device. There is insufficient evidence to support the superiority or inferiority of any of the sound therapy options (hearing aid, sound generator or combination hearing aid) over each other. The quality of evidence for the reported outcomes, assessed using GRADE, was low. Using a combination device, hearing aid or sound generator might result in little or no difference in tinnitus symptom severity.

Future research into the effectiveness of sound therapy in patients with tinnitus should use rigorous methodology. Randomisation and blinding should be of the highest quality, given the subjective nature of tinnitus and the strong likelihood of a placebo response. The CONSORT statement should be used in the design and reporting of future studies. We also recommend the use of validated, patient-centred outcome measures for research in the field of tinnitus.

\section{PLAIN LANGUAGE SUMMARY}

\section{Sound therapy (using amplification devices or sound generators) for tinnitus}

\section{Review question}

Is sound therapy (using amplification devices, sound generators or both) effective for tinnitus in adults?

\section{Background}

Tinnitus is the awareness of a sound in the ear or head without any outside source. It affects $10 \%$ to $15 \%$ of the adult population. About $20 \%$ of people with tinnitus experience symptoms that negatively affect their quality of life including sleep disturbances, difficulties with hearing and concentration, social isolation, anxiety, depression, irritation or stress. Tinnitus can be managed through education and advice, relaxation therapy, psychological therapy, or devices that improve hearing or generate sound such as sound generators or hearing aids. Sometimes drugs are prescribed to manage problems associated with tinnitus such as sleep problems, anxiety or depression. The purpose of this review is to evaluate the evidence from high-quality clinical trials to work out the effects of sound therapy (hearing aids, sound generators and combination hearing aids) on adults with tinnitus. We particularly wanted to look at the effects of sound therapy on tinnitus severity and any side effects.

\section{Study characteristics}


Our review identified eight randomised controlled trials with 590 participants in total. Seven studies looked at the effects of hearing aids, four combination hearing aids and three sound generators. Seven studies allocated participants into parallel groups and in one study participants tried each intervention in a random order. The outcomes that we looked for were severity of tinnitus symptoms, depression, anxiety, quality of life and side effects. In general, the risk of bias in the studies was unclear. There was also little or no use of blinding.

\section{Key results}

We did not find any data for our outcomes for any of our three main comparisons (comparing hearing aids, sound generators and combination devices with a waiting list control group, placebo or education/information only). There were also few data for our additional comparisons (comparing these devices with each other) and it was difficult to pool (combine) the data.

\section{Hearing aid only versus sound generator device only}

One study compared patients fitted with sound generators with those fitted with hearing aids and found no difference between them in their effects on our primary outcome, tinnitus symptom severity, at 3, 6 or 12 months. The use of both types of device was associated with a clinically significant reduction in tinnitus symptom severity.

\section{Combination hearing aid versus hearing aid only}

Three studies compared combination hearing aids/sound generators with hearing aids alone and measured tinnitus symptom severity. When we combined the data for tinnitus symptom severity we found no difference between them. The use of both types of device was again associated with a clinically significant reduction in tinnitus symptom severity.

Adverse effects were not assessed in any of the included studies.

None of the studies measured depressive symptoms or depression, anxiety symptoms or generalised anxiety, or other important outcomes of interest in this review.

\section{Quality of evidence}

Where outcomes that we were interested in for this review were reported, we assessed the quality of the evidence available as low. Using a hearing aid, sound generator or combination device might result in little or no difference in tinnitus symptom severity. 


\begin{tabular}{|c|c|c|c|c|c|c|c|}
\hline \multirow{12}{*}{ 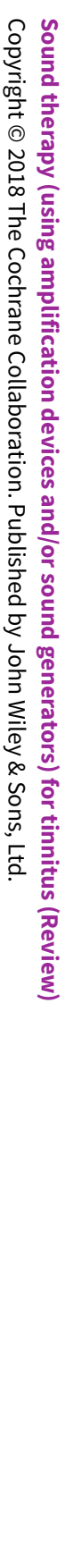 } & \multicolumn{7}{|c|}{$\begin{array}{l}\text { S U M M A R Y O F F I N D I N G S } \\
\text { Summary of findings for the main comparison. Hearing aid compared to sound generator for tinnitus in adults }\end{array}$} \\
\hline & \multicolumn{7}{|c|}{ Hearing aid compared to sound generator for tinnitus in adults } \\
\hline & \multicolumn{7}{|l|}{$\begin{array}{l}\text { Patient or population: adults with tinnitus } \\
\text { Setting: audiology } \\
\text { Intervention: amplification only } \\
\text { Comparison: sound generator }\end{array}$} \\
\hline & \multirow[t]{2}{*}{ Outcomes } & \multicolumn{2}{|c|}{$\begin{array}{l}\text { Anticipated absolute effects ( } 95 \% \\
\mathrm{Cl} \text { ) }\end{array}$} & \multirow[t]{2}{*}{$\begin{array}{l}\text { Difference } \\
(95 \% \mathrm{CI})\end{array}$} & \multirow{2}{*}{$\begin{array}{l}\text { № of partici- } \\
\text { pants } \\
\text { (studies) }\end{array}$} & \multirow{2}{*}{$\begin{array}{l}\text { Certainty of } \\
\text { the evidence } \\
\text { (GRADE) }\end{array}$} & \multirow[t]{2}{*}{ Comments } \\
\hline & & With hearing aid & $\begin{array}{l}\text { With sound gen- } \\
\text { erator }\end{array}$ & & & & \\
\hline & $\begin{array}{l}\text { Tinnitus symptom severity } \\
\text { Assessed with: Tinnitus Handicap Inventory } \\
\text { Scale from: } 0 \text { to } 100 \\
\text { Follow-up: mean } 3 \text { months }\end{array}$ & $\begin{array}{l}\text { The mean score } \\
\text { for tinnitus symp- } \\
\text { tom severity was } \\
-18.9 \text { points }\end{array}$ & $\begin{array}{l}\text { The mean score } \\
\text { for tinnitus symp- } \\
\text { tom severity was } \\
-20.2 \text { points }\end{array}$ & $\begin{array}{l}\text { MD } 1.30(-5.72 \\
\text { to } 8.32)\end{array}$ & $\begin{array}{l}91 \\
(1 \mathrm{RCT})\end{array}$ & $\begin{array}{l}\oplus \oplus \ominus \ominus \\
\mathbf{L O W} \mathbf{1 , 2}\end{array}$ & - \\
\hline & $\begin{array}{l}\text { Tinnitus symptom severity } \\
\text { Assessed with: Tinnitus Handicap Inventory } \\
\text { Scale from: } 0 \text { to } 100 \\
\text { Follow-up: mean } 6 \text { months }\end{array}$ & $\begin{array}{l}\text { The mean score } \\
\text { for tinnitus symp- } \\
\text { tom severity was } \\
-25.6 \text { points }\end{array}$ & $\begin{array}{l}\text { The mean score } \\
\text { for tinnitus symp- } \\
\text { tom severity was } \\
-23.8 \text { points }\end{array}$ & $\begin{array}{l}\text { MD -1.80 }(-8.82 \\
\text { to } 5.22)\end{array}$ & $\begin{array}{l}91 \\
(1 \mathrm{RCT})\end{array}$ & $\begin{array}{l}\oplus \oplus \odot \odot \\
\mathbf{L O W} \mathbf{1 , 2}\end{array}$ & - \\
\hline & $\begin{array}{l}\text { Tinnitus symptom severity } \\
\text { Assessed with: Tinnitus Handicap Inventory } \\
\text { Scale from: } 0 \text { to } 100 \\
\text { Follow-up: mean } 12 \text { months }\end{array}$ & $\begin{array}{l}\text { The mean score } \\
\text { for tinnitus symp- } \\
\text { tom severity was } \\
-30.1 \text { points }\end{array}$ & $\begin{array}{l}\text { The mean score } \\
\text { for tinnitus symp- } \\
\text { tom severity was } \\
-29.2 \text { points }\end{array}$ & $\begin{array}{l}\text { MD }-\mathbf{0 . 9 0}(-7.92 \\
\text { to } 6.12)\end{array}$ & $\begin{array}{l}91 \\
(1 \mathrm{RCT})\end{array}$ & $\begin{array}{l}\oplus \oplus \oplus \ominus \\
\text { LOW'1,2 }\end{array}$ & - \\
\hline & $\begin{array}{l}\text { Significant adverse effect: increase in self-reported } \\
\text { tinnitus loudness }\end{array}$ & Not measured & & & & & \\
\hline & $\begin{array}{l}\text { Depressive symptoms or depression as measured } \\
\text { by a validated instrument }\end{array}$ & Not reported & & & & & \\
\hline & $\begin{array}{l}\text { Anxiety symptoms or generalised anxiety as mea- } \\
\text { sured by a validated instrument }\end{array}$ & Not reported & & & & & \\
\hline & $\begin{array}{l}\text { Health-related quality of life as measured by a } \\
\text { validated instrument }\end{array}$ & Not measured & & & & & \\
\hline
\end{tabular}

Setting: audiology 


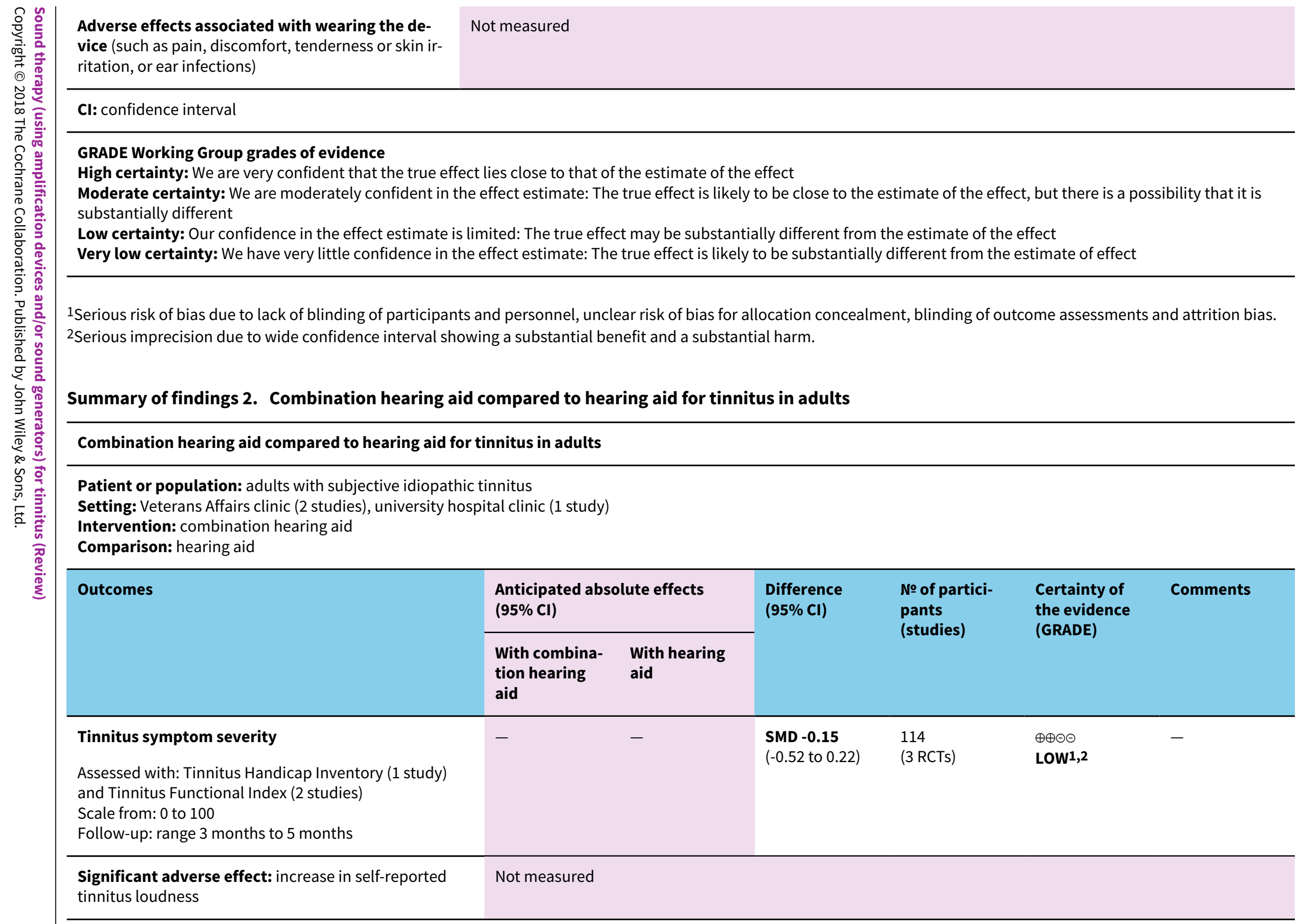




\begin{tabular}{|c|c|c|c|}
\hline 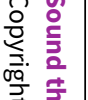 & $\begin{array}{l}\text { Depressive symptoms or depression as measured by } \\
\text { a validated instrument }\end{array}$ & Not measured & 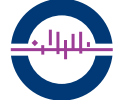 \\
\hline 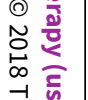 & $\begin{array}{l}\text { Anxiety symptoms or generalised anxiety as mea- } \\
\text { sured by a validated instrument }\end{array}$ & Not measured & ㄷํำ \\
\hline 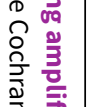 & $\begin{array}{l}\text { Health-related quality of life as measured by a vali- } \\
\text { dated instrument }\end{array}$ & Not measured & $<\frac{\bar{D}}{\mathrm{D}}$ \\
\hline 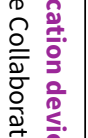 & $\begin{array}{l}\text { Adverse effects associated with wearing the device } \\
\text { (such as pain, discomfort, tenderness or skin irritation, } \\
\text { or ear infections) }\end{array}$ & Not measured & 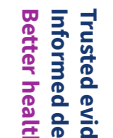 \\
\hline 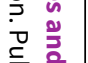 & Cl: confidence interval; SMD: standardised mean differe & & \\
\hline 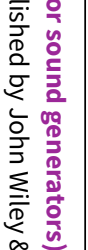 & $\begin{array}{l}\text { GRADE Working Group grades of evidence } \\
\text { High certainty: We are very confident that the true effec } \\
\text { Moderate certainty: We are moderately confident in the } \\
\text { substantially different } \\
\text { Low certainty: Our confidence in the effect estimate is li } \\
\text { Very low certainty: We have very little confidence in the }\end{array}$ & $\begin{array}{l}\text { ies close to that of the estimate of the effect } \\
\text { ffect estimate: The true effect is likely to be close to the estimate of the effect, but there is a possibility that it is } \\
\text { ited: The true effect may be substantially different from the estimate of the effect } \\
\text { ffect estimate: The true effect is likely to be substantially different from the estimate of effect }\end{array}$ & \\
\hline 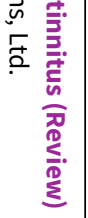 & $\begin{array}{l}\text { 1Serious risk of bias due to lack of blinding of participants, } \\
2 \text { Serious imprecision due to wide confidence interval shon }\end{array}$ & $\begin{array}{l}\text { ersonnel and outcome assessments as well as selection bias. } \\
\text { g a small benefit and a moderate harm. }\end{array}$ & \\
\hline
\end{tabular}




\section{B A C K G R O U N D}

This new review supersedes two earlier Cochrane Reviews on sound therapy (masking) and on amplification with hearing aids for tinnitus that were first published in the Cochrane Library in Issue 12, 2010 and updated in 2012 (Hobson 2012) and in Issue 1, 2014 (Hoare 2014), respectively. The following paragraphs and Description of the condition are based on the latter Cochrane Review 'Amplification with hearing aids for patients with tinnitus and co-existing hearing loss' and are reproduced with permission (Hoare 2014).

Tinnitus is defined as the perception of sound in the absence of an external source (Jastreboff 2004). It is typically described by those who experience it as a ringing, hissing, buzzing or whooshing sound and is thought to result from abnormal neural activity at some point or points in the auditory pathway, which is erroneously interpreted by the brain as sound. Tinnitus can be either objective or subjective. Objective tinnitus refers to the perception of sound that can be also heard by the examiner and is usually due to turbulent blood flow or muscular contraction (Roberts 2010). Most commonly, however, tinnitus is subjective; the sound is only heard by the person experiencing it and no source of the sound is identified (Jastreboff 1988).

Tinnitus affects between $5 \%$ and $43 \%$ of the general population and prevalence increases with age (McCormack 2016). It can be experienced acutely, recovering spontaneously within minutes to weeks, but is considered chronic and unlikely to resolve spontaneously when experienced for more than three months (Gallus 2015; Hall 2011).

For many people tinnitus is persistent and troublesome, and has disabling effects such as insomnia, difficulty concentrating, difficulties in communication and social interaction, and negative emotional responses such as anxiety and depression (Hall 2018). In approximately $90 \%$ of cases, chronic tinnitus is co-morbid with some degree of measurable hearing loss, which may confound these disabling effects (Fowler 1944; Sanchez 2002). Nevertheless, the association between hearing loss and tinnitus is not simple or straightforward; not all people with hearing loss experience tinnitus, and conversely some people with clinically normal hearing have tinnitus (Baguley 2013). It has been reported that $40 \%$ of patients are unable to identify what health condition is associated with their tinnitus onset, i.e. the tinnitus is idiopathic (Henry 2005).

An important implication in clinical research is that outcome measures need to distinguish benefits specific to improved hearing from those specific to improvement in the psychological aspects of tinnitus.

\section{Description of the condition}

\section{Diagnosis and clinical management of tinnitus}

There is no standard procedure for the diagnosis or management of tinnitus. Practice guidelines and the approaches described in studies of usual clinical practice typically reflect differences between the clinical specialisms of the authors or differences in the clinical specialisms charged with meeting tinnitus patients' needs (medical, audiology/hearing therapy, clinical psychology, psychiatry), or the available resources of a particular country or region (access to clinicians or devices, for example) (Biesinger 2010; Cima 2012; Department of Health 2009; Hall 2011; Henry 2008;
Hoare 2011). Common across all these documents, however, is the use or recommendation of written questionnaires to assess tinnitus and its impact on patients and their families by measuring tinnitus symptom severity (e.g. impact of tinnitus on quality of life, activities of daily living or sleep), and a judgement about patients who are experiencing a degree of psychological distress (depression or anxiety). Assessment of the perceptual characteristics of tinnitus (pitch, loudness, minimum masking level) and residual inhibition are also recommended (Cima 2018). Although these measures do not correlate well with tinnitus symptom severity (Hiller 2006), they can prove useful in patient counselling (Henry 2004), as a baseline before start of treatment (El Refaie 2004), or by demonstrating stability of the tinnitus percept over time (Department of Health 2009).

Clinical management strategies include education and advice, relaxation therapy, tinnitus retraining therapy (TRT), cognitive behavioural therapy (CBT), sound enrichment using ear-level sound generators or hearing aids, and drug therapies to manage co-morbid symptoms such as insomnia, anxiety or depression (for example, Department of Health 2009; Tunkel 2014). As yet, no drug has been approved for tinnitus by a regulatory body (e.g. the European Medicines Agency or US Food and Drug Administration).

\section{Pathophysiology}

Most people with chronic tinnitus have some degree of measurable hearing loss (Ratnayake 2009), and the prevalence of tinnitus increases with greater hearing loss (Han 2009; Martines 2010). The varying theories of tinnitus generation involve changes in either function or activity of the peripheral (cochlea and auditory nerve) or central auditory nervous systems (Henry 2005). Theories involving the peripheral systems include the discordant damage theory, which predicts that the loss of outer hair cell function, where inner hair cell function is left intact, leads to a release from inhibition of inner hair cells and aberrant activity (typically hyperactivity) in the auditory nerve (Jastreboff 1990). Such aberrant auditory nerve activity can also have a biochemical basis, resulting from excitotoxicity or stress-induced enhancement of inner hair cell glutamate release with upregulation of $\mathrm{N}$-methyl-D-aspartate (NMDA) receptors (Guitton 2003; Sahley 2001).

In the central auditory system, structures implicated as possible sites of tinnitus generation include the dorsal cochlear nucleus (Middleton 2011; Pilati 2012), the inferior colliculus (Dong 2010; Mulders 2010), and the auditory and non-auditory cortex (discussed further below). There is a strong rationale that tinnitus is a direct consequence of maladaptive neuroplastic responses to hearing loss (Moller 2000; Muhlnickel 1998). This process is triggered by sensory deafferentation and a release from lateral inhibition in the central auditory system allowing irregular spontaneous hyperactivity within the central neuronal networks involved in sound processing (Eggermont 2004; Rauschecker 1999; Seki 2003). As a consequence of this hyperactivity, a further physiological change noted in tinnitus patients is increased spontaneous synchronous activity occurring at the subcortical and cortical level, measurable using electroencephalography (EEG) or magnetoencephalography (MEG) (Dietrich 2001; Tass 2012; Weisz 2005). Another physiological change thought to be involved in tinnitus generation is a process of functional reorganisation, which amounts to a change in the response properties of neurons within the primary auditory cortex to external sounds. This effect is well demonstrated physiologically in animal models of hearing loss 
(Engineer 2011; Norena 2005). Evidence in humans, however, is limited to behavioural evidence of cortical reorganisation after hearing loss, demonstrating improved frequency discrimination ability at the audiometric edge (Kluk 2006; McDermott 1998; Moore 2009; Thai-Van 2002; Thai-Van 2003), although Buss 1998 did not find this effect. For comprehensive reviews of these physiological models, see Adjamian 2009 and Norena 2011.

It is also proposed that spontaneous hyperactivity could cause an increase in sensitivity or 'gain' at the level of the cortex, whereby neural sensitivity adapts to the reduced sensory inputs, in effect stabilising mean firing and neural coding efficiency (Norena 2011; Schaette 2006; Schaette 2011). Such adaptive changes would be achieved at the cost of amplifying 'neural noise' due to the overall increase in sensitivity, ultimately resulting in the generation of tinnitus.

Increasingly, non-auditory areas of the brain, particularly areas associated with emotional processing, are also implicated in bothersome tinnitus (Rauschecker 2010; Vanneste 2012). Vanneste 2012 describes tinnitus as "an emergent property of multiple parallel dynamically changing and partially overlapping subnetworks", implicating the involvement of many structures of the brain more associated with memory and emotional processing in tinnitus generation. However, identification of the structural components of individual neural networks responsible for either tinnitus generation or tinnitus intrusiveness, which are independent of those for hearing loss, remains open to future research (Melcher 2013). One further complication in understanding the pathophysiology of tinnitus is that not all people with hearing loss have tinnitus and not all people with tinnitus have a clinically significant and measurable hearing loss. Other variables, such as the profile of a person's hearing loss, may account for differences in their tinnitus report. For example, Konig 2006 found that the maximum slope within audiograms was higher in people with tinnitus than in people with hearing loss who do not have tinnitus, despite the 'non-tinnitus' group having the greater mean hearing loss. This suggests that a contrast in sensory inputs between regions of normal and elevated threshold may be more likely to result in tinnitus. However, this finding is not consistent across the literature (Sereda 2011; Sereda 2015a).

\section{Description of the intervention}

\section{Amplification devices (hearing aids)}

The following description of hearing aids is taken from the Cochrane Review 'Amplification with hearing aids for patients with tinnitus and co-existing hearing loss' and reproduced with permission Hoare 2014.

The standard function of a hearing aid is to amplify and modulate sound, primarily for the purpose of making sound more accessible and aiding communication. Using hearing aids in tinnitus management has been proposed as a useful strategy since the 1940s (Saltzman 1947), although benefit reportedly varies and there is no clear consensus on when a person would or would not benefit from amplification (Henry 2005; Hoare 2012). Beck 2011 proposes that hearing aid fittings for people with very mild up to moderate sensorineural hearing loss (who might not ordinarily look for or be prescribed a hearing aid) can lead to significant improvements in tinnitus. Currently, hearing aids, supplemented with education and advice, form a common intervention for someone who has tinnitus and an aidable hearing loss (Hoare 2012; Sereda 2015). This combination of hearing aid provision with education and advice might be considered a complex intervention with interdependent components (Shepperd 2009).

There are many options for hearing aid fitting that complicate their use in tinnitus. For example, Del Bo 2007 suggests that the best clinical result for someone with tinnitus requires binaural amplification. Trotter 2008, however, in describing a 25-year experience of hearing aids in tinnitus therapy found no difference in tinnitus improvement between unilaterally and bilaterally aided patients.

For other aspects of hearing aid fitting there appears greater consensus, such as the value of using open-fitting aids (if acoustically suitable), which allow natural environmental sound to enter the ear, as well as amplifying those sounds, thus improving perceived sound quality (Del Bo 2007; Forti 2010).

The bandwidth amplified by the hearing aid may also be important to its effect on tinnitus. In a study by Moffat 2009 the tinnitus percept was not at all affected in a group receiving high-bandwidth amplification, which had less gain at frequencies below $1 \mathrm{kHz}$ and more gain at frequencies above $1 \mathrm{kHz}$ than conventional amplification. In a group receiving conventional amplification, however, there was a significant reduction of the contribution of all low-frequency components of the measured tinnitus spectrum to matched tinnitus. This suggests an interaction between the perceptual characteristics of tinnitus and the pattern of sensory inputs in this group.

Finally, hearing aid prescription might also be combined with other forms of therapy such as formal counselling, albeit with mixed evidence for the efficacy of such combinations of therapies (Hiller 2005; Searchfield 2010).

\section{Sound generator devices}

Sound generators are ear-level devices that produce sounds for therapeutic use.

Sound generator devices were introduced in 1976, on the principle of distraction, turning complete masking of tinnitus with white noise into a clinical management technique (Vernon 1976). The purpose of the 'masking' method was described by Vernon as making the tinnitus inaudible with a more acceptable sound (Vernon 1976; Vernon 1977). With the introduction of combination hearing aids partial masking became an acceptable outcome of the sound therapy. Partial masking provided only partial reduction in tinnitus, meaning that the tinnitus could still be heard but in a suppressed form (Vernon 1988).

Current views on sound generators acknowledge that masking is only one of the goals of sound therapy, alongside achieving tinnitus relief (i.e. reduction in tinnitus annoyance) regardless of the mechanism by which it is achieved (complete masking, partial masking or not masking the tinnitus; Henry 2008a). Other philosophies include the use of noise as a form of sound enrichment, counteracting the effects of sensory deprivation (Jastreboff 1993).

Recommendations regarding choice of sounds or level of sound that should be used vary across the literature and often strongly depend on the management programme followed. For example, 
tinnitus masking (TM) permits the use of any sound that provides maximum masking benefit (Henry 2002). The choice of sound, therefore, is based on a combination of effectiveness and acceptability for the patient. On the other hand, tinnitus retraining therapy (TRT) recommends the use of broadband noise to be adjusted to a 'mixing' or 'blending' point (Jastreboff 2007; Korres 2010; McFerran 2009), or below that level (Jastreboff 2006), to allow for habituation.

Many studies describe sound therapy in the context of a larger management programme, combining multiple approaches to manage tinnitus, where the counselling component plays a major role (e.g. Progressive Tinnitus Management, TRT, Neuromonics). It is therefore often difficult or even impossible to draw conclusions specific to the sound therapy component of the programme. It is possible that other components, rather than the devices, might have played a role in the observed improvements in tinnitus distress or handicap.

\section{Combination hearing aids}

Combination hearing aids combine amplification and sound generation options within one device, and new generations of such devices offer the same quality of amplification as 'standard' hearing aids (Henry 2004a; Sereda 2017; Tutaj 2018).

\section{How the intervention might work}

Hearing aids may be beneficial for people with tinnitus in a number of ways. The amplification of external sounds may reverse or reduce the drive responsible for 'pathological' changes in the central auditory system associated with hearing loss, such as increased gain or auditory cortex reorganisation, possibly by strengthening lateral inhibitory connections. Increased neuronal activity that results from amplified sounds may reduce the contrast between tinnitus activity and background activity thus reducing the audibility and awareness of tinnitus. Alternatively, amplification may simply refocus attention on alternative auditory stimuli that are incompatible and unrelated to the tinnitus sound. As the main function of hearing aids is to improve communication, for many people this inherently reduces stress and anxiety (Carmen 2002; Surr 1985), and so may indirectly affect improvements in tinnitus report. Finally, it is unquestioned that there is the potential for a large placebo effect in any study of tinnitus (Dobie 1999), and so it is essential that any investigation of hearing aids for tinnitus considers the potential impact of this effect.

Postulated mechanisms through which sound generators may be beneficial for tinnitus include tinnitus masking by reducing audibility (Vernon 1977) or by inducing a sense of relief (Vernon 2000), through habituation (Jastreboff 1993), by reversing abnormal cortical reorganisation or activity thought to contribute to tinnitus (Norena 2005; Tass 2012), or through the promotion of relaxation (Sweetow 2010).

Combination hearing aids combine the above approaches within one device (Tutaj 2018).

Potential modifiers of treatment outcome include the presence of hearing loss, clinically significant anxiety or depression, or high levels of tinnitus distress (which may be intractable to sound therapy alone) (Hoare 2012; Hoare 2014a; Jastreboff 2004; Searchfield 2010; Searchfield 2017).

\section{Why it is important to do this review}

In England alone there are an estimated $3 / 4$ million general practice consultations every year where the primary complaint is tinnitus (El-Shunnar 2011), equating to a major burden on healthcare services. Hearing aids, sound generators and combination devices (amplification aid sound generation within one device) are a component of many tinnitus management programmes and together with information and advice are a first line of management in UK audiology departments for someone who has tinnitus (Hoare 2014; Hobson 2012; Sereda 2015; Tutaj 2018). These options are also subject to ongoing research and development, for example to examine the effectiveness of new technologies such as mobile applications, wireless streaming and alternative sound options such as 3D sounds (Tutaj 2018).

Two previous Cochrane Reviews concluded that there was a lack of evidence for the effectiveness of these management options (Hobson 2012; Hoare 2014). The first review looked at sound therapy (masking) in the management of tinnitus in adults (Hobson 2012). The methods and searches in that review are now outdated, as is the use of term 'masking' as the only suggested mechanism of action for sound therapy. The second review looked at amplification with hearing aids for patients with tinnitus and co-existing hearing loss and an update of that review is now due (Hoare 2014). The current review provides an update to both of these Cochrane Reviews and extends them to separately consider the specific effects and safety of the three different sound therapy options.

\section{O B JECT IVES}

To assess the effects of sound therapy (using amplification devices and/or sound generators) for tinnitus in adults.

\section{METHODS}

\section{Criteria for considering studies for this review}

\section{Types of studies}

We included studies with the following design characteristics:

- randomised controlled trials, including cluster-randomised (cross-over trials were eligible if data from before the crossover could be extracted, to avoid the potential for a carry-over phenomenon).

We excluded studies with the following design characteristics:

- quasi-randomised controlled studies.

We applied no restrictions on language, year of publication or publication status.

\section{Types of participants}

Adults ( $\geq 18$ years) with acute ( $\leq 3$ months) or chronic ( $>3$ months) subjective idiopathic tinnitus.

\section{Types of interventions}

Amplification-only devices, sound generators and combination devices (combined amplification and sound generation). 
The comparators were amplification only, sound generator only and combination device.

The main comparison pair(s) were:

- amplification only versus waiting list control or placebo or education/information only with no device;

- sound generator only versus waiting list control or placebo or education/information only with no device;

- combination device versus waiting list control or placebo or education/information only with no device.

Other possible comparison pairs included:

- amplification only versus sound generator only;

- combination device versus amplification only;

- combination device versus sound generator only.

We excluded studies evaluating complex interventions, which explicitly included a sound therapy and other non-sound components (e.g. psychotherapy) as a part of a programme (e.g. Neuromonics). We excluded studies of neuromodulation (desynchronisation) devices (reviewed in Hoare 2015).

\section{Types of outcome measures}

We planned to analyse the following outcomes in the review, but we did not use them as a basis for including or excluding studies.

\section{Primary outcomes}

- Tinnitus symptom severity (such as the impact of tinnitus on quality of life, activities of daily living and sleep), as measured by the global score on a multi-item tinnitus questionnaire (Table 1). These included:

* Tinnitus Questionnaire (Hallam 1996; Hiller 1992);

* Tinnitus Functional Index (TFI) (Meikle 2012);

* Tinnitus Handicap Inventory (THI) (Newman 1996);

* Tinnitus Handicap Questionnaire (Kuk 1990);

* Tinnitus Reaction Questionnaire (Wilson 1991);

* Tinnitus Severity Scale (Sweetow 1990).

- Significant adverse effect: increase in self-reported tinnitus loudness.

\section{Secondary outcomes}

- Depressive symptoms or depression as measured by a validated instrument, such as the Beck Depression Inventory (Beck 1988; Beck 1996), the depression scale of the Hospital Anxiety and Depression Scale (HADS; Zigmond 1983), and the Hamilton Rating Scale for Depression (Hamilton 1960).

- Anxiety symptoms or generalised anxiety as measured by a validated instrument, such as the anxiety scale of the Beck Anxiety Inventory (Beck 1988), the anxiety scale of the HADS (Zigmond 1983), or the Anxiety Sensitivity Index (Reiss 1986).

- Health-related quality of life as measured by a validated instrument, such as the Short-Form 36 (Hays 1993), WHOQOLBREF (Skevington 2004), other WHOQOL versions or Health Utilities Index (Furlong 2001).

- Adverse effects associated with wearing the device such as pain, discomfort, tenderness or skin irritation, or ear infections.
In addition, we planned to report the newly developed core outcomes for trials of sound therapy for tinnitus, these being tinnitus intrusiveness, ability to ignore, concentration, quality of sleep and sense of control (Hall 2018a).

We reported long-term effects as three to six months.

\section{Search methods for identification of studies}

The Cochrane ENT Information Specialist conducted systematic searches for randomised controlled trials and controlled clinical trials. There were no language, publication year or publication status restrictions. The date of the search was 23 July 2018.

\section{Electronic searches}

The Information Specialist searched:

- the Cochrane ENT Register (searched via the Cochrane Register of Studies 23 July 2018);

- the Cochrane Central Register of Controlled Trials (CENTRAL) (searched via the Cochrane Register of Studies 23 July 2018);

- Ovid MEDLINE(R) Epub Ahead of Print, In-Process \& Other NonIndexed Citations, Ovid MEDLINE(R) Daily and Ovid MEDLINE(R) (1946 to 23 July 2018);

- Ovid EMBASE (1974 to 23 July 2018);

- LILACS (Latin American and Caribbean Health Science Information database), lilacs.bvsalud.org (searched 23 July 2018);

- Web of Knowledge, Web of Science (1945 to 23 July 2018);

- EBSCO CINAHL (1982 to 23 July 2018);

- Ovid PsycINFO (1910 to 23 July 2018);

- ClinicalTrials.gov, (searched via the Cochrane Register of Studies 23 July 2018);

- World Health Organization (WHO) International Clinical Trials Registry Platform (ICTRP), www.who.int/ictrp (searched 23 July 2018).

The Information Specialist modelled subject strategies for databases on the search strategy designed for CENTRAL. Where appropriate, they were combined with subject strategy adaptations of the highly sensitive search strategy designed by Cochrane for identifying randomised controlled trials and controlled clinical trials (as described in the Cochrane Handbook for Systematic Reviews of Interventions Version 5.1.0, Box 6.4.b. (Handbook 2011). Search strategies for major databases including CENTRAL are provided in Appendix 1.

\section{Searching other resources}

We scanned the reference lists of identified publications for additional trials and contacted trial authors if necessary. In addition, the Information Specialist searched Ovid MEDLINE to retrieve existing systematic reviews relevant to this systematic review, so that we could scan their reference lists for additional trials. The Information Specialist also ran non-systematic searches of Google Scholar to retrieve grey literature and other sources of potential trials.

We did not perform a separate search for adverse effects of sound therapy (using amplification devices and/or sound generators) for tinnitus. We considered adverse effects described in the included studies only. 


\section{Data collection and analysis}

\section{Selection of studies}

Two out of three authors (MS, AER and DAH) independently reviewed each study retrieved to determine their eligibility for inclusion in the review. Four further authors (MS, DJH, AER, and $J X)$ then reviewed the full-text reports of the retrieved studies and applied the inclusion criteria independently. We discussed any disagreements until a consensus was reached.

\section{Data extraction and management}

MS, DJH, AER and JX independently extracted data using a purposefully designed data extraction form. We piloted the data extraction form on a subset of articles and revised it as indicated before formal data extraction began. Where necessary or where insufficient data were provided for the study, we contacted study authors for further information.

Information extracted included: study design, setting, methods or randomisation and blinding, power, inclusion and exclusion criteria, type of intervention and control, treatment duration, treatment fidelity, type and duration of follow-up, and outcome measures and statistical tests.

Data extracted included: baseline characteristics of participants (age, sex, duration of tinnitus, tinnitus symptom severity, tinnitus loudness and pitch estimates, details of co-morbid hearing loss, anxiety or depression) and details of any attrition or exclusion.

Outcome data included: group mean and standard deviation at preand post-intervention and follow-up, and results of any statistical tests of between-group comparisons.

Where not reported or provided by the authors we estimated standard deviations in RevMan 5.3 (RevMan 2014) using the available data, such as standard errors, confidence intervals, $\mathrm{P}$ values and $t$ values. Where data were only available in graph form, we made and agreed numeric estimates.

After independent data extraction by MS, DJH, AER and JX, all authors reviewed the extracted data for disagreements, and revisited and discussed the relevant studies as required to reach a final consensus.

\section{Assessment of risk of bias in included studies}

MS, DJH, AER and JX independently assessed risk of bias of the included studies, with the following taken into consideration, as guided by theCochrane Handbook for Systematic Reviews of Interventions (Handbook 2011):

- sequence generation;

- allocation concealment;

- blinding;

- incomplete outcome data;

- selective outcome reporting; and

- other sources of bias.

We used the Cochrane 'Risk of bias' tool in RevMan 5.3 (RevMan 2014), which involves describing each of these domains as reported in the study and then assigning a judgement about the adequacy of each entry: 'low', 'high' or 'unclear' risk of bias. We resolved differences of opinion by discussion.

\section{Measures of treatment effect}

We analysed dichotomous data as risk ratios (RR) with 95\% confidence intervals (Cls). We summarised continuous outcomes as mean difference (MD) with $95 \% \mathrm{Cl}$. We used the standardised mean difference (SMD) (Cohen's d effect size (ES)) when different scales of measurement were used to measure the same outcome. A positive effect size indicated that the treatment group achieved better outcomes than the control group.

\section{Unit of analysis issues}

For parallel-group RCTs the unit of analysis was the group mean.

To avoid unit of analysis errors we planned to consider alternative analyses for cluster-randomised trials and for studies with more than two intervention groups. For cluster-randomised trials we planned to adopt approximate analyses - effective sample sizes (Donner 2002). For studies with more than two intervention groups, we planned either to combine groups to create a single pair-wise comparison or, if this was not appropriate, to select the most relevant pair of interventions for comparison.

\section{Dealing with missing data}

Where necessary and where sufficient data from the study were not provided, we contacted authors of the study requesting further details about missing data and reasons for the incompleteness of the data. We were alert to potential mislabelling or nonidentification of standard errors and standard deviations. Our method for imputation was according to chapter 7.7.3 of the Cochrane Handbook for Systematic Reviews of Interventions (Handbook 2011). If data were missing, we used available case analysis using all data (as reported) for all randomised patients available at the end of the study/time point of interest, regardless of the actual treatment received. We considered the quality of outcome assessment as a study limitation (GRADE) and not as a stratifying factor.

\section{Assessment of heterogeneity}

We assessed studies for clinical, statistical and methodological heterogeneity. We quantified statistical heterogeneity using the 12 statistic and the $\mathrm{Chi}^{2}$ test. An approximate guide to interpretation of the $1^{2}$ statistic is provided in the Cochrane Handbook for Systematic Reviews of Interventions (Handbook 2011). An $1^{2}$ value of $50 \%$ or higher may represent substantial or considerable heterogeneity. Where $\mathrm{Chi}^{2}$ is greater than the degrees of freedom ( $\mathrm{K}-1$ degrees of freedom, where $\mathrm{K}$ is the number of studies), then heterogeneity is likely to be present. We considered heterogeneity to be statistically significant if the $P$ value was less than 0.10 . We performed metaanalysis using fixed-effect modelling.

\section{Assessment of reporting biases}

For each sound therapy intervention, we investigated potential publication bias and the influence of individual studies on the overall outcome identified in this review. We searched for and requested study protocols for the included studies and, where available, we evaluated whether there was evidence of selective reporting. There were too few studies included to assess publication bias. 


\section{Data synthesis}

We analysed separately the different sound therapy options (amplification only, sound generation only, combined amplification and sound generation) and different durations of tinnitus (acute and chronic). We performed only one meta-analysis comparing combination hearing aids to amplification only.

We pooled data using a fixed-effect model and SMD.

We considered the psychometric properties of outcome instruments with regard to their suitability for pooling. For metaanalyses on the primary outcome (tinnitus symptom severity), whenever studies reported outcomes measured by more than one instrument, we included data only when those instruments were known to measure the same underlying construct of tinnitus symptom severity (high convergent validity) and showed a similar direction of treatment-related effect. We planned to take the same approach for secondary outcomes.

\section{Network meta-analysis}

We had planned to perform a network meta-analysis to assess the connection between the interventions for each outcome but the data from the included studies were inadequate.

\section{Subgroup analysis and investigation of heterogeneity}

We panned to carry out subgroup analyses to explore the potential effect modifiers of hearing loss, baseline tinnitus symptom severity and baseline anxiety or depression. However, insufficient data were available.

\section{Sensitivity analysis}

We planned to conduct a sensitivity analysis by excluding those studies with a high risk of bias, thereby checking the robustness of the conclusion from the studies included in the meta-analysis. However, only three studies were included in the meta-analysis, all with similar, non-significant estimates of effect. We judged two out of three studies (both by the same authors: Henry 2015 and Henry 2017) to have a high risk of bias, therefore sensitivity analysis could not be performed.

\section{GRADE and 'Summary of findings' table}

Two authors (MS and JX) independently used the GRADE approach to rate the overall quality of evidence using GRADEpro GDT (https:// gradepro.org/). The quality of evidence reflects the extent to which we are confident that an estimate of effect is correct and we applied this in the interpretation of results. The quality of evidence can be high, moderate, low or very low. High-quality evidence implies that we are confident in our estimate of effect and that further research is very unlikely to change our confidence in the estimate of effect. Very low-quality evidence implies that any estimate of effect obtained is very uncertain.

The GRADE approach can downgrade the quality of evidence for RCTs from high to moderate, low or very low for the following factors:

- study limitations (risk of bias);

- inconsistency;

- indirectness of evidence;
- imprecision;

- publication bias.

We planned to include 'Summary of findings' tables, constructed according to the recommendations described in the Cochrane Handbook for Systematic Reviews of Interventions (Handbook 2011), for the following main comparison(s):

- Amplification only versus waiting list control, placebo, education/information only with no device.

- Sound generator only versus waiting list control, placebo, education/information only with no device.

- Combination devices versus waiting list control, placebo, education/information only with no device, amplification only, sound generator only.

However, no data were available for these main comparisons.

We did include 'Summary of findings' tables for the two additional comparisons for which data were available:

- Combination hearing aid versus hearing aid.

- Hearing aid versus sound generator.

We included the following outcomes in the 'Summary of findings' tables:

- tinnitus symptom severity;

- significant adverse effect (increase in self-reported tinnitus loudness);

- depressive symptoms;

- symptoms of generalised anxiety;

- health-related quality of life;

- other adverse effects associated with wearing the device.

\section{RE S U L T S}

\section{Description of studies}

\section{Results of the search}

Our electronic database search on 23 July 2018 identified 2527 records, of which 1202 remained after removing duplicates. We discarded 1173 records based on title and/or abstract. We retrieved 29 records for full-text assessment. We excluded 17 studies because they were not randomised controlled trials $(n=11)$ or because the intervention or control used did not meet the criteria pre-defined in the protocol $(n=6)$ (see Excluded studies).

Two records were ongoing clinical trials (see below). Two records supplemented the methodological information that was extracted for two included studies (NCT01857661 trial registration for dos Santos 2014; Hazell 1985 paper for Stephens 1985).

In total, eight completed studies met our inclusion criteria (dos Santos 2014; Erlandsson 1987; Henry 2015; Henry 2017; Melin 1987; Parazzini 2011; Stephens 1985; Zhang 2013). Three of these studies reported quantitative data that were included in meta-analyses (dos Santos 2014; Henry 2015; Henry 2017).

We identified no additional records from other sources. A flowchart of study retrieval and selection is provided in Figure 1. 
Figure 1. Study flow diagram.

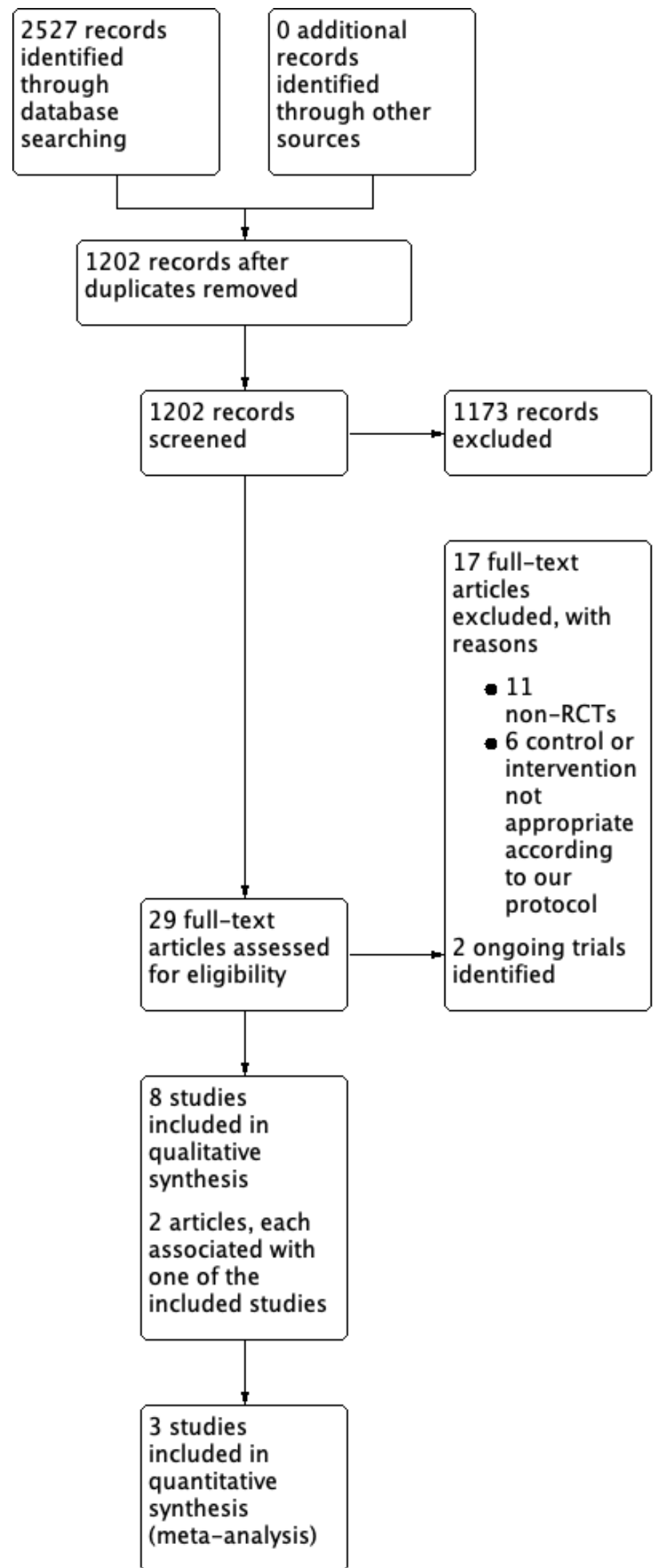




\section{Included studies}

See Characteristics of included studies.

We included eight published studies (dos Santos 2014; Erlandsson 1987; Henry 2015; Henry 2017; Melin 1987; Parazzini 2011; Stephens 1985; Zhang 2013).

\section{Design}

Seven studies were parallel-group RCTs (dos Santos 2014; Henry 2015; Henry 2017; Melin 1987; Parazzini 2011; Stephens 1985; Zhang 2013) and one was a randomised cross-over trial (Erlandsson 1987). Stephens 1985 was a randomised sub-study (two separated trials) within a multi-centre study evaluating sound generator devices (Stephens 1985, Hazell 1985 paper).

Two of the included studies had more than two treatment arms. Henry 2017 was a three-arm trial comparing standard hearing aids, extended wear hearing aids (EWHA) and combination hearing aids. Stephens 1985 reported results of two three-arm trials. One compared two types of sound generator device to counselling in participants who did not report hearing difficulties, and the other compared hearing aids, sound generator devices and combination hearing aids in participants who reported hearing difficulties.

\section{Sample sizes}

The total sample size for all included studies was 590 (range 21 to 154 participants).

\section{Setting}

Two studies were set in Veterans Affairs clinics in the USA (Henry 2015; Henry 2017), three in university hospital clinics in Brazil, Sweden and China (dos Santos 2014; Melin 1987; Zhang 2013), one in a hospital ENT department in the UK (Stephens 1985), one in a hospital audiology department in Sweden (Erlandsson 1987), and one in two tinnitus clinics in Italy and USA (Parazzini 2011).

\section{Participants}

All studies recruited adult participants (18 years or over). The mean age of participants in the included studies ranged from 38.8 to 74.4 years. Mean age was not reported in Stephens 1985.

Forty-four percent of participants were women and 56\% were men. Men accounted for between $33 \%$ and $81 \%$ of participants, depending on the study. Three studies had a larger proportion of men than women (Erlandsson 1987; Henry 2015; Henry 2017; 81\%, $73 \%$ and $78 \%$ respectively), and one had a larger proportion of women (Melin 1987; 66\%).

All studies recruited patients with hearing loss and/or perceived hearing difficulties, with Stephens 1985 recruiting an additional group of participants without perceived hearing difficulties (the actual hearing status of that group was not reported). Zhang 2013 specifically recruited participants with moderate to severe hearing loss, dos Santos 2014 recruited participants with mild to moderate hearing loss, and Parazzini 2011 had a specific hearing loss eligibility criterion of $<25 \mathrm{~dB}$ at $2 \mathrm{kHz}$ and $>25 \mathrm{~dB}$ at frequencies higher than $2 \mathrm{kHz}$ (i.e. bordering between Categories 1 and 2 according to the TRT classification, Jastreboff 2000).

Individual tinnitus duration ranged from three months to over 20 years. Tinnitus duration was not reported in Henry 2017. Most studies specified an inclusion criterion that considered tinnitus symptom severity, namely high impact on life (Parazzini 2011), bothersome tinnitus (Henry 2017), clinically significant tinnitus (Henry 2015), tinnitus as a major problem and main symptom (Stephens 1985), tinnitus affecting work and life (Zhang 2013), and minimum THI score above 20 (indicating mild handicap; dos Santos 2014). Melin 1987 and Erlandsson 1987 did not specify any inclusion criterion based on tinnitus symptom severity. Melin 1987 classified participants according to a three-point severity grading, where a majority of participants were graded 1 (audible only in quiet environment) and 2 (audible in ordinary but not in noisy environments; not noticeable in specific situations, such as when the attention is focused on interesting work etc.; occasionally causes disturbances in sleep), with only two participants graded 3 (constantly noticed in all ordinary acoustical environments and causing severe disturbances of concentration and continuous disturbance of sleep). Erlandsson 1987 described eligible participants as "clinically judged to have severe tinnitus and to be in need of treatment". Two studies reported mean baseline THI scores, with both reporting mean handicap to be in the moderate to severe range (mean THI scores $=53.2$ and 59.0; dos Santos 2014; Parazzini 2011, respectively). Two studies reported mean baseline TFI scores, with both reporting the score indicating tinnitus to be a "big problem" (mean TFI scores = 56.1 to 60.5; Henry 2015; Henry 2017, respectively).

Baseline anxiety and/or depression scores were not reported in any of the included studies. Four studies had eligibility criteria regarding mental and emotional state. Henry 2017 included participants reporting being in good mental, emotional and health conditions. Henry 2015 included participants with no mental, emotional or health conditions that would prevent participating in the study who in addition passed the Mini-Mental State Examination. Zhang 2013 excluded participants with severe mental illness, and the inclusion criterion was tinnitus that affects work and life, such as affecting sleep and work, causes anxiety or depression, etc. Stephens 1985 excluded participants undergoing intensive psychiatric treatment. Two studies accepted participants with anxiety/depression. In Parazzini 2011, about 20\% to 30\% of participants were on medication for unrelated conditions, including for pre-existing anxiety, depression and sleep problems. Three studies did not mention anxiety/depression in their eligibility criteria (dos Santos 2014; Erlandsson 1987; Melin 1987).

\section{Interventions and comparisons}

Seven included studies investigated the effects of hearing aids (dos Santos 2014; Henry 2015; Henry 2017; Melin 1987; Parazzini 2011; Stephens 1985; Zhang 2013), four combination hearing aids (dos Santos 2014; Henry 2015; Henry 2017; Stephens 1985), and three sound generator devices (Erlandsson 1987; Parazzini 2011; Stephens 1985). Four studies included the main comparisons specified in our protocol (Sereda 2018):

\section{Amplification only versus waiting list control or placebo or education/ information only with no device}

One study compared a hearing aid group to waiting list controls (Melin 1987), and one compared a group fitted with hearing aids and practising relaxation at home to a group who only practised relaxation at home (Zhang 2013). Participants in Zhang 2013 were fitted with hearing aids manufactured by GN ReSound, Denmark, although the type of devices was not specified by Melin 1987. The majority of participants in Melin 1987 were fitted bilaterally $(n=$ 
18) with only two fitted unilaterally. The number of devices (one or two) was not reported by Zhang 2013. Both groups in Zhang 2013 practiced relaxation twice daily for 10 to 20 minutes, usually in the morning and before sleeping.

\section{Sound generator only versus waiting list control or placebo or education/information only with no device}

One study compared sound generator devices to placebo devices (Erlandsson 1987), and one compared two types of sound generator device to counselling (Stephens 1985). Erlandsson 1987 used sound generator devices constructed specifically for the study, and sound stimulation was delivered unilaterally. Two types of sound generator devices in Stephens 1985 were A\&M masker and Viennatone masker, and all were fitted unilaterally.

\section{Combination device versus waiting list control or placebo or} education/information only with no device

No studies compared combination devices to waiting list control or placebo or education/information only.

\section{Six studies included additional comparisons:}

\section{Hearing aids versus sound generators}

Two studies compared hearing aids to sound generator devices (Parazzini 2011; Stephens 1985). Parazzini 2011 fitted participants with bilateral open-ear hearing aids or with bilateral sound generator devices. All hearing aids were the 'ResoundAir' device (GN Resound), programmed according to standard audiological practice. All sound generator devices were behind-the-ear open fit 'Silent Star' devices (Viennatone) which produce a broadband sound. All patients received the same educational counselling component of TRT, with follow-up to optimise the therapy at 3, 6 and 12 months. Stephens 1985 compared hearing aids to sound generator devices as part of a three-arm trial (the third group received combination hearing aids). Patients reporting hearing disability were fitted with a standard National Health Service (NHS) behind the ear hearing aid or A\&M tinnitus masker. All sound generator devices were fitted unilaterally, but hearing aids were fitted unilaterally or bilaterally, according to normal clinical indications. Those fitted with devices all received similar counselling.

\section{Combination hearing aids versus hearing aids}

Four studies compared combination hearing aids to hearing aids (dos Santos 2014; Henry 2015; Henry 2017; Stephens 1985). dos Santos 2014 compared bilateral hearing aids with integrated sound generator devices developed by the Department of Otolaryngology of the University of São Paulo in two modes: a combined mode (amplification and sound generation activated) and a simple mode (amplification only). Henry 2015 fitted participants bilaterally with "commercially available" receiver-in-the-canal combination hearing aids with the sound generator activated or not (amplification only). Henry 2017 compared combination hearing aids to two brands of hearing aids (amplification only). Combination hearing aids were Audeo Q (Phonak) receiver-in-thecanal devices with the sound generator activated. Hearing aids (amplification only) were Audeo Q (Phonak) hearing aids and EWHA; Lyric (Phonak). All three groups received education, which took place following device fitting and adjustment. In the study by Stephens 1985, patients reporting hearing disability were allocated to a standard NHS behind the ear hearing aid $(n=26)$, Danavox
775-PP-AGC/masker module combination hearing aid $(n=23)$, or A\&M sound generator device $(n=23)$. All sound generator devices were fitted unilaterally, but hearing aids were fitted unilaterally or bilaterally, according to normal clinical indications. Those fitted with devices all received similar counselling.

\section{Combination hearing aids versus sound generators}

One study compared combination hearing aids to sound generators (Stephens 1985). Patients reporting hearing disability were fitted with Danavox 775-PP-AGC/masker module combination hearing aid or A\&M sound generator device. All devices were fitted unilaterally. Those fitted with instruments all received similar counselling.

\section{Outcomes}

\section{Primary outcomes}

Four studies reported changes in tinnitus symptom severity before and after treatment as measured by the global score on a multiitem questionnaire (dos Santos 2014; Henry 2015; Henry 2017; Parazzini 2011). dos Santos 2014 and Parazzini 2011 used the Tinnitus Handicap Inventory (THI) (Table 1; Newman 1996). Henry 2015 and Henry 2017 used the Tinnitus Functional Index (TFI) (Table 1; Meikle 2012). Outcomes were measured at three months (dos Santos 2014), three to four months (Henry 2015), four to five months (Henry 2017), and three, six and 12 months (Parazzini 2011).

Serious adverse effects were not assessed in any of the included studies.

\section{Secondary outcomes}

Stephens 1985 measured anxiety, phobic anxiety, somatic anxiety and depression using the subscales of the Crown Crisp Experiential Index (data for the randomised and non-randomised groups pooled together are available in Stephens 1985, Hazell 1985 paper), however data for the randomised part of the study were not reported in the manuscript (Stephens 1985), and we were not able to contact the authors to obtain the data.

Health-related quality of life was not measured in the included studies.

Adverse effects were not assessed in the included studies.

\section{Other core outcomes}

None of the studies measured the newly developed core outcomes for trials of sound therapy: tinnitus intrusiveness, ability to ignore, concentration, quality of sleep or sense of control.

\section{Non-relevant outcomes}

Three studies did not use any outcome measures relevant to this review (Types of outcome measures) (Erlandsson 1987; Melin 1987; Zhang 2013). Erlandsson 1987 reported a 10-point visual analogue scale of tinnitus intensity, usage, specific effects (self-rated changes in tinnitus intensity and in the degree of negative reactions to tinnitus) and non-specific effects (self-rated changes of mood, stress, somatic symptoms other than tinnitus and medication). Melin 1987 reported a visual analogue scale $(10 \mathrm{~cm}$, unmarked) assessing tinnitus and hearing ability in four different hearing situations using a semi-structured interview. Zhang 2013 assessed tinnitus symptom severity using a single item with four categories of therapeutic effect: (i) complete adaptation: tinnitus symptom 
disappears or significantly relieves, with normal emotion, sleeping, work and life; (ii) basic adaptation: tinnitus symptom disappears, relieves or still exists, but with normal emotion, sleeping, work and life; (iii) partial adaptation: tinnitus still exists, partially affecting emotion, sleeping, work and life; (iv) no adaptation: tinnitus symptom still exists or even worse, seriously affecting emotion, sleeping, work and life.

\section{Excluded studies}

We excluded a total of 17 studies. We excluded 11 studies because they were not RCTs (Al-Jassim 1988; Andersson 2002; Benton 2016; Del Bo 2006; Gudex 2009; Hernández Moñiz 1998; Hiller 2005; Lipman 2007; Mehlum 1984; Shabana 2018; Sweetow 2010). We excluded six studies because of the intervention or control they used (Durai 2017; Henry 2016; Hodgson 2017; Strauss 2015; Tao 2017; Thedoroff 2017). See Characteristics of excluded studies for details.

\section{Ongoing studies}

Two records identified in our search are ongoing clinical trials, which are reported in Characteristics of ongoing studies (ISRCTN15178771; TCTR20180225002).

\section{Risk of bias in included studies}

We assessed risk of bias based on the information provided in the published reports. See Figure 2 and Figure 3 for a graph and summary of risk of bias across studies.

Figure 2. 'Risk of bias' graph: review authors' judgements about each risk of bias item presented as percentages across all included studies.

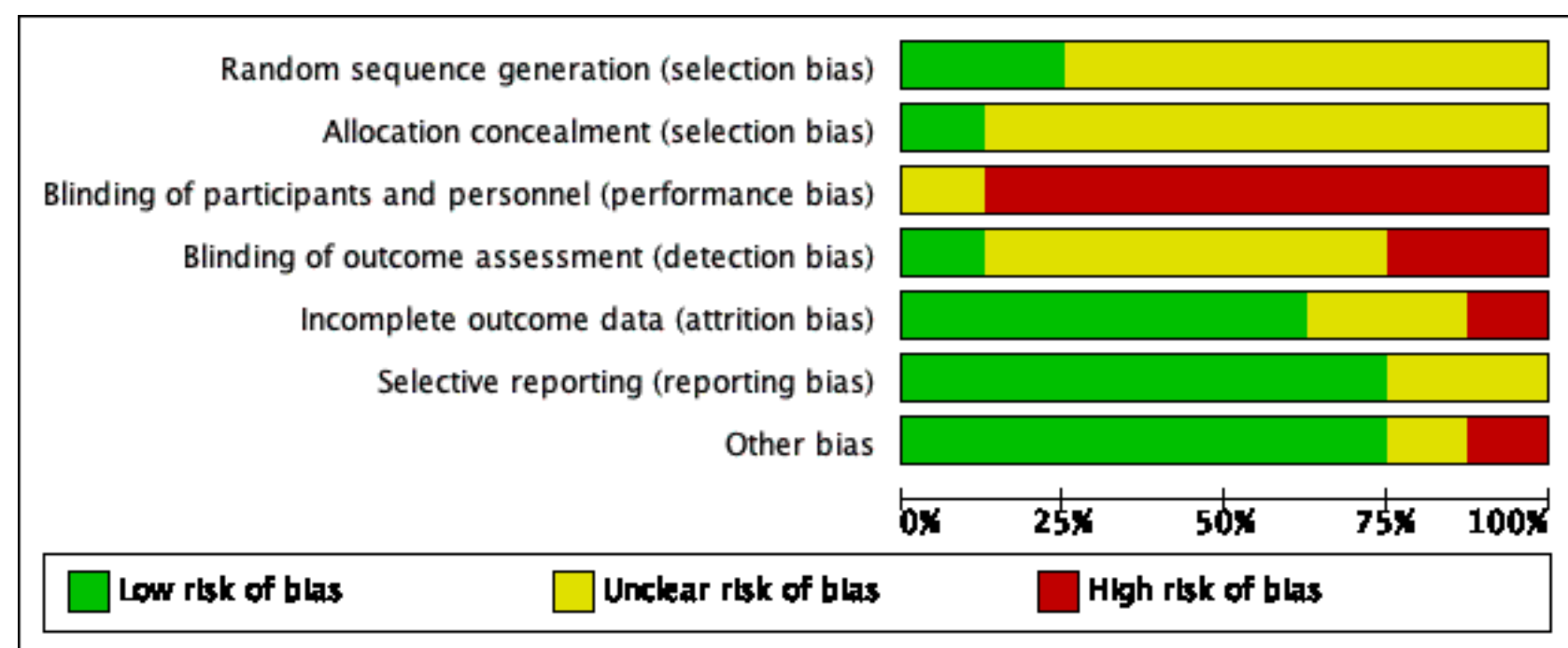


Figure 3. 'Risk of bias' summary: review authors' judgements about each risk of bias item for each included study.

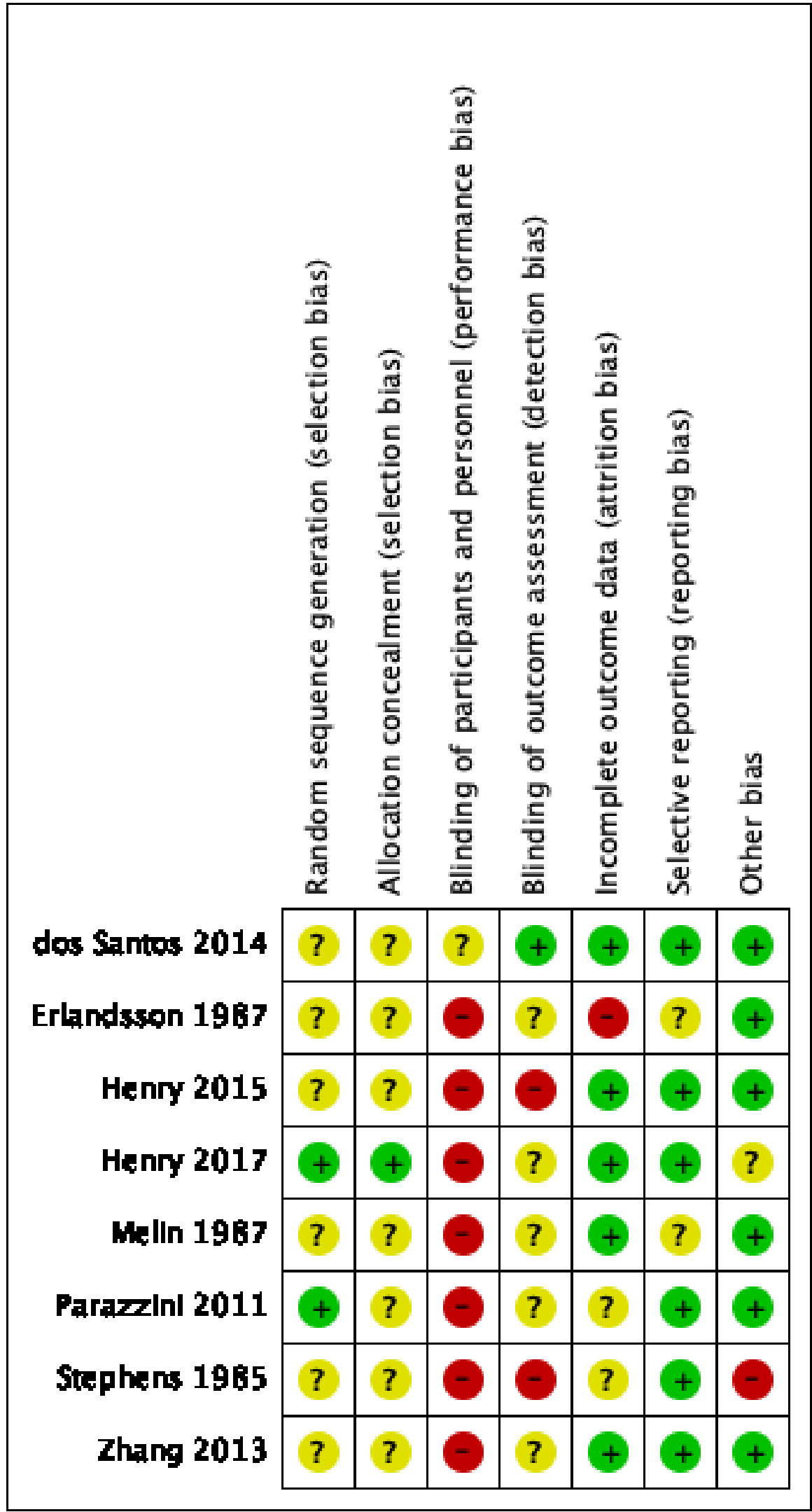




\section{Allocation}

\section{Random sequence generation}

We considered the risk of selection bias due to inadequate sequence generation to be unclear in six studies (dos Santos 2014; Erlandsson 1987; Henry 2015; Melin 1987; Stephens 1985; Zhang 2013). We judged the remaining two studies to have a low risk of bias (Henry 2017; Parazzini 2011). Henry 2017 achieved random sequence generation using computer software and Parazzini 2011 stated that "randomisation was obtained on the basis of a random table".

\section{Allocation concealment}

We judged Henry 2017 to have low risk of bias as allocation concealment was achieved using sequentially numbered, opaque, sealed envelopes, which were opened by study staff to randomise and enrol participants. For the remaining seven studies, risk of bias due to allocation concealment was unclear as the information was not reported (dos Santos 2014; Erlandsson 1987; Henry 2015; Melin 1987; Parazzini 2011; Stephens 1985; Zhang 2013).

\section{Blinding}

\section{Blinding of participants and personnel}

The blinding of participants was not possible in any of the studies because the groups received visibly different interventions (device or no device, different types of devices). Blinding of personnel was not attempted in seven studies and therefore we judged the risk of bias to be high (Erlandsson 1987; Henry 2015; Henry 2017; Melin 1987; Parazzini 2011; Stephens 1985; Zhang 2013). For dos Santos 2014 , only in the trial registration was it stated that the initial and final evaluation of the primary outcome was performed by an investigator who was blinded to group allocation and so we rated the risk of bias as unclear.

\section{Blinding of outcome assessment}

We judged two studies to have a high risk of bias due to lack of blinding of outcome assessments (Henry 2015; Stephens 1985). In dos Santos 2014, the initial and final evaluations were performed by a blind evaluator and so we judged the risk of bias to be low. In five studies, the risk of performance bias and detection bias as a result of inadequate blinding was unclear (Melin 1987; Erlandsson 1987; Henry 2017; Parazzini 2011; Zhang 2013).

\section{Incomplete outcome data}

We judged Erlandsson 1987 to have high risk of bias due to incomplete outcome data. The authors reported that data were omitted for four participants because of inadequate use (not specified) of rating scales and that data for "specific and nonspecific effects" for two participants were incomplete due to "a lack of cooperation" (not explained). Handling of missing data was not described.

We judged Parazzini 2011 and Stephens 1985 to have unclear risk of bias. In Parazzini 2011, 10 participants out of 101 were excluded due to missing recordings, however no additional explanation was included. Structured interview data were recorded, analysed and reported for the subset of 51 out of 91 participants only. For Stephens 1985, a full description of the study provided in Stephens 1985, Hazell 1985 paper, reports 153 patients starting the study and 119 reaching the first evaluation. However, data from only 147 participants were reported in Stephens 1985. Dropout between the start of the study and the first evaluation was not explained.

We judged five studies to have low risk of bias due to incomplete outcome data as all participant data were reported or reasons for dropout were explained (dos Santos 2014; Henry 2015; Henry 2017; Melin 1987; Zhang 2013).

\section{Selective reporting}

We identified one study protocol for the included studies, namely a prospective trial registration that was available for dos Santos 2014. We judged this study to have a low risk of bias due to selective reporting as all pre-specified outcome measures were reported. In five studies, the outcomes that were mentioned in the abstract and/ or methods section were also reported in the results section and therefore we considered the risk of selective reporting to be low in these studies (Henry 2015; Henry 2017; Parazzini 2011; Stephens 1985; Zhang 2013).

We judged two studies to have unclear risk of bias (Erlandsson 1987; Melin 1987). Erlandsson 1987 did not report between-group differences at six weeks, after the first part of a cross-over trial. Melin 1987 did not report any dropout for the experimental period and it was unclear if all interview data were reported.

\section{Other potential sources of bias}

Conflict of interest was not reported in five studies (Erlandsson 1987; Henry 2017; Melin 1987; Stephens 1985; Zhang 2013), and funding was not reported in one study (Henry 2017). As Henry 2017 did not report either conflict of interest or funding we judged the risk of bias as unclear. We judged Stephens 1985 to have high risk of bias due to reported differences between two therapists conducting the study and because only some of the patients underwent a full neuro-otological examination. For seven studies there was no prospective protocol available (Erlandsson 1987; Henry 2015; Henry 2017; Melin 1987; Parazzini 2011; Stephens 1985; Zhang 2013). No other sources of bias were identified for the remaining studies.

\section{Effects of interventions}

See: Summary of findings for the main comparison Hearing aid compared to sound generator for tinnitus in adults; Summary of findings 2 Combination hearing aid compared to hearing aid for tinnitus in adults

See Summary of findings for the main comparison; Summary of findings 2 .

Data from Erlandsson 1987, Melin 1987, Parazzini 2011, Stephens 1985 and Zhang 2013 were not included in the meta-analysis (see Characteristics of included studies).

No data were available for any of our three main comparisons: 'Hearing aid only versus waiting list control or placebo or education/information only with no device'; 'Sound generator device only versus waiting list control or placebo or education/ information only with no device'; 'Combination hearing aid versus waiting list control or placebo or education/information only with no device'. 
Data were available only for the additional comparisons: 'Hearing aid only versus sound generator device only' and 'Combination hearing aid versus hearing aid only'.

\section{Hearing aid only versus waiting list control or placebo or education/information only with no device}

Two studies made this comparison (Melin 1987; Zhang 2013).

\section{Primary outcomes}

Tinnitus symptom severity

Tinnitus symptom severity measured with a multi-item questionnaire was not reported.

\section{Significant adverse effects}

Significant adverse effects of self-reported increase in tinnitus loudness were not reported.

\section{Secondary outcomes}

No secondary outcomes relevant to this review were reported.

\section{Additional (core) outcomes}

No additional outcomes relevant to this review were reported.

\section{Sound generator device only versus waiting list control or placebo or education/information only with no device}

Two studies made this comparison (Erlandsson 1987; Stephens 1985).

\section{Primary outcomes}

Tinnitus symptom severity

Tinnitus symptom severity measured with a multi-item questionnaire was not reported.

\section{Significant adverse effects}

Significant adverse effects of self-reported increase in tinnitus loudness were not reported.

\section{Secondary outcomes}

No secondary outcomes relevant to this review were reported.

\section{Additional (core) outcomes}

No additional outcomes relevant to this review were reported.

Combination hearing aid versus waiting list control or placebo or education/information only with no device

None of the included studies made this comparison.

\section{Hearing aid only versus sound generator device only}

Two studies made this comparison (Parazzini 2011; Stephens 1985).

\section{Primary outcomes}

Tinnitus symptom severity

Parazzini 2011 reported tinnitus symptom severity as measured using the Tinnitus Handicap Inventory (THI) at three, six and
12 months. Parazzini 2011 reported no statistically significant difference in change in tinnitus symptom severity between groups. We estimated mean values from the data plots. For patients who were fitted with hearing aids, the THI score reduced from 58.9 to 40.0 points at three months, $\sim 33.3$ at six months and 28.8 at 12 months. The group who received sound generators reported a reduction from $\sim 56.8$ to $~ 36.6$ points at three months, $~ 33$ at six months and 27.6 at 12 months. Parazzini 2011 performed a two-way ANOVA showing that the reduction in THI was statistically significant overall $(P<0.001)$. However, there was no clear difference between groups at three, six or 12 months. The mean difference was 1.30 (95\% confidence interval $(\mathrm{Cl})-5.72$ to 8.32 ) at three months, -1.80 (-8.82 to 5.22$)$ at six months and $-0.90(95 \% \mathrm{Cl}$ -7.92 to 6.12 ) at 12 months (Analysis 1.1; Analysis 1.2; Analysis 1.3). The reduction in THI score was clinically significant (i.e. more than 20 points, Newman 1996) at three, six and 12 months for the sound generator group and at six and 12 months for the hearing aid group.

Using GRADE we assessed the quality of evidence for tinnitus symptom severity at three months, six months and 12 months as low.

\section{Significant adverse effects}

Significant adverse effects of self-reported increase in tinnitus loudness were not reported.

\section{Secondary outcomes}

No secondary outcomes relevant to this review were reported.

\section{Additional (core) outcomes}

No additional outcomes relevant to this review were reported.

\section{Combination hearing aid versus hearing aid only}

Four studies made this comparison (dos Santos 2014; Henry 2015; Henry 2017; Stephens 1985).

\section{Primary outcomes}

\section{Tinnitus symptom severity}

Three studies measured tinnitus symptom severity. dos Santos 2014 used the THI, while Henry 2015 and Henry 2017 used the Tinnitus Functional Index (TFI). Henry 2015 reported TFI scores with and without the devices, but we have included only scores with the devices in the analysis for consistency with the other included studies. For Henry 2017, we included only two groups in the meta-analysis (combination hearing aids and conventional hearing aids) and excluded the extended wear hearing aids (EWHA) group as it was not directly comparable to the other hearing aids used in the included studies. For Henry 2015, no standard deviation for the mean change was reported and so we used the standard deviation from another study by the same author (Henry 2017) as a reasonable alternative. There was no clear difference between the hearing aid and combination hearing aid groups. The pooled standardised mean difference was $-0.15(95 \% \mathrm{Cl}-0.52$ to 0.22 ; lowquality evidence; Analysis 2.1; Figure 4). Outcomes were measured at three months (dos Santos 2014), three to four months (Henry 2015), and four to five months (Henry 2017). 
Figure 4. Forest plot of comparison: 2 Combination hearing aid versus hearing aid, outcome: 2.1 Tinnitus symptom severity.

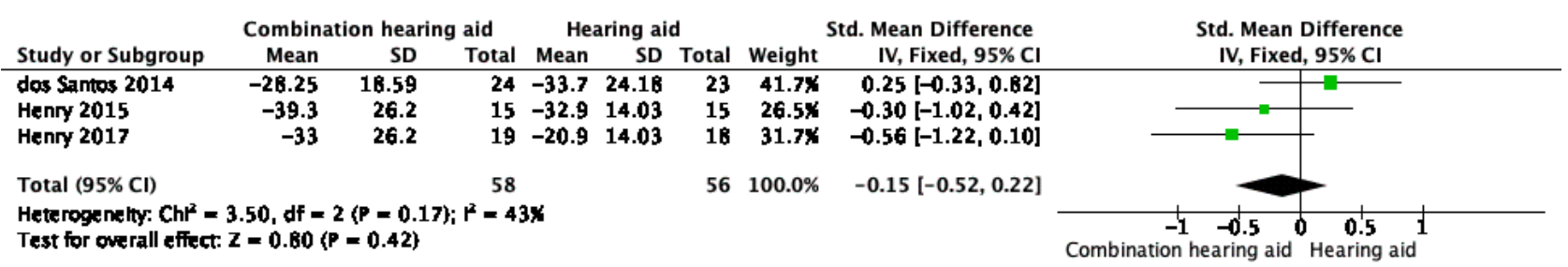

\section{Significant adverse effects}

Significant adverse effects of self-reported increase in tinnitus loudness were not reported.

\section{Secondary outcomes}

No secondary outcomes relevant to this review were reported.

\section{Additional (core) outcomes}

No additional outcomes relevant to this review were reported.

\section{Combination hearing aid versus sound generator only}

One study made this comparison (Stephens 1985).

\section{Primary outcomes}

\section{Tinnitus symptom severity}

Tinnitus symptom severity measured with a multi-item questionnaire was not reported.

\section{Significant adverse effects}

Significant adverse effects of self-reported increase in tinnitus loudness were not reported.

\section{Secondary outcomes}

No secondary outcomes relevant to this review were reported.

\section{Additional (core) outcomes}

No additional outcomes relevant to this review were reported.

\section{DISCUSSION}

\section{Summary of main results}

The objective of this review was to assess the effects of sound therapy (using amplification devices and/or sound generators) for acute ( $\leq 3$ months) or chronic ( $>3$ months) subjective idiopathic tinnitus in adults. This review includes eight studies (590 participants). Seven studies investigated the effects of hearing aids (dos Santos 2014; Henry 2015; Henry 2017; Melin 1987; Parazzini 2011; Stephens 1985; Zhang 2013), four combination hearing aids (dos Santos 2014; Henry 2015; Henry 2017; Stephens 1985), and three sound generators (Erlandsson 1987; Parazzini 2011; Stephens 1985).

Only four studies reported outcome measures and comparisons of interest to this review and no data were available for any of our three main comparisons: hearing aid only/sound generator device only/combination hearing aid versus waiting list control or placebo or education/information only with no device. One study compared patients fitted with sound generators versus those fitted with hearing aids (Parazzini 2011), finding no difference between them in the effects on our primary outcome, tinnitus symptom severity (Summary of findings for the main comparison). The use of both types of devices was associated with a clinically significant reduction in tinnitus symptom severity. In summary, hearing aids were not better or worse than sound generators. No evidence was found in this study for the other outcomes of interest in this review.

Three studies compared combination hearing aids with hearing aids (dos Santos 2014; Henry 2015; Henry 2017). These studies found no difference between them in their effects on the change in tinnitus symptom severity (Summary of findings 2). The use of both types of devices was associated with a clinically significant reduction in tinnitus symptom severity. In summary, hearing aids were not better or worse than combination hearing aids. No evidence was found in these studies for the other outcomes of interest in this review.

There is insufficient evidence to support the superiority or inferiority of any of the sound therapy options (hearing aid, sound generator or combination hearing aid) over each other. There is no evidence to support the superiority of sound therapy for tinnitus over waiting list control, placebo or education/information with no device.

\section{Overall completeness and applicability of evidence}

All of the included studies included patients with subjective idiopathic tinnitus. All studies included patients with a minimum duration of tinnitus of at least three months. No studies included only patients with acute tinnitus ( $\leq 3$ months). All studies recruited patients with hearing loss and/or perceived hearing difficulties.

Six out of the eight included studies specified eligibility criteria concerning tinnitus symptom severity. Five studies used descriptive criteria of high impact on life (Parazzini 2011), bothersome tinnitus (Henry 2017), clinically significant tinnitus (Henry 2015), tinnitus as a major problem and main symptom (Stephens 1985), and tinnitus affecting work and life (Zhang 2013). One study used a criterion based on a Tinnitus Handicap Inventory (THI) score of 20 or more, but the mean baseline $\mathrm{THI}$ in the included population was higher than this, being in the moderate to severe range (Parazzini 2011). Melin 1987 and Erlandsson 1987 did not specify eligibility criteria concerning tinnitus symptom severity. Melin 1987 classified recruited participants according to a three-point severity grading system, where a majority of participants fell within grades 1 and 2. Erlandsson 1987 described included participants as "clinically judged to have severe tinnitus and to be in need of treatment".

Baseline anxiety and/or depression scores were not reported in the included studies. Some studies had inclusion criteria 
regarding mental and emotional state: Henry 2017 included participants reporting as being in good mental, emotional and health conditions, Henry 2015 included participants with no mental, emotional or health conditions that would prevent participation in the study who in addition passed the MiniMental State Examination, Zhang 2013 excluded participants with severe mental illness, and Stephens 1985 excluded participants undergoing intensive psychiatric treatment. However, two studies specified that they accepted participants with anxiety/depression. In Parazzini 2011, about $20 \%$ to $30 \%$ of participants were on medication for unrelated conditions, including pre-existing anxiety, depression and sleep problems. In Zhang 2013, the inclusion criterion was tinnitus that affects work and life, such as affecting sleep and work, causing anxiety or depression, etc. Three studies did not mention anxiety/depression in their inclusion criteria and did not report anxiety/depression scores in the baseline characteristics of participants (dos Santos 2014; Erlandsson 1987; Melin 1987).

The study dos Santos 2014 used combination hearing aids that were developed by the Department of Otorhinolaryngology of the University of São Paulo and therefore might not be directly comparable to commercially available devices. Two studies used devices by specific manufacturers only (Henry 2015; Henry 2017).

Only four studies reported our pre-specified outcome measures. Among these only tinnitus symptom severity measured with a standardised instrument was reported. Different instruments were used to assess tinnitus symptom severity. Two studies used the THI (dos Santos 2014; Parazzini 2011) and two the Tinnitus Functional Index (TFI) (Henry 2015; Henry 2017). All studies assessed tinnitus symptom severity at three to six months from baseline, with one study also conducting follow-up at 12 months (Parazzini 2011).

Adverse effects were not assessed in any of the included studies.

\section{Quality of the evidence}

For the comparison 'Combination hearing aids versus hearing aids' the quality of evidence for the primary outcome, tinnitus symptom severity, was low. We downgraded the quality of evidence by two levels due to serious risk of bias and imprecision. Serious risk of bias presented as a lack of blinding of participants, personnel and outcome assessors, as well as selection bias. Serious imprecision presented as a wide confidence interval showing a small benefit and a moderate harm.

For the comparison 'Hearing aids versus sound generators' the quality of evidence for tinnitus symptom severity at three months, six months and 12 months was low. For all outcomes, we downgraded the quality of the evidence by two levels due to serious risk of bias and imprecision. Serious risk of bias presented as a lack of blinding of participants and personnel, unclear risk of bias for allocation concealment, blinding of outcome assessors, and attrition bias. Serious imprecision presented as a wide confidence interval showing a substantial benefit and a substantial harm.

\section{Potential biases in the review process}

Our searches of the electronic databases were comprehensive. We also searched the reference lists of the included studies and previous Cochrane Reviews (Hoare 2014; Hobson 2012). Language was not a barrier to inclusion and, in addition to English, we reviewed full-text articles in Chinese and Spanish for eligibility assessment. All author roles were pre-defined in the review process. We adhered to a pre-published protocol and no post hoc decisions or changes were made.

\section{Agreements and disagreements with other studies or reviews}

This is a new review, superseding two previous Cochrane Reviews on sound therapy (masking) and on amplification with hearing aids for tinnitus that were first published in the Cochrane Library in Issue 12, 2010 and updated in 2012 (Hobson 2012) and in Issue 1, 2014 (Hoare 2014), respectively. Hobson 2012 included six studies that varied in design, with significant heterogeneity in the evaluation of subjective tinnitus perception, with different scores, scales, tests and questionnaires as well as variance in the outcome measures used to assess the improvement in tinnitus sensation/quality of life. Due to this variability meta-analysis was not conducted. The main difference between Hobson 2012 and the current review regards the inclusion criteria, as the current review excluded studies evaluating complex interventions, which explicitly included a sound therapy and other non-sound components (e.g. psychotherapy) as a part of a programme (e.g. Neuromonics). Therefore only one study included in Hobson 2012 was also included in this review. Similar to our review, Hobson 2012 concluded that the limited data from the included studies showed that sound therapy on its own is of unproven benefit in the treatment of tinnitus. As with the current review, Hoare 2014 included only one randomised controlled trial (RCT) that is also included in this review, comparing amplification only (hearing aid) to a sound generator (Parazzini 2011), and found no difference between the two interventions. No studies comparing hearing aids to placebo or no intervention were identified.

In 1999 a broad systematic review mapped out the evidence for the therapeutic efficacy of known promising interventions that deserve further research, considering reports of all RCTs of any tinnitus intervention (Dobie 1999). That review included two RCTs looking at 'masking' (Erlandsson 1987; Stephens 1985; both also included in this review). Neither of those studies reported outcome measures pre-specified for the current review, therefore we were not able to derive any conclusions regarding sound therapy based on those studies.

A systematic review and meta-analysis by Hoare 2011b included one study (Stephens 1985; also included in this review). This involved groups of participants with hearing aids, sound generators and combination devices, compared to limited counselling with no device, described in the context of sound enrichment therapy. The review reported no improvements in this study, with one group using sound generators reporting a significant increase in anxiety (measured with the Crown Crisp Experiential Index) compared to controls. The study by Stephens 1985 did not report any of the outcome measures of interest for the current review, therefore we were not able to derive any conclusions regarding sound therapy based on this study.

In summary, similar to the current review, previous reviews have concluded that there is no evidence of a therapeutic benefit of sound therapy for tinnitus. 


\section{AUTHORS' CONCLUSIONS}

\section{Implications for practice}

Sound therapy is the preferred mode of audiological tinnitus management in many countries, including the United Kingdom (Hall 2011). Postulated mechanisms through which sound therapy can be beneficial for tinnitus include reducing tinnitus intrusiveness, aiding habituation, distracting attention from tinnitus and triggering neuroplasticity within the brain (Hoare 2014a). However, we did not find evidence to support or refute the provision of sound therapy as the primary intervention for people with tinnitus. We did not find evidence to suggest that one type of sound therapy device (i.e. hearing aid, sound generator or combination hearing aid) is better than others. However, there were also no reports of adverse effects in the included studies.

In line with the lack of evidence for the effectiveness of sound therapy current tinnitus management guidelines do not make strong recommendations regarding its use in clinical practice and allow patients' preferences to play a significant role in the choice of this management option (Cima 2018; Tunkel 2014). The American Academy of Audiology Clinical Practice Guideline recommends that clinicians should offer a hearing aid evaluation for patients with hearing loss and persistent, bothersome tinnitus (Tunkel 2014). This recommendation was informed by findings from observational studies with a preponderance of benefit over harm and by the lack of high-quality evidence. Highlighted benefits of amplification in patients with hearing loss and tinnitus were improvement in communication function and health-related quality of life with "potential benefit for tinnitus relief". While a recent Cochrane Review found evidence of improvements in communication and general health-related quality of life in people with mild to moderate hearing loss (Ferguson 2017), the current review did not find evidence of benefit for tinnitus. More in line with the evidence presented here, the Multidisciplinary European Guideline for Tinnitus recommends hearing aids for the management of hearing loss and that they should be considered as an option for patients with tinnitus and hearing loss, but should not be offered to patients with tinnitus but without hearing loss (Cima 2018).

With regard to other sound therapy options, namely sound generators and combination hearing aids, neither Tunkel 2014 nor Cima 2018 made a recommendation because they judged the strength of evidence for effectiveness to be low. This is very much in line with the findings of this review. Tunkel 2014 stated that clinicians might recommend sound therapy to patients with persistent, bothersome tinnitus, with a significant role for the patient in deciding whether to pursue sound therapy and choosing among the available options. Cima 2018 concluded that sound therapy may be useful for the purposes of acute tinnitus relief but did not consider it to be effective over the long term.

\section{Implications for research}

Future research into the effectiveness of sound therapy in patients with tinnitus should use rigorous methodology. Randomisation and blinding should be of the highest quality, given the subjective nature of tinnitus and the strong likelihood of a placebo response. The CONSORT statement should be used in the design and reporting of future studies (CONSORT 2010).
We also recommend the use of standardised and validated, patientcentred outcome measures for research in the field of tinnitus. Visual analogue scales have limited value in this regard because quantifying change using only a single item has inadequate measurement properties (e.g. internal consistency cannot be established and test-retest scores are at greater risk of instability). Although most recent studies included in this review used multiitem questionnaires of tinnitus symptom severity, other outcomes such as depressive symptoms or depression, anxiety symptoms or generalised anxiety and health-related quality of life were not measured. None of the studies reported adverse effects. In future trials, in addition to multi-item questionnaires of tinnitus symptom severity, validated instruments measuring depression, anxiety and health-related quality of life should also be used. Adverse effects such as increased tinnitus loudness and adverse effects associated with wearing the device such as pain, discomfort, tenderness, skin irritation or ear infections should be collected and reported.

At the time of the publication of this review, core outcome measures for adults with subjective tinnitus have only recently been identified (Hall 2018a). For sound-based interventions, these are tinnitus intrusiveness, ability to ignore, concentration, quality of sleep and sense of control. None of the trials directly reported any of the core outcome measures. Use of the core outcome set as a minimum standard for what should be assessed and reported in randomised controlled trials will facilitate comparison between studies and meta-analyses (Tunis 2016).

Given the heterogeneity of tinnitus patients, future trials should assess and report baseline characteristics so that the risk of potential confounding factors can be better understood. Examples include tinnitus duration, tinnitus symptom severity, age, hearing loss and co-morbidities since these might reasonably modify treatment success. Future trials might also consider, as a subgroup analysis, the differential effect of sound therapy on acute (i.e. less that three months duration) versus chronic (more than three months duration) subjective idiopathic tinnitus.

Currently there are no trials that consider the effectiveness of sound therapy for acute tinnitus. Only two included studies performed a sample size estimation (dos Santos 2014; Henry 2017), and even then not necessarily reaching the pre-specified targets (dos Santos 2014). Future studies should seek to recruit an adequate sample size based on an appropriate power calculation for the primary outcome.

Evidence for the effectiveness of hearing aids, combination aids and sound generators compared to no intervention, placebo intervention or education/information only is lacking and only a limited number of small-scale studies compared different sound therapy options (hearing aids, combination hearing aids and sound generators). Further research should concentrate on generating the evidence for the effectiveness of each of those management options for tinnitus, followed by trials comparing the effectiveness of different sound therapy options.

All studies included follow-up at three to six months, which was shown to be sufficient for demonstrating improvements with sound therapy (Hobson 2012). However, as the use of sound is intended to alter the tinnitus perception and/or the reactions to tinnitus, the timescale for different mechanisms of action might be different and extend beyond that limit (Hoare 2013). Future studies might consider including long-term follow-up in order to explore 
differences in the mechanisms of action of different sound therapy options (i.e. short- versus long-term intervention; Cima 2012) and changes in patterns of use (Sweetow 2015).

\section{ACKN OWLEDGEMENTS}

We are grateful to Dr Sujana Chandrasekhar for peer reviewing the manuscript for this review and to Sandy Walsh for her input as the consumer referee.

Samantha Cox, Cochrane Information Specialist, designed the search strategy for the review.
Dr Yu-qing Zhang from the Ningbo GRADE Centre, the University of Nottingham Ningbom, provided advice regarding the GRADE ratings and 'Summary of findings' tables.

This project was supported by the National Institute for Health Research, via Cochrane Infrastructure, Cochrane Programme Grant or Cochrane Incentive funding to Cochrane ENT. The views and opinions expressed therein are those of the authors and do not necessarily reflect those of the Systematic Reviews Programme, NIHR, NHS or the Department of Health. 
R E F E R E N C E S

\section{References to studies included in this review}

dos Santos 2014 \{published data only\}

NCT01857661. The influence of the sound generator combined with conventional amplification for tinnitus control: blind randomized clinical trial. https://clinicaltrials.gov/ct2/show/ NCT01857661 (first received 20 May 2013). [NCT01857661]

* dos Santos GM, Bento RF, de Medeiros IR, Oiticcica J, da Silva EC, Penteado S. The influence of sound generator associated with conventional amplification for tinnitus control: randomized blind clinical trial. Trends in Hearing 2014;18:1-9. [DOI: 10.1177/2331216514542657]

\section{Erlandsson 1987 \{published data only\}}

Erlandsson S, Ringdahl A, Hutchins T, Carlsson SG. Treatment of tinnitus: a controlled comparison of masking and placebo. British Journal of Audiology 1987;21:37-44.

Henry 2015 \{published data only\}

Henry JA, Frederick M, Sell S, Griest S, Abrams H. Validation of a novel combination hearing aid and tinnitus therapy device. Ear and Hearing 2015;36(1):42-52. [DOI: 10.1097/ AUD.0000000000000093]

\section{Henry 2017 \{published data only\}}

Henry JA, McMillan G, Dann S, Bennett K, Griest S, Theodoroff S, et al. Tinnitus management: randomized controlled trial comparing extended-wear hearing aids, conventional hearing aids, and combination instruments. Journal of American Academy of Audiology 2017;28:546-61. [DOI: 10.3766/ jaaa.16067]

\section{Melin 1987 \{published data only\}}

Melin L, Scott B, Lindberg P, Lyttkens L. Hearing aids and tinnitus--an experimental group study. British Journal of Audiology 1987;21(2):91-7.

\section{Parazzini 2011 \{published data only\}}

Parazzini M, Del Bo L, Jastreboff M, Tognola G, Ravazzani P. Open ear hearing aids in tinnitus therapy: an efficacy comparison with sound generators. International Journal of Audiology 2011;50:548-53. [DOI: 10.3109/14992027.2011.572263]

\section{Stephens 1985 \{published data only\}}

Hazell JWP, Wood SM, Cooper HR, Stephens SDG, Corcoran AL, Coles RRA, et al. A clinical study of tinnitus maskers. British Journal of Audiology 1985;19:65-146.

* Stephens SDG, Corcoran AL. A controlled study of tinnitus masking. British Journal of Audiology 1985;19:159-67.

Zhang 2013 \{published data only\}

Zhang M, Zhou H, Zhang J, Guo Y, Wang X, Wang N. Evaluating the effects of hearing aids combined with psychological counselling on tinnitus in patients with deafness. Journal of Clinical Otorhinolaryngology Head and Neck Surgery (China) 2013;27(10):461-4.

\section{References to studies excluded from this review}

Al-Jassim 1988 \{published data only\}

Al-Jassim AHH. The use of Walkman mini-stereo system as a tinnitus masker. Journal of Laryngology and Otology 1988;102:27-8.

\section{Andersson 2002 \{published data only\}}

Andersson G, Khakpoor A, Lyttkens L. Masking of tinnitus and mental activity. Clinical Otolaryngology \& Allied Sciences 2002;27(4):270-4.

\section{Benton 2016 \{published data only\}}

Benton SL. Bedside sound generators as a tool for tinnitus management. Hearing Journal 2016;69(5):31-4.

Del Bo 2006 \{published data only\}

Del Bo L, Ambrosetti U, Bettinelli M, Domenichetti E, Fagnani E, Scotti A. Using open-ear hearing aids in tinnitus therapy. Hearing Review 2006;13(9):30.

Durai 2017 \{published data only\}

Durai M, Searchfield GD. A mixed-methods trial of broad band noise and nature sounds for tinnitus therapy: group and individual responses modeled under the adaptation level theory of tinnitus. Frontiers in Aging Neuroscience 2017;9:44.

\section{Gudex 2009 \{published data only\}}

Gudex C, Skellgaard PH, West T, Sørensen J. Effectiveness of a tinnitus management programme: a 2-year follow-up study. BMC Ear, Nose and Throat Disorders 2009;9:6.

\section{Henry 2016 \{published data only\}}

Henry JA, Stewart BJ, Griest S, Kaelin C, Zaugg TL, Carlson K. Multisite randomized controlled trial to compare two methods of tinnitus intervention to two control conditions. Ear and Hearing 2016;37(6):e346-59.

\section{Hernández Moñiz 1998 \{published data only\}}

Hernández Moñiz F, Barrio A, Pérez A, Pertierra MA, Salafranca JM, González M. Prospective therapeutic trial of masking treatment in patients with tinnitus. Acta Otorrinolaringológica Española 1998;49(6):437-41.

Hiller 2005 \{published data only\}

Hiller W, Haerkotter C. Does sound stimulation have additive effects on cognitive-behavioral treatment of chronic tinnitus? Behaviour Research and Therapy 2005;43(5):595-612.

\section{Hodgson 2017 \{published data only\}}

Hodgson SA, Herdering R, Singh Shekhawat G, Searchfield GD. A crossover trial comparing wide dynamic range compression and frequency compression in hearing aids for tinnitus therapy. Disability and Rehabilitation. Assistive Technology 2017;12(1):97-103. 
Lipman 2007 \{published data only\}

Lipman RI, Lipman SP. Phase-shift treatment for predominant tone tinnitus. Otolaryngology - Head and Neck Surgery 2007;136(5):763-8.

\section{Mehlum 1984 \{published data only\}}

Mehlum D, Grasel G, Frankhauser C. Prospective crossover evaluation of four methods of clinical management of tinnitus. Otolaryngology--Head and Neck Surgery 1984;92(4):448-53.

\section{Shabana 2018 \{published data only\}}

Shabana MI, Dabbous AO, Abdelmajeed MA, Abdelkarim AMM. Counselling and amplification with and without fractal music (Zen tones) for management of patients suffering from hearing loss and tinnitus. Hearing, Balance and Communication 2018;16(1):41-55.

\section{Strauss 2015 \{published data only\}}

Strauss DJ, Corona-Strauss FI, Seidler H, Haab L, Hannemann R. Notched environmental sounds: a new hearing aid supported tinnitus treatment evaluated in 20 patients. Clinical Otolaryngology 2015;42(1):172-5.

\section{Sweetow 2010 \{published data only\}}

Sweetow RW, Sabes JH. Effects of acoustical stimuli delivered through hearing aids on tinnitus. Journal of the American Academy of Audiology 2010;21(7):461-73.

\section{Tao 2017 \{published data only\}}

Tao Y, Chang X, Ye S, Chu G, Guan T, Wang J, et al. Multiplefrequency matching treatment strategy for tinnitus. Journal of International Advanced Otology 2017;13(2):221-5.

\section{Thedoroff 2017 \{published data only\}}

Theodoroff SM, McMillan GP, Zaugg TL, Cheslock M, Roberts C, Henry JA. Randomized controlled trial of a novel device for tinnitus sound therapy during sleep. American Journal of Audiology 2017;26(4):543-54.

\section{References to ongoing studies}

\section{ISRCTN15178771 \{unpublished data only\}}

ISRCTN15178771. Efficacy of a combination hearing aid and sound generator. http://www.isrctn.com/ISRCTN15178771 (first received 27 April 2015).

\section{TCTR20180225002 \{unpublished data only\}}

TCTR20180225002. A randomized controlled trial of music therapy in tinnitus patient. http://www.clinicaltrials.in.th/index.php?

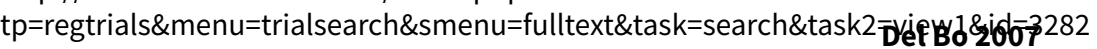
(first received 24 February 2018).

\section{Additional references}

\section{Adjamian 2009}

Adjamian P, Sereda M, Hall DA. The mechanisms of tinnitus: perspectives from human functional neuroimaging. Hearing Research 2009;253(1-2):15-31.

\section{Baguley 2013}

Baguley D, McFerran D, Hall D. Tinnitus. Lancet 2013;382(9904):1600-7. [PUBMED: 23827090]

\section{Beck 1988}

Beck AT, Epstein N, Brown G, Steer RA. An inventory for measuring clinical anxiety: psychometric properties. Journal of Consulting and Clinical Psychology 1988;56(6):893-7.

\section{Beck 1996}

Beck AT, Steer RA, Brown GK. Manual for the Beck Depression Inventory-II. San Antonio, TX: Psychological Corporation, 1996.

\section{Beck 2011}

Beck DL. Hearing aid amplification and tinnitus: 2011 overview. Hearing Journal 2011;64(6):12-4.

\section{Biesinger 2010}

Biesinger E, Del Bo L, De Ridder D, Goodey R, Herraiz C, Kleinjung $\mathrm{T}$, et al. Algorithm for the diagnostic \& therapeutic management of tinnitus. Tinnitus Clinic Network, Tinnitus Research Initiative. Available at: www.tinnitus research.org/en/ documents/downloads/TRI_Tinnitus_Flowchart.pdf (accessed 9 August 2010) 2010

\section{Buss 1998}

Buss E, Hall JW, Grose JH, Hatch DR. Perceptual consequences of peripheral hearing loss: do edge effects exist for abrupt cochlear lesions?. Hearing Research 1998;125(1-2):98-108.

\section{Carmen 2002}

Carmen R, Uram S. Hearing loss and anxiety in adults. Hearing Journal 2002:55(4):48-50.

\section{Cima 2012}

Cima RF, Maes IH, Joore MA, Scheyen DJ, El Refaie A, Baguley DM, et al. Specialised treatment based on cognitive behaviour therapy versus usual care for tinnitus: a randomised controlled trial. Lancet 2012;379(9830):1951-9.

\section{Cima 2018}

Cima R. Multidisciplinary European Guideline for Tinnitus: Diagnostics, Assessment and Treatment. Proceedings of the 11th Tinnitus Research Initiative Conference. Regensburg, Germany, 14-16 March 2018.

\section{CONSORT 2010}

Schulz KF, Altman DG, Moher D, for the CONSORT Group. CONSORT 2010 Statement: updated guidelines for reporting parallel group randomised trials. BMJ 2010;340:c332.

Del Bo L, Ambrosetti U. Hearing aids for the treatment of tinnitus. Progress in Brain Research 2007;166:341-5.

\section{Department of Health 2009}

Department of Health. Provision of Services for Adults with Tinnitus. A Good Practice Guide. London: Central Office of Information, 2009. 


\section{Dietrich 2001}

Dietrich V, Nieschalk M, Stoll W, Rajan R, Pantev C. Cortical reorganization in patients with high frequency cochlear hearing loss. Hearing Research 2001;158(1-2):95-101.

\section{Dobie 1999}

Dobie RA. A review of randomized clinical trials in tinnitus. Laryngoscope 1999;109(8):1202-11.

\section{Dong 2010}

Dong S, Rodger J, Mulders WH, Robertson D. Tonotopic changes in GABA receptor expression in guinea pig inferior colliculus after partial unilateral hearing loss. Brain Research 2010;1342:24-32.

\section{Donner 2002}

Donner A, Klar N. Issues in the meta-analysis of cluster randomized trials. Statistics in Medicine 2002;21:2971-80.

\section{Eggermont 2004}

Eggermont JJ, Roberts LE. The neuroscience of tinnitus. Trends in Neurosciences 2004;27(11):676-82.

\section{El Refaie 2004}

El Refaie A, Davis A, Kayan A, Baskill J, Lovell E, Owen V. A questionnaire study of the quality of life and quality of family life of individuals complaining of tinnitus pre- and post-attendance at a tinnitus clinic. International Journal of Audiology 2004;43(7):410-6.

\section{El-Shunnar 2011}

El-Shunnar SK, Hoare DJ, Smith S, Gander PE, Kang S, Fackrell K, et al. Primary care for tinnitus: practice and opinion among GPs in England. Journal of Evaluation in Clinical Practice 2011;17(4):684-92.

\section{Engineer 2011}

Engineer ND, Riley JR, Seale JD, Vrana WA, Shetake JA, Sudanagunta SP, et al. Reversing pathological neural activity using targeted plasticity. Nature 2011;470(7332):101-4.

\section{Ferguson 2017}

Ferguson MA, Kitterick PT, Chong LY, Edmondson-Jones M, Barker F, Hoare DJ. Hearing aids for mild to moderate hearing loss in adults. Cochrane Database of Systematic Reviews 2017, Issue 9. [DOI: 10.1002/14651858.CD012023.pub2]

\section{Forti 2010}

Forti S, Crocetti A, Scotti A, Costanzo S, Pignataro L, Ambrosetti $U$, et al. Tinnitus sound therapy with open ear canal hearing aids. B-ENT 2010;6(3):195-9.

\section{Fowler 1944}

Fowler EP. Head noises in normal and in disordered ears: significance, measurement, differentiation and treatment. Archives of Otolaryngology 1944;39(6):498-503.

\section{Furlong 2001}

Furlong WJ, Feeny DH, Torrance GW, Barr RD. The Health Utilities Index $\left(\mathrm{HUI}^{\circledR}\right)$ system for assessing health-related quality of life in clinical studies. Annals of Medicine 2001;33:375-84.

\section{Gallus 2015}

Gallus S, Lugo A, Garavello W, Bosetti C, Santoro E, Colombo P, et al. Prevalence and determinants of tinnitus in the Italian adult population. Neuroepidemiology 2015;45(1):12-9. [PUBMED: 26182874]

\section{Guitton 2003}

Guitton MJ, Caston J, Ruel J, Johnson RM, Pujol R, Puel JL. Salicylate induces tinnitus through activation of cochlear NMDA receptors. Journal of Neuroscience 2003;23(9):3944-52.

\section{Hall 2011}

Hall DA, Lainez MJ, Newman CW, Sanchez TG, Egler M, Tennigkeit $F$, et al. Treatment options for subjective tinnitus: self reports from a sample of general practitioners and ENT physicians within Europe and the USA. BMC Health Services Research 2011;11:302.

\section{Hall 2018}

Hall DA, Fackrell K, Li AB, Thavayogan R, Smith S, Kennedy V, et al. A narrative synthesis of research evidence for tinnitusrelated complaints as reported by patients and their significant others. Health and Quality of Life Outcomes 2018;16(1):61. [PUBMED: 29642913]

\section{Hall 2018a}

Hall DA, Smith H, Hibbert A, Colley V, Haider HF, Horobin A, et al. The COMiT'ID study: developing core outcome domains sets for clinical trials of sound-, psychology-, and pharmacology-based interventions for chronic subjective tinnitus in adults. Trends in Hearing 2018;22:2331216518814384. [PUBMED: 30488765]

\section{Hallam 1996}

Hallam RS. Manual of the Tinnitus Questionnaire (TQ). London: The Psychological Corporation, Brace \& Co, 1996.

\section{Hamilton 1960}

Hamilton M. A rating scale for depression. Journal of Neurology, Neurosurgery \& Psychiatry 1960;23(1):56-62.

\section{Han 2009}

Han BI, Lee HW, Kim TY, Lim JS, Shin KS. Tinnitus: characteristics, causes, mechanisms, and treatments. Journal of Clinical Neurology 2009;5(1):11-9.

\section{Handbook 2011}

Higgins JPT, Green S (editors). Cochrane Handbook for Systematic Reviews of Interventions Version 5.1.0 [updated March 2011]. The Cochrane Collaboration, 2011. Available from www.cochrane-handbook.org.

\section{Hays 1993}

Hays RD, Sherbourne CD, Mazel RM. The RAND 36-Item Health Survey 1.0. Health Economics 1993;2(3):217-27.

\section{Henry 2002}

Henry JA, Schechter MA, Nagler SM, Fausti SA. Comparison of tinnitus masking and tinnitus retraining therapy. Journal of the American Academy of Audiology 2002;13(10):559-81. 


\section{Henry 2004}

Henry JA, Snow JB (editors). Tinnitus: Theory and Management. Ontario: BC Becker Inc, 2004.

\section{Henry 2004a}

Henry JA, Rheinsburg B, Zaugg T. Comparison of custom sounds for achieving tinnitus relief. Journal of the American Academy of Audiology 2004;15(8):585-98.

\section{Henry 2005}

Henry JA, Dennis KC, Schechter MA. General review of tinnitus: prevalence, mechanisms, effects, and management. Journal of Speech, Language, and Hearing Research 2005;48(5):1204-35.

\section{Henry 2008}

Henry JA, Zaugg TL, Myers PJ, Schechter MA. The role of audiologic evaluation in progressive audiologic tinnitus management. Trends in Amplification 2008;12(3):170-87.

\section{Henry 2008a}

Henry JA, Zaugg TL, Myers PJ, Schechter MA. Using therapeutic sound with progressive audiologic tinnitus management. Trends in Amplification 2008;12(3):188-209.

\section{Henry 2010}

Henry JA, Zaugg TL, Myers PM, Kendall CJ. Progressive Tinnitus Management: Counseling Guide. San Diego, CA: Plural Publishing, 2010.

\section{Hiller 1992}

Hiller W, Goebel G. A psychometric study of complaints in chronic tinnitus. Journal of Psychosomatic Research 1992;36(4):337-48. [PUBMED: 1593509]

\section{Hiller 2006}

Hiller W, Goebel G. Factors influencing tinnitus loudness and annoyance. Archives of Otolaryngology--Head \& Neck Surgery 2006;132(12):1323-30.

\section{Hoare 2011}

Hoare DJ, Hall DA. Clinical guidelines and practice: a commentary on the complexity of tinnitus management. Evaluation \& the Health Professions 2011;34(4):413-20.

\section{Hoare 2011b}

Hoare DJ, Kowalkowski V, Kang S, Hall DA. Systematic review and meta-analyses of randomized controlled trials examining tinnitus management. Laryngoscope 2011;121(7):1555-64.

\section{Hoare 2012}

Hoare DJ, Gander PE, Collins L, Smith S, Hall DA. Management of tinnitus in English NHS audiology departments: an evaluation of current practice. Journal of Evaluation in Clinical Practice 2012;18(2):326-34.

\section{Hoare 2013}

Hoare DJ, Searchfield GD, El Refaie A, Henry JA. Sound therapy for tinnitus management: practicable options. Journal of the American Academy of Audiology 2014;25(1):62-75.

\section{Hoare 2014}

Hoare DJ, Edmondson-Jones M, Sereda M, Akeroyd MA, Hall D. Amplification with hearing aids for patients with tinnitus and co-existing hearing loss. Cochrane Database of Systematic Reviews 2014, Issue 1. [DOI: 10.1002/14651858.CD010151.pub2]

\section{Hoare 2014a}

Hoare DJ, Searchfield GD, El Refaie A, Henry JA. Sound therapy for tinnitus management: practicable options. Journal of the American Academy of Audiology 2014;25:62-75.

\section{Hoare 2015}

Hoare DJ, Whitham D, Henry JA, Shorter GW. Neuromodulation (desynchronisation) for tinnitus in adults. Cochrane Database of Systematic Reviews 2015, Issue 6. [DOI: 10.1002/14651858.CD011760]

\section{Hobson 2012}

Hobson J, Chisholm E, El Refaie A. Sound therapy (masking) in the management of tinnitus in adults. Cochrane Database of Systematic Reviews 2012, Issue 11. [DOI: 10.1002/14651858.CD006371.pub3]

\section{Jastreboff 1988}

Jastreboff PJ, Brennan JF, Coleman JK, Sasaki CT. Phantom auditory sensation in rats: an animal model for tinnitus. Behavioral Neuroscience 1988;102(6):811-22.

\section{Jastreboff 1990}

Jastreboff PJ. Phantom auditory perception (tinnitus): mechanisms of generation and perception. Neuroscience Research 1990;8(4):221-54.

\section{Jastreboff 1993}

Jastreboff PJ, Hazell JW. A neurophysiological approach to tinnitus: clinical implications. British Journal of Audiology 1993;27(1):7-17.

\section{Jastreboff 2000}

Jastreboff PJ, Jastreboff MM. Tinnitus retraining therapy (TRT) as a method for treatment of tinnitus and hyperacusis patients. Journal of the American Academy of Audiology 2000;11(3):162-77.

\section{Jastreboff 2004}

Jastreboff PJ, Hazell JWP. Tinnitus Retraining Therapy: Implementing the Neurophysiological Model. New York: Cambridge University Press, 2004.

\section{Jastreboff 2006}

Jastreboff PJ, Jastreboff MM. Tinnitus retraining therapy: a different view on tinnitus. ORL; Journal for Oto-rhinolaryngology and Its Related Specialties 2006;68(1):23-9; discussion 29-30.

\section{Jastreboff 2007}

Jastreboff PJ. Tinnitus retraining therapy. Progress in Brain Research 2007;166:415-23. 


\section{Kluk 2006}

Kluk K, Moore BC. Dead regions in the cochlea and enhancement of frequency discrimination: effects of audiogram slope, unilateral versus bilateral loss, and hearing-aid use. Hearing Research 2006;222(1-2):1-15.

\section{Konig 2006}

Konig O, Schaette R, Kempter R, Gross M. Course of hearing loss and occurrence of tinnitus. Hearing Research 2006;221(1-2):59-64.

\section{Korres 2010}

Korres S, Mountricha A, Balatsouras D, Maroudias N, Riga M, Xenelis I. Tinnitus retraining therapy (TRT): outcomes after oneyear treatment. International Tinnitus Journal 2010;16(1):55-9.

\section{Kuk 1990}

Kuk FK, Tyler RS, Russell D, Jordan H. The psychometric properties of a tinnitus handicap questionnaire. Ear and Hearing 1990;11:434-45.

\section{Martines 2010}

Martines F, Bentivegna D, Di Piazza F, Martines E, Sciacca V, Martinciglio $\mathrm{G}$. Investigation of tinnitus patients in Italy: clinical and audiological characteristics. International Journal of Otolaryngology 2010;2010:265861.

\section{McCormack 2016}

McCormack A, Edmondson-Jones M, Somerset S, Hall D. A systematic review of the reporting of tinnitus prevalence and severity. Hearing Research 2016;337:70-9. [PUBMED: 27246985]

\section{McDermott 1998}

McDermott HJ, Lech M, Kornblum MS, Irvine DR. Loudness perception and frequency discrimination in subjects with steeply sloping hearing loss: possible correlates of neural plasticity. Journal of the Acoustical Society of America 1998;104(4):2314-25.

\section{McFerran 2009}

McFerran D. Tinnitus and hyperacusis. In: Graham JM, Baguley DM editor(s). Ballantyne's Deafness. Chichester, UK: WileyBlackwell, 2009:175-88.

\section{Meikle 2012}

Meikle MB, Henry JA, Griest SE, Stewart BJ, Abrams HB, McArdle R, et al. The tinnitus functional index: development of a new clinical measure for chronic, intrusive tinnitus. Ear and Hearing 2012;33:153-76.

\section{Melcher 2013}

Melcher JR, Knudson IM, Levine RA. Subcallosal brain structure: correlation with hearing threshold at supra-clinical frequencies $(>8 \mathrm{kHz})$, but not with tinnitus. Hearing Research 2013;295:79-86.

\section{Middleton 2011}

Middleton JW, Kiritani T, Pedersen C, Turner JG, Shepherd GM, Tzounopoulos T. Mice with behavioral evidence of tinnitus exhibit dorsal cochlear nucleus hyperactivity because of decreased GABAergic inhibition. Proceedings of the
National Academy of Sciences of the United States of America 2011;108(18):7601-6.

\section{Moffat 2009}

Moffat G, Adjout K, Gallego S, Thai-Van H, Collet L, Norena AJ. Effects of hearing aid fitting on the perceptual characteristics of tinnitus. Hearing Research 2009;254(1-2):82-91.

\section{Moller 2000}

Moller AR. Similarities between severe tinnitus and chronic pain. Journal of the American Academy of Audiology 2000;11(3):115-24

\section{Moore 2009}

Moore BC, Vinay SN. Enhanced discrimination of low-frequency sounds for subjects with high-frequency dead regions. Brain 2009;132(Pt 2):524-36.

\section{Muhlnickel 1998}

Muhlnickel W, Elbert T, Taub E, Flor H. Reorganization of auditory cortex in tinnitus. Proceedings of the National Academy of Sciences of the United States of America 1998;95(17):10340-3.

\section{Mulders 2010}

Mulders WH, Seluakumaran K, Robertson D. Efferent pathways modulate hyperactivity in inferior colliculus. Journal of Neuroscience 2010;30(28):9578-87.

\section{Newman 1996}

Newman CW, Jacobson GP, Spitzer JB. Development of the tinnitus handicap inventory. Archives of Otolaryngology--Head and Neck Surgery 1996;122:143-8.

\section{Norena 2005}

Norena AJ, Eggermont JJ. Enriched acoustic environment after noise trauma reduces hearing loss and prevents cortical map reorganization. Journal of Neuroscience 2005;25(3):699-705.

\section{Norena 2011}

Norena AJ. An integrative model of tinnitus based on a central gain controlling neural sensitivity. Neuroscience and Biobehavioral Reviews 2011;35(5):1089-109.

\section{Pilati 2012}

Pilati N, Large C, Forsythe ID, Hamann M. Acoustic overexposure triggers burst firing in dorsal cochlear nucleus fusiform cells. Hearing Research 2012;283(1-2):98-106.

\section{Ratnayake 2009}

Ratnayake SA, Jayarajan V, Bartlett J. Could an underlying hearing loss be a significant factor in the handicap caused by tinnitus?. Noise \& Health 2009;11(44):156-60.

\section{Rauschecker 1999}

Rauschecker JP. Auditory cortical plasticity: a comparison with other sensory systems. Trends in Neurosciences 1999;22(2):74-80. 


\section{Rauschecker 2010}

Rauschecker JP, Leaver AM, Mühlau M. Tuning out the noise: limbic-auditory interactions in tinnitus. Neuron 2010;66(6):819-26

\section{Reiss 1986}

Reiss S, Peterson RA, Gursky DM, McNally RJ. Anxiety sensitivity, anxiety frequency and the prediction of fearfulness. Behaviour Research and Therapy 1986;24(1):1-8.

\section{RevMan 2014 [Computer program]}

The Nordic Cochrane Centre, The Cochrane Collaboration. Review Manager (RevMan). Version 5.3. Copenhagen: The Nordic Cochrane Centre, The Cochrane Collaboration, 2014.

\section{Roberts 2010}

Roberts LE, Eggermont JJ, Caspary DM, Shore SE, Melcher JR, Kaltenbach JA. Ringing ears: the neuroscience of tinnitus. Journal of Neuroscience 2010;30(45):14972-9.

\section{Sahley 2001}

Sahley TL, Nodar RH. A biochemical model of peripheral tinnitus. Hearing Research 2001;152(1-2):43-54.

\section{Saltzman 1947}

Saltzman M, Ersner MS. A hearing aid for the relief of tinnitus aurium. Laryngoscope 1947;57(5):358-66

\section{Sanchez 2002}

Sanchez TG, Ferrari GMS. The control of tinnitus through hearing aids: suggestions for optimal use. Pró-Fono Rev Atualização Cient 2002;14:111-8.

\section{Schaette 2006}

Schaette R, Kempter R. Development of tinnitus-related neuronal hyperactivity through homeostatic plasticity after hearing loss: a computational model. European Journal of Neuroscience 2006;23(11):3124-38.

\section{Schaette 2011}

Schaette R, McAlpine D. Tinnitus with a normal audiogram: physiological evidence for hidden hearing loss and computational model. Journal of Neuroscience 2011;31(38):13452-7.

\section{Searchfield 2010}

Searchfield GD, Kaur M, Martin WH. Hearing aids as an adjunct to counseling: tinnitus patients who choose amplification do better than those that don't. International Journal of Audiology 2010;49(8):574-9.

\section{Searchfield 2017}

Searchfield GD, Durai M, Linford T. A state-of-the-art review: personalization of tinnitus sound therapy. Frontiers in Psychology 2017;8:1599.

\section{Seki 2003}

Seki S, Eggermont JJ. Changes in spontaneous firing rate and neural synchrony in cat primary auditory cortex after localized tone-induced hearing loss. Hearing Research 2003;180(1-2):28-38.

\section{Sereda 2011}

Sereda M, Hall DA, Bosnyak DJ, Edmondson-Jones M, Roberts LE, Adjamian P, et al. Re-examining the relationship between audiometric profile and tinnitus pitch. International Journal of Audiology 2011;50(5):303-12.

\section{Sereda 2015}

Sereda M, Hoare DJ, Nicholson R, Smith S, Hall DA. Consensus on hearing aid candidature and fitting for mild hearing loss, with and without tinnitus: Delphi review. Ear and Hearing 2015;36(4):417-29.

\section{Sereda 2015a}

Sereda M, Edmondson-Jones M, Hall DA. Relationship between tinnitus pitch and edge of hearing loss in individuals with a narrow tinnitus bandwidth. International Journal of Audiology 2015;54(4):249-56.

\section{Sereda 2017}

Sereda M, Davies J, Hall DA. Pre-market version of a commercially available hearing instrument with a tinnitus sound generator: feasibility of evaluation in a clinical trial. International Journal of Audiology 2017;56(4):286-94.

\section{Shepperd 2009}

Shepperd S, Lewin S, Straus S, Clarke M, Eccles MP, Fitzpatrick R, et al. Can we systematically review studies that evaluate complex interventions?. PLoS Medicine 2009;6(8):e1000086.

\section{Skevington 2004}

Skevington SM, Lotfy M, O'Connell KA. The World Health Organization's WHOQOL-BREF quality of life assessment: psychometric properties and results of the international field trial. A report from the WHOQOL group. Quality of Life Research 2004;13(2):299-310.

\section{Surr 1985}

Surr RK, Montgomery AA, Mueller HG. Effect of amplification on tinnitus among new hearing aid users. Ear and Hearing $1985 ; 6(2): 71-5$

\section{Sweetow 1990}

Sweetow RW, Levy MC. Tinnitus severity scaling for diagnostic/ therapeutic usage. Hearing Instruments 1990;41:20-1.

\section{Sweetow 2015}

Sweetow RW, Fehl M, Ramos PM. Do tinnitus patients continue to use amplification and sound therapy post habilitation?. Hearing Review 2015;19:20-7.

\section{Tass 2012}

Tass PA, Adamchic I, Freund HJ, von Stackelberg T, Hauptmann C. Counteracting tinnitus by acoustic coordinated reset neuromodulation. Restorative Neurology and Neuroscience 2012;30(2):137-59.

\section{Thai-Van 2002}

Thai-Van H, Micheyl C, Norena A, Collet L. Local improvement in auditory frequency discrimination is associated with hearing- 
loss slope in subjects with cochlear damage. Brain 2002;125(Pt 3):524-37.

\section{Thai-Van 2003}

Thai-Van H, Micheyl C, Moore BC, Collet L. Enhanced frequency discrimination near the hearing loss cut-off: a consequence of central auditory plasticity induced by cochlear damage?. Brain 2003;126(Pt 10):2235-45.

\section{Trotter 2008}

Trotter MI, Donaldson I. Hearing aids and tinnitus therapy: a 25-year experience. Journal of Laryngology and Otology 2008;122(10):1052-6.

\section{Tunis 2016}

Tunis SR, Clarke M, Gorst SL, Gargon E, Blazeby JM, Altman DG, et al. Improving the relevance and consistency of outcomes in comparative effectiveness research. Journal of Comparative Effectiveness Research 2016;5(2):193-205. [PUBMED: 26930385]

\section{Tunkel 2014}

Tunkel DE, Bauer CA, Sun GH, Rosenfeld RM, Chandrasekhar SS, Cunningham ER Jr, et al. Clinical practice guideline: tinnitus executive summary. Otolaryngology--Head and Neck Surgery 2014;151(4):533-41. [PUBMED: 25274374]

\section{Tutaj 2018}

Tutaj L, Hoare DJ, Sereda M. Combined amplification and sound generation for tinnitus: a scoping review. Ear and Hearing 2018;39(3):412-22.

\section{Vanneste 2012}

Vanneste S, De Ridder D. The auditory and non-auditory brain areas involved in tinnitus. An emergent property of multiple parallel overlapping subnetworks. Frontiers in Systems Neuroscience 2012;6:31.

\section{Vernon 1976}

Vernon J, Silverstein $\mathrm{H}$, Norrell $\mathrm{H}$. The use of masking for relief of tinnitus. Neurological Surgery of the Ear 1976;2:104-18.

\section{CHARACTERISTICS OF STUDIES}

Characteristics of included studies [ordered by study ID]

\section{Vernon 1977}

Vernon JA. Attempts to relieve tinnitus. Journal of the American Audiology Society 1977;2:124-31.

\section{Vernon 1988}

Vernon JA. Current use of masking for the relief of tinnitus. In: Kitahara M editor(s). Tinnitus: Pathophysiology and Management. Tokyo: Igaku-Shoin, 1988:96-106.

\section{Vernon 2000}

Vernon JA, Meikle MB. Tinnitus masking. Tinnitus Handbook. San Diego: Singular, 2000:313-56.

\section{Weisz 2005}

Weisz N, Moratti S, Meinzer M, Dohrmann K, Elbert T. Tinnitus perception and distress is related to abnormal spontaneous brain activity as measured by magnetoencephalography. PLoS Medicine 2005;2(6):e153.

\section{Wilson 1991}

Wilson PH, Henry J, Bowen M, Haralambous G. Tinnitus reaction questionnaire: psychometric properties of a measure of distress associated with tinnitus. Journal of Speech and Hearing Research 1991;34:197-201.

\section{Zigmond 1983}

Zigmond AS, Snaith RP. The hospital anxiety and depression scale. Acta Psychiatrica Scandinavica 1983;67:361-70.

\section{References to other published versions of this review Sereda 2018}

Sereda M, Xia J, El Refaie A, Hall DA, Hoare DJ. Sound therapy (using amplification devices and/or sound generators) for tinnitus in adults. Cochrane Database of Systematic Reviews 2018, Issue 8. [DOI: 10.1002/14651858.CD013094]

* Indicates the major publication for the study

dos Santos 2014

Methods 2-arm, single-centre, randomised, controlled (parallel) trial with 3 months duration of treatment and 3 months duration of follow-up

Participants Setting: patients were screened and treated at the Department of Otorhinolaryngology, University of São Paulo, Brazil

\section{Sample size:}

- Number randomised: 49

- Number completed: 47

49 participants were enrolled, but due to 2 participants lost to follow-up data from 47 participants were included in the analysis. Sample size calculations based on the Tinnitus Handicap Inventory indicated that to achieve $80 \%$ power to detect a minimum difference of 20 points between the groups at a two- 

fore due to excluding patients lost to follow-up from the analysis $(n=2)$ the sample size was lower than required ( $n=47 ; n=24$ and 23 per group).

\section{Participant (baseline) characteristics:}

- Age: group level data for age were not provided. The 47 participants included in the analysis were between 26 and 91 years old

- Gender: group level data for gender were not provided. 25 women and 22 men were included in the study.

\section{- Other characteristics:}

Group level data for laterality of tinnitus, characteristics of tinnitus and depression/anxiety were not provided. The most frequent location of tinnitus was in both ears $(n=18)$, followed by the head $(n=15)$ and in only one ear $(n=14)$. The most common types of tinnitus were whistling $(n=9)$, roaring $(n=7)$ and buzzing $(n=6)$.

Group level data for participants included in the analysis for age, duration of tinnitus, baseline tinnitus severity, psychoacoustic characteristics of tinnitus (loudness, minimum masking level and pitch) and hearing loss were provided. The group who received combination aids had a mean age of 74.4 years (SD 10.7) and the group who received hearing aids had a mean age of 69.7 years (14.2). Mean duration of tinnitus was 12.7 years (SD 8.3) in the combination aid group and 7.6 years (SD 6.6) in the hearing aid group. Tinnitus duration was significantly different between the 2 groups (Wilcoxon test; $P=$ 0.02). The mean Tinnitus Handicap Inventory score was 53.2 (SD 20.5) in the combination aid group and 57.5 (SD 16.4) in the hearing aid group, numeric scale of tinnitus discomfort score was 7.8 (SD 1.9) in both groups. Mean tinnitus loudness measured using loudness matching was $10.2 \mathrm{dBSL}$ (SD 4.7) in the combination aid group and $9 \mathrm{dBSL}(4.5)$ in the hearing aid group, mean minimum masking level was 25.2 dBSL (SD 24.8) and 23.5 dBSL (SD 18.1) respectively, and mean tinnitus pitch measured with pitch matching procedure was $5041 \mathrm{~Hz}$ (SD 1983) and $4773 \mathrm{~Hz}$ (SD 2207) respectively. In the combination aid group 14 participants had mild and 10 moderate hearing loss; 17 had sloping and 7 flat hearing loss. In the hearing aid group 12 participants had mild and 11 moderate hearing loss; 19 had sloping and 4 flat hearing loss. None of the baseline measures, except tinnitus duration, were significantly different between groups.

Inclusion criteria: adults (18 years and older), mild to moderate bilateral symmetrical sensorineural hearing loss, with complaints of constant tinnitus for at least 6 months, with THI score more than 20 points and without prior experience with hearing aids or any other type of sound therapy

Exclusion criteria: profound hearing loss, conductive hearing loss, $\mathrm{THI}$ score $<20$

The combination hearing aid group was fitted bilaterally with hearing aids with integrated sound generator developed by the Department of Otorhinolaryngology of the University of São Paulo, in combined mode or, in other words, with the combined use of amplification and sound generator. This was a behind-the-ear (BTE) digital hearing aid with 16 channels of gain adjustments. It was equipped with an integrated white noise that could be used together with the amplification mode or not. The hearing aids group was fitted bilaterally with the same hearing aid, but in simple mode, meaning amplification alone. The patients were advised to use the device for at least 8 hours per day. Duration of treatment was 3 months.

Use of additional interventions: both groups received the same specific counselling about the aspects relevant to tinnitus

Secondary: numeric scale of tinnitus discomfort (1 to 10) and psychometric measures of tinnitus (tinnitus pitch obtained through pitch matching procedure, tinnitus loudness obtained through loudness matching procedure and minimum masking level) 
dos Santos 2014 (Continued)

Outcomes were measured at 3 months

Funding sources This study was financially supported in the form of Research Grants by the Foundation for Research Support of São Paulo state

\begin{tabular}{ll}
\hline Declarations of interest & None declared \\
\hline Notes & -
\end{tabular}

\section{Risk of bias}

\begin{tabular}{lll}
\hline Bias & Authors' judgement & Support for judgement \\
\hline $\begin{array}{ll}\text { Random sequence genera- } \\
\text { tion (selection bias) }\end{array}$ & Unclear risk & $\begin{array}{l}\text { The authors stated that participants were randomly allocated to groups but } \\
\text { did not provide any details on methods: "(...) the patients were randomly as- } \\
\text { signed into two groups: a combined fitting group and an amplification alone } \\
\text { group". The trial was registered in clinicaltrials.gov as a randomised controlled } \\
\text { trial. }\end{array}$ \\
\hline
\end{tabular}

\begin{tabular}{lll}
\hline $\begin{array}{l}\text { Allocation concealment } \\
\text { (selection bias) }\end{array}$ & Unclear risk & Information not reported in the manuscript or trial registration \\
\hline $\begin{array}{l}\text { Blinding of participants } \\
\begin{array}{l}\text { and personnel (perfor- } \\
\text { mance bias) }\end{array}\end{array}$ & $\begin{array}{l}\text { Unclear risk } \\
\text { All outcomes }\end{array}$ & $\begin{array}{l}\text { Initial evaluation and final evaluation was performed by a blind evaluator. Sin- } \\
\text { gle blinding (investigator) stated in the trial registration. Participants were not } \\
\text { blinded. }\end{array}$
\end{tabular}

All outcomes

\begin{tabular}{lll}
\hline $\begin{array}{l}\text { Blinding of outcome as- } \\
\text { sessment (detection bias) } \\
\text { All outcomes }\end{array}$ & Low risk & $\begin{array}{l}\text { Initial evaluation and final evaluation was performed by a blind evaluator. Sin- } \\
\text { gle blinding (investigator) stated in the trial registration. }\end{array}$ \\
\hline $\begin{array}{l}\text { Incomplete outcome data } \\
\text { (attrition bias) }\end{array}$ & Low risk & $\begin{array}{l}2 \text { participants did not attend the final evaluation; reasons were reported in } \\
\text { the manuscript: "Of the } 49 \text { patients who took part in the study, two did not at- } \\
\text { tend the final evaluation. One of them was not located, and the other suffered } \\
\text { a heart attack which made it impossible to attend. They were both therefore } \\
\text { excluded from the statistical analysis for missing the follow-up." }\end{array}$
\end{tabular}

\begin{tabular}{|c|c|c|}
\hline $\begin{array}{l}\text { Selective reporting (re- } \\
\text { porting bias) }\end{array}$ & Low risk & $\begin{array}{l}\text { Primary outcome reported in clinicaltrials.gov record. Additional secondary } \\
\text { outcomes were reported in the manuscript that were not stated in the trial } \\
\text { registration (numeric scale of tinnitus discomfort, tinnitus pitch, tinnitus loud- } \\
\text { ness, minimum masking level). }\end{array}$ \\
\hline Other bias & Low risk & $\begin{array}{l}\text { No other biases identified. Trial registered in clinicaltrials.gov, trial identifier: } \\
\text { NCT01857661. }\end{array}$ \\
\hline
\end{tabular}

\section{Erlandsson 1987}

\begin{tabular}{ll}
\hline Methods & $\begin{array}{l}\text { 2-arm, single-centre, cross-over randomised trial with } 6 \text { weeks duration of treatment (primary end- } \\
\text { point) }\end{array}$ \\
\hline Participants & $\begin{array}{l}\text { Setting: patients were screened and treated at the Department of Audiology, Sahlgrenska Hospital, } \\
\text { Göteborg, Sweden }\end{array}$ \\
Sample size: & - Number randomised: 21 \\
- Number completed: 21
\end{tabular}




\section{Participant (baseline) characteristics:}

- Age: group level data for age were not provided. The 21 patients enrolled in the study had a mean age of 51 years (range 21 to 66 years).

- Gender: group level data for age were not provided. 4 women and 17 men were included in the study.

\section{- Other characteristics:}

Group level data for baseline characteristics of participants were not provided. The 21 patients enrolled in the study had tinnitus for at least 1 year, reported tinnitus in left ear $(n=7)$, right ear $(n=7)$, both ears $(n=4)$ or inside the head $(n=3) .13$ participants reported tonal and 7 noise tinnitus, centre frequencies ranged from $277 \mathrm{~Hz}$ to $8660 \mathrm{~Hz}$. All participants were "clinically judged to have severe tinnitus and to be in need of treatment". The mean pure tone average $(0.5,1$ and $2 \mathrm{kHz}$ ) of the treated ear was $29 \mathrm{~dB}$ (SD 19.5).

Inclusion criteria: participants able to follow study instructions

Exclusion criteria: not reported

Intervention group: sound generator

Comparator group: placebo device

The masker equipment was constructed for this study and allowed frequency adjustment between 250 $\mathrm{Hz}$ and $10,000 \mathrm{~Hz}$ and continuous variation of bandwidth between these frequencies. Touch controls allowed the user to activate the specific sound, or a sound with a free choice of parameters. Noise was set at the level "enough to cause total masking". The placebo unit called "Elstimulator (electrical stimulator)" was identical in size, with about the same degree of variation available to the user. Duration of each treatment was 6 weeks. Overall masker use ranged from 0 to 390 minutes per day, and Elstimulator use from 0 to 600 minutes per day.

Use of additional interventions: none

\begin{tabular}{|c|c|c|}
\hline \multirow[t]{3}{*}{ Outcomes } & \multicolumn{2}{|c|}{ Primary: tinnitus intensity (10-point scale) } \\
\hline & \multicolumn{2}{|c|}{$\begin{array}{l}\text { Secondary: usage, specific (self-rated changes in tinnitus intensity and in the degree of negative reac- } \\
\text { tions to it) and non-specific effects (self-rated changes of mood, stress, somatic symptoms other than } \\
\text { tinnitus, and medication) }\end{array}$} \\
\hline & \multicolumn{2}{|c|}{$\begin{array}{l}\text { Outcomes were measured after each treatment (at } 6 \text { and } 12 \text { weeks), however outcomes after } 6 \text { weeks } \\
\text { were not reported }\end{array}$} \\
\hline Funding sources & \multicolumn{2}{|c|}{$\begin{array}{l}\text { This research was supported by the Swedish Ministry of Health and Social Affairs, Delegation for Social } \\
\text { Research (project no. 82/120), the Swedish Council for Planning and Coordination of Research, the Na- } \\
\text { tional Swedish Board for Technical Development and the Swedish Medical Research Council (project } \\
\text { no. B 85-17X-06574) }\end{array}$} \\
\hline Declarations of interest & \multicolumn{2}{|l|}{ None reported } \\
\hline Notes & \multicolumn{2}{|l|}{-} \\
\hline \multicolumn{3}{|l|}{ Risk of bias } \\
\hline Bias & Authors' judgement & Support for judgement \\
\hline $\begin{array}{l}\text { Random sequence genera- } \\
\text { tion (selection bias) }\end{array}$ & Unclear risk & $\begin{array}{l}\text { The authors stated that participants were randomly allocated to groups but } \\
\text { did not provide any details on methods: "The } 21 \text { patients were randomised in- } \\
\text { to two groups ( } n=10 \text { and } 11 \text {, respectively); both groups received both treat- } \\
\text { ments but in different order." }\end{array}$ \\
\hline
\end{tabular}


Erlandsson 1987 (Continued)

Allocation concealment Unclear risk Information not provided in the manuscript
(selection bias)

\begin{tabular}{|c|c|c|}
\hline $\begin{array}{l}\text { Blinding of participants } \\
\text { and personnel (perfor- } \\
\text { mance bias) } \\
\text { All outcomes }\end{array}$ & High risk & $\begin{array}{l}\text { No blinding; both interventions were explained to participants at baseline: } \\
\text { "The nature of each of the two procedures was described in detail, and the pa- } \\
\text { tients were assured that there were no harmful side effects to be afraid of." In- } \\
\text { formation about personnel blinding was not provided in the manuscript. }\end{array}$ \\
\hline
\end{tabular}

\begin{tabular}{lll}
\hline $\begin{array}{l}\text { Blinding of outcome as- } \\
\text { sessment (detection bias) } \\
\text { All outcomes }\end{array}$ & Unclear risk & Information not reported in the manuscript \\
\hline $\begin{array}{l}\text { Incomplete outcome data } \\
\text { (attrition bias) }\end{array}$ & High risk & $\begin{array}{l}\text { Data were omitted for 4 participants because of inadequate use (not specified) } \\
\text { of rating scales. Data for "specific and non-specific effects" for } 2 \text { participants } \\
\text { All outcomes } \\
\text { missing data was not described. }\end{array}$ \\
\hline
\end{tabular}

Selective reporting (re- Unclear risk Between-group differences at 6 weeks were not reported
porting bias)

Other bias Low risk No prospective protocol available. No other biases identified.

Henry 2015

Methods 2-arm, single-centre, randomised, controlled (parallel) trial with 3 to 4 months duration of treatment and 3 to 4 months duration of follow-up

Participants

Setting: patients were screened and treated at the National Center for Rehabilitative Auditory Research (NCRAR) located at the Portland (Oregon) Veterans Affairs Medical Center, USA

\section{Sample size:}

- Number randomised: 30

- Number completed: 30

\section{Participant (baseline) characteristics:}

- Age: mean age was 67.9 years (SD 11) in the group receiving combination aids and 66.5 years (SD 7.4) in the group receiving hearing aids

- Gender: the group who received combination aids included 5 women and 10 men, and the group receiving hearing aids included 3 women and 12 men

\section{- Other characteristics:}

Tinnitus duration varied between under 1 year and over 20 years. The group receiving combination aids and hearing aids reported tinnitus duration of: $<1$ year ( $3 \%$ and $0 \%$ respectively), 1 to 2 years ( $7 \%$ and $7 \%), 3$ to 5 years ( $3 \%$ and $0 \%), 6$ to 10 years ( $10 \%$ and $13 \%), 11$ to 20 years ( $27 \%$ and $27 \%)$, > 20 years ( $40 \%$ and $46 \%$ ), and $10 \%$ and $7 \%$ were unsure of duration. Groups did not differ significantly on the above characteristics. The mean Tinnitus Functional Index score at baseline was 60.5 (SD 15.3) for the combination aid group and 56.1 (16.5) for the hearing aids group.

Data for tinnitus laterality, baseline tinnitus loudness and quality, and baseline anxiety/depression were not reported. However, to qualify for a hearing aid assessment, candidates needed to have a symmetrical (defined as a difference between left and right ear 4-frequency $(0.5,1,2,4 \mathrm{kHz})$ pure-tone averages of $15 \mathrm{~dB}$ or less) sensorineural hearing loss within the mild to moderately severe range (4-frequency pure-tone average 25 to $70 \mathrm{~dB} \mathrm{HL}$ ).

Inclusion criteria: (1) at least 18 years of age; (2) English-speaking; (3) perceived hearing difficulties; (4) no hearing aid experience within the previous 12 months; (5) no mental, emotional or health con- 
Henry 2015 (Continued)

ditions that would prevent participating in the study (6) Tinnitus and Hearing Survey minimum score of 4 on section $A$; if the score was 4 to 6 , then at least one of the items required a score of at least 3 ; (7) TFI score greater than 25; (8) a pass on the Mini Mental State Exam; (9) symmetrical (defined as a difference between left and right ear 4-frequency $(0.5,1,2,4 \mathrm{kHz})$ pure-tone averages of $15 \mathrm{~dB}$ or less) sensorineural hearing loss within the mild to moderately severe range (4-frequency pure-tone average 25 to $70 \mathrm{~dB} \mathrm{HL}$ )

Exclusion criteria: (1) active external ear disease or conductive component to hearing loss (i.e. abnormal tympanometry and/or air-bone gaps exceeding $10 \mathrm{~dB}$ at 2 consecutive frequencies); (2) diagnosis of retrocochlear pathology, Ménière's disease, endolymphatic hydrops, or perilymphatic fistula; (3) presence of medical contraindications to a hearing aid fitting, including sudden onset hearing loss, fluctuating hearing sensitivity, ear pain and vertigo

$\begin{array}{ll}\text { Interventions } & \text { Intervention group: combination device }(n=15) \\ \text { Comparator group: amplification only (hearing aids, } n=15)\end{array}$

All participants were fitted bilaterally with a commercially available receiver-in-the-canal combination device. For the intervention group, the noise generators were activated and adjusted according to the participants' individual preferences to achieve "immediate relief from tinnitus". More specifically, the amplitude- and frequency-modulated noise stimulus was fine-tuned across 16 channels to each individual user in the effort to optimise relief from tinnitus. Duration of treatment was 3 to 4 months.

Use of additional interventions: both groups received the same scripted tinnitus counselling (education) immediately after fitting and adjustments of the devices that described how sound can be used to make tinnitus less of a problem. The counselling followed pp. 31-64 in the flip-chart counselling book Progressive Tinnitus Management: Counselling Guide (Henry 2010).

\begin{tabular}{ll}
\hline Outcomes & Primary: tinnitus symptom severity (Tinnitus Functional Index, TFI) \\
& $\begin{array}{l}\text { Secondary: Hearing Handicap Inventory for Elderly, interview } \\
\text { Outcomes were measured at } 3 \text { to } 4 \text { months }\end{array}$ \\
\hline Funding sources & $\begin{array}{l}\text { This research was funded by Starkey Hearing Technologies (387001) and by the Department of Veterans } \\
\text { Affairs, Rehabilitation Research \& Development (RR\&D) Service (F7070-S and C9230-C) }\end{array}$ \\
\hline Declarations of interest & $\begin{array}{l}\text { Dr. Abrams is employed by Starkey Hearing Technologies, which funded the study. However, the study } \\
\text { procedures and data analyses were conducted independent of any company influence. }\end{array}$
\end{tabular}

Notes -

\section{Risk of bias}

Bias Authors' judgement Support for judgement

Random sequence genera- Unclear risk tion (selection bias)
The authors stated that participants were randomly allocated to groups but did not provide any details on methods: "Participants were randomised to either the hearing-aid-plus-noise (experimental) or the hearing-aid-only (control) group."

\begin{tabular}{lll}
\hline $\begin{array}{l}\text { Allocation concealment } \\
\text { (selection bias) }\end{array}$ & Unclear risk & Information not reported in the manuscript \\
\hline $\begin{array}{l}\text { Blinding of participants } \\
\text { and personnel (perfor- } \\
\text { mance bias) }\end{array}$ & High risk & $\begin{array}{l}\text { Participants were not blinded as } 2 \text { different types of instruments were fitted, } \\
\text { one being a hearing aid and one combination hearing aid. There is no evidence } \\
\text { of blinding of the personnel, outcome measures collection, counselling and in- } \\
\text { terviews seemed to be performed by the same people. }\end{array}$
\end{tabular}

Blinding of outcome as-

High risk

No evidence of blinding; audiologists seemed to perform both instrument checking and collecting outcome assessments. Data were entered into the 
Henry 2015 (Continued)

All outcomes database by the NCRAR data manager and analyses overseen by NCRAR biostatistician, however it is stated that "data were analysed for the two groups separately: experimental and control" and blinding is not stated.

Incomplete outcome data Low risk Main outcome data complete. No loss to follow-up.
(attrition bias)
All outcomes

\begin{tabular}{lll}
\hline $\begin{array}{l}\text { Selective reporting (re- } \\
\text { porting bias) }\end{array}$ & Low risk & No prospective protocol available but all listed outcomes reported in full \\
\hline Other bias & Low risk & No prospective protocol available. No other biases identified. \\
\hline
\end{tabular}

Henry 2017

Methods

3-arm, single-centre, randomised, controlled (parallel) trial with 4 to 5 months duration of treatment and 1 to 3 weeks, 2 months and 4 to 5 months (primary endpoint) duration of follow-up

Participants

Setting: patients were screened and treated at the National Center for Rehabilitative Auditory Research (NCRAR) located at the VA Portland Health Care System (VAPORHCS), USA

\section{Sample size:}

- Number randomised: 55

- Number completed: 54

55 participants were enrolled, but 1 participant was lost at follow-up. Sample size was based on an interim power analysis conducted after the first 21 participants had been randomised. For a total of 55 participants, this analysis gave better than $87 \%$ power to detect a significant contrast between the Extended Wear Hearing Aid and the conventional hearing aid, and better than $80 \%$ power to detect a significant contrast between the combination device and conventional hearing aid.

\section{Participant (baseline) characteristics:}

- Age: the group who received combination aids had a mean age of 64 years (range 54 to 75 years). The group who received hearing aids had a mean age of 61.1 years (range 48 to 75 years).

- Gender: the group who received combination aids included 4 women and 15 men. The group who received hearing aids included 4 women and 14 men.

\section{- Other characteristics:}

There were no significant between-group differences on any of the baseline measures. The group who received combination aids had a baseline mean TFI score of 57.1 , and mean 4-frequency $(0.5,1,2$ and $4 \mathrm{kHz}$ ) pure-tone average of 35.5 (SD 8.7) and 34.9 (SD 10; left and right ear respectively). The group who received hearing aids had a baseline mean TFI score of 57.2, and mean 4-frequency $(0.5,1,2$ and 4 $\mathrm{kHz}$ ) pure-tone average of 36.9 (SD 8) and 34.9 (SD 9; left and right ear respectively). The group who received extended wear hearing aids (EWHA) had a mean age of 64.3 years (range 33 to 81 years), included 4 women and 14 men, baseline mean TFI score of 54.1 , and mean 4-frequency $(0.5,1,2$, and $4 \mathrm{kHz})$ pure-tone average of 39.2 (SD 6.4) and 39.6 (SD 6.6; left and right ear respectively). Data for duration and laterality of tinnitus, baseline tinnitus loudness and characteristics, baseline depression and anxiety were not provided.

Inclusion criteria: participants were required to report both a suspected hearing loss and bothersome tinnitus. More specifically, the 10-item Tinnitus and Hearing Survey was administered over the phone, requiring a minimum total score of 4 on the tinnitus section $A$. In addition, they needed to speak fluent English, not have worn hearing aids for the past 6 months, and report being in good mental, emotional and health conditions to comply with full study participation. 
Exclusion criteria: the EWHA had manufacturer-defined medical and lifestyle contraindications (e.g. radiation to head or neck, scuba diving, skydiving) that precluded wearing the EWHA. If candidates could not be fit bilaterally with both types of hearing aids, they were not eligible to participate.

Interventions

Intervention group 1: combination device $(n=19)$

Intervention group 2: amplification only (conventional hearing aids, $\mathrm{n}=19$ )

Intervention group 3: amplification only (extended wear hearing aids, $\mathrm{n}=18$ )

The combination device group was fitted with Audeo $Q$ line of receiver-in-the-canal (RIC) hearing instruments with sound generator (Audeo Q90 312-T; Phonak). The hearing aids group was fitted AudeoQ line of RIC hearing instruments (Audeo Q90 312-T; Phonak). The EWHA group was fitted with the extended-wear, deep seated device (Lyric; Phonak). Duration of treatment was 4 to 5 months.

Use of additional interventions: all 3 groups received informational counselling, which took place following device fitting and adjustment. Hearing aid orientation and informational counselling involved use of a device-specific PowerPoint presentation to ensure that standardised information was provided. Content included information about use, care, troubleshooting and maintenance of the device; communication tips, both with and without amplification; safety issues; goals and realistic expectations of amplification; and overall adjustment to amplification. Hearing aid and combination aid participants practised insertion and removal; learned how to adjust the volume, change the batteries and distinguish right/left devices; and verified cell and/or landline phone compatibility. EWHA participants learned how to adjust the volume, change the listening modes (on/off/sleep) and remove the devices if necessary. They also watched a video demonstrating these device-specific manipulations produced by the manufacturer.

All participants received the same scripted counselling to describe briefly how sound can be used to make tinnitus less problematic. The counselling followed pages 31-64 in a flip-chart counselling guide (Henry et al, 2010a). Participants also received a copy of a tinnitus self-help workbook (Henry et al, $2010 \mathrm{~b}$ ) to read on their own (their use of the workbook was not tracked). The research audiologists were available to answer questions or address concerns at any time during study participation. Participants were telephoned within 2 business days of the fitting appointment to ensure that the devices were comfortable and working properly.

Outcomes Primary: tinnitus symptom severity (Tinnitus Functional Index, TFI)

Secondary: Quick Speech in Noise, Hearing Handicap Inventory for the Elderly/Adults, 12-item version of the Speech, Spatial, and Qualities of Hearing questionnaire, International Outcome Inventory for Hearing Aids and a semi-structured exit interview developed specifically for this study

Outcomes were measured at 1 to 3 weeks, 2 months and 4 to 5 months

\begin{tabular}{|c|c|c|}
\hline Funding sources & Not reported & \\
\hline Declarations of interest & Not reported & \\
\hline Notes & - & \\
\hline \multicolumn{3}{|l|}{ Risk of bias } \\
\hline Bias & Authors' judgement & Support for judgement \\
\hline $\begin{array}{l}\text { Random sequence genera- } \\
\text { tion (selection bias) }\end{array}$ & Low risk & $\begin{array}{l}\text { "Within } 4 \text { weeks of the initial assessment, eligible candidates returned to the } \\
\text { laboratory and were randomized into one of three groups: (a) EWHA, (b) HA, or } \\
\text { (c) HA + SG. A simple randomization allocation method was sued. The random } \\
\text { allocation sequence was generated using computer software." }\end{array}$ \\
\hline
\end{tabular}


Henry 2017 (Continued)

$\begin{array}{ll}\begin{array}{l}\text { Allocation concealment } \\ \text { (selection bias) }\end{array} & \begin{array}{l}\text { "Allocation concealment was achieved using sequentially numbered, opaque, } \\ \text { sealed envelopes, which were opened by study staff to randomize and enrol } \\ \text { participants." }\end{array}\end{array}$

\begin{tabular}{|c|c|c|}
\hline $\begin{array}{l}\text { Blinding of participants } \\
\text { and personnel (perfor- } \\
\text { mance bias) } \\
\text { All outcomes }\end{array}$ & High risk & $\begin{array}{l}\text { Participants were not blinded as } 3 \text { different types of instruments were fitted, } \\
\text { one being a conventional hearing aid, one a combination hearing aid and one } \\
\text { an extended wear hearing aid. There is no evidence of blinding of the person- } \\
\text { nel: outcome measures collection, counselling and scripted questions seemed } \\
\text { to be performed by the same person. }\end{array}$ \\
\hline
\end{tabular}

\begin{tabular}{lll}
\hline $\begin{array}{l}\text { Blinding of outcome as- } \\
\text { sessment (detection bias) } \\
\text { All outcomes }\end{array}$ & Unclear risk & Information not provided in the manuscript \\
\hline $\begin{array}{l}\text { Incomplete outcome data } \\
\text { (attrition bias) } \\
\text { All outcomes }\end{array}$ & Low risk & $\begin{array}{l}\text { Main outcome data almost complete; only 1 participant (out of 55) lost to fol- } \\
\text { low-up in the EWHA group (did not provide any follow-up data) }\end{array}$ \\
\hline $\begin{array}{l}\text { Selective reporting (re- } \\
\text { porting bias) }\end{array}$ & Low risk & No prospective protocol available but all listed outcomes reported in full \\
\hline $\begin{array}{l}\text { Other bias } \\
\text { Unclear risk }\end{array}$ & $\begin{array}{l}\text { No prospective protocol available. Funding and conflicts of interest were not } \\
\text { reported; all devices tested were manufactured by Phonak, LLC: any links with } \\
\text { the company are not clear. }\end{array}$
\end{tabular}

Melin 1987

$\begin{array}{ll}\text { Methods } & \begin{array}{l}\text { 2-arm, single-centre, randomised, controlled (parallel) trial with } 6 \text { weeks duration of treatment and } 6 \\ \text { weeks duration of follow-up }\end{array}\end{array}$

Participants

Setting: patients were screened and treated at the hearing centre at a Swedish university hospital

\section{Sample size:}

- Number randomised: 39

- Number completed: 39

\section{Participant (baseline) characteristics:}

- Age: the group who received hearing aids had a mean age of 73.1 years (SD 12; range 50 to 87 years) and the waiting list control group had a mean age of 72.2 (SD 9.5; range 53 to 87 )

- Gender: the hearing aids group included 13 women and 7 men and the waiting list control included 13 women and 6 men

\section{- Other characteristics:}

Tinnitus duration was from $\leq$ year to over 5 years in both groups. Participants reported their tinnitus to be in both ears ( $n=12$ in both groups), one ear ( $n=6$ in hearing aids group and $n=3$ in waiting list control), both ears and head ( $n=2$ and $n=3$, respectively), 1 participant in hearing aid group reported tinnitus in the head and 1 in waiting list control reported tinnitus in left ear and the head. The severity of tinnitus was classified into 3 grades. 7 participants in the hearing aid group and 10 in the waiting list group were classified as tinnitus severity Grade 1 (audible only in quiet environment), 11 and 9 respectively as Grade 2 (audible in ordinary but not in noisy environments; not noticeable in specific situations, such as when the attention is focused on interesting work etc.; occasionally causes disturbances in sleep), and 2 and 0 respectively as Grade 3 (constantly noticed in all ordinary acoustical environments and causing severe disturbances of concentration and continuous disturbance of sleep). Mean pure tone average (0.5, 1 and $2 \mathrm{kHz}$ ) was 39.4 (SD 10.9) in right and 40.4 (SD 12.7) in left ear for hearing aid group and 38.7 (SD 15.8) in right and 42 (SD 11.4) in left ear for waiting list controls. No sta- 
Melin 1987 (Continued)

tistical analyses of differences between groups regarding baseline characteristics were reported. From 39 participants taking part in the study $87 \%$ had bilateral hearing loss and $56 \%$ claimed that hearing was their main problem.

Inclusion criteria: hearing impairment to such a degree that hearing aids are needed, no earlier experience of hearing aids, tinnitus of more than 6 months duration

Exclusion criteria: not reported

Interventions
Comparator group: waiting list $(\mathrm{n}=19)$
$\begin{aligned} & 18 \text { participants in the hearing aid group were fitted unilaterally and } 2 \text { bilaterally. Hearing aids fittings } \\ & \text { were conducted according to a standard procedure and comprised of } 4 \text { visits - for information, fitting, } \\ & \text { practice and adjustment of the aid. }\end{aligned}$

Use of additional interventions: participants fitted with hearing aids received information (not specified)

Hearing ability in 4 different hearing situations was assessed using a visual analogue scale (VAS) (from
"no hearing at all" to "complete hearing ability"). Tinnitus in 4 different hearing situations was as-
sessed using a VAS (from "no tinnitus" to "worst tinnitus ever"). Semi-structured interviews with force-
choice answers asked whether the hearing impairment or tinnitus was the main problem, about fluc-
tuations in annoyance caused by tinnitus and problems such as muscle tension, headaches and dizzi-
ness, general expectations of the hearing aid and its potential ability to decrease tinnitus, frequency
and duration of hearing aid use, whether the use of hearing aid had influenced the tinnitus in any way.

Funding sources

This study was supported financially by the Bank of Sweden Tercentenary Foundation (Grant No. 83/16) and grants from Stiftelsen Tysta Skolan, Stockholm and the Oticon Foundation, Copenhagen

\begin{tabular}{ll}
\hline Declarations of interest & Not reported \\
\hline Notes & - \\
\hline
\end{tabular}

\section{Risk of bias}

\begin{tabular}{lll}
\hline Bias & Authors' judgement & Support for judgement \\
\hline $\begin{array}{l}\text { Random sequence genera- } \\
\text { tion (selection bias) }\end{array}$ & Unclear risk & $\begin{array}{l}\text { Manuscript reports use of a randomisation plan but provides no details: "Dur- } \\
\text { ing the first } 6 \text { weeks of the study, the experiment had a between-group design, } \\
\text { where subjects were randomly assigned to one of two groups. Group } 1 \text { was fit- } \\
\text { ted with hearing aids, while group } 2 \text { served as a waiting list control group. To } \\
\text { prevent bias, the random allocations of the subjects were done after their first } \\
\text { interview according to randomisation plan." }\end{array}$ \\
\end{tabular}

\begin{tabular}{lll}
\hline $\begin{array}{l}\text { Allocation concealment } \\
\text { (selection bias) }\end{array}$ & Unclear risk & Information not reported in the manuscript \\
\hline $\begin{array}{l}\text { Blinding of participants } \\
\text { and personnel (perfor- }\end{array}$ & High risk & $\begin{array}{l}\text { Participants were not blinded as they were either fitted with hearing aids or } \\
\text { served as a waiting list control. Personnel were not blinded - assessments (vi- } \\
\text { mance bias) }\end{array}$ \\
$\begin{array}{l}\text { All outcomes } \\
\text { sual analogue scales and interviews) were performed by } 3 \text { audiological assis- } \\
\text { tants and the participants always met the same assistant throughout the reha- } \\
\text { bilitation programme. }\end{array}$
\end{tabular}

Blinding of outcome as- Unclear risk sessment (detection bias) All outcomes

\begin{abstract}
Assessments were conducted by audiological assistants but it is unlikely that they were blinded as one group was fitted with hearing aids and the other was a waiting list control, and assistants were conducting interviews. It was not stated who conducted the analysis.
\end{abstract}


Melin 1987 (Continued)

Incomplete outcome data Low risk $\quad$ Outcomes reported in detail
(attrition bias)

All outcomes

\begin{tabular}{|c|c|c|}
\hline $\begin{array}{l}\text { Selective reporting (re- } \\
\text { porting bias) }\end{array}$ & Unclear risk & $\begin{array}{l}\text { No dropout reported for experimental period. Unclear if all interview question } \\
\text { data are reported. }\end{array}$ \\
\hline
\end{tabular}

Other bias Low risk No prospective protocol available. No other potential biases identified.

Parazzini 2011

$\begin{array}{ll}\text { Methods } & \begin{array}{l}\text { 2-arm, 2-centre, randomised, controlled (parallel) trial with } 12 \text { months duration of treatment and } 3 \\ \text { (primary endpoint), } 6 \text { and } 12 \text { months duration of follow-up }\end{array}\end{array}$

Participants

Setting: patients were screened and treated in 1 of 2 tinnitus clinics (Italy or USA)

\section{Sample size:}

- Number randomised: 101

- Number completed: 91

101 patients were enrolled, but due to missing records the final data set included only 91 patients

\section{Participant (baseline) characteristics:}

- Age: group level data for age were not provided. The 91 patients included in the final analysis had a mean age of 38.8 years (SD 18.1).

- Gender: the group who received hearing aids included 21 women and 28 men, and the group receiving sound generators included 19 and 23 men

\section{- Other characteristics:}

The 91 patients included in the final analysis had a mean tinnitus duration of 69.5 months (SD 89.7). Baseline measures included an audiological test for hearing loss. Mean hearing loss was not reported per group but inclusion in the study required patients to have hearing levels $<25 \mathrm{~dB}$ at $2 \mathrm{kHz}$ and $>$ $25 \mathrm{~dB}$ at frequencies higher than $2 \mathrm{kHz}$. This was taken as the borderline between two categories: "no hearing loss" and "significant hearing loss". According to Jastreboff 2004, patients with this hearing level can be managed with either hearing aids or sound generators. The participants in this study therefore had a very particular audiological profile. Patients who had previously been prescribed hearing aids were excluded from participation in the trial.

The mean Tinnitus Handicap Inventory (THI) score at baseline was 57 for the hearing aid group and 59 for the sound generator group.

Inclusion criteria: (1) borderline between category 1 and category 2 (according to Jastreboff classification, TRT); (2) HL $\leq 25 \mathrm{~dB}$ at $2 \mathrm{kHz}$ and $\mathrm{HL} \geq 25 \mathrm{~dB}$ at frequencies higher than $2 \mathrm{kHz}$; (3) all tinnitus aetiologies excluding Ménière's and middle-external ear disease; (4) tinnitus duration of at least 6 months; (5) bilateral symmetrical hearing loss (i.e. difference less than $15 \mathrm{~dB}$ ); (6) age between 18 and 75 years

Exclusion criteria: Ménière's and middle-external ear disease, tinnitus retraining therapy in the past, hearing aids in the past 
Parazzini 2011 (Continued)

tients received the same educational counselling component of tinnitus retraining therapy (TRT), with

follow-up to optimise the therapy at 3, 6 and 12 months.

Use of additional interventions: none

Outcomes Primary: tinnitus symptom severity (Tinnitus Handicap Inventory, THI)

Secondary: a number of visual analogue scales were used to rate tinnitus loudness over the preceding month (rated from $0=$ no tinnitus to 10 = "as loud as you can imagine"), effect on life, tinnitus annoyance, percentage of time when patients were annoyed and percentage of time when patients were aware of their tinnitus

Outcomes were measured at 3, 6 and 12 months during the tinnitus treatment

\begin{tabular}{ll}
\hline Funding sources & $\begin{array}{l}\text { This research was partially supported by grants from the Tinnitus Research Initiative, by Fondazione } \\
\text { Ascolta e Vivi, and GN ReSound A/S }\end{array}$ \\
\hline Declarations of interest & The authors reported no conflict of interest \\
\hline Notes & -
\end{tabular}

\section{Risk of bias}

\begin{tabular}{lll}
\hline Bias & Authors' judgement & Support for judgement \\
\hline $\begin{array}{l}\text { Random sequence genera- } \\
\text { tion (selection bias) }\end{array}$ & Low risk & $\begin{array}{l}\text { "Specifically, subjects were randomly assigned to two treatments groups: half } \\
\text { of the subjects were fitted with binaural sound generators (identified in the } \\
\text { subsequent text as the SG group), whereas the other half were fitted with bin- } \\
\text { aural open ear hearing aids (identified in the subsequent text as the OE-HA } \\
\text { group). Randomization was obtained on the basis of a random table." }\end{array}$ \\
\hline
\end{tabular}

\begin{tabular}{|c|c|c|}
\hline $\begin{array}{l}\text { Allocation concealment } \\
\text { (selection bias) }\end{array}$ & Unclear risk & Information not reported in the manuscript \\
\hline $\begin{array}{l}\text { Blinding of participants } \\
\text { and personnel (perfor- } \\
\text { mance bias) } \\
\text { All outcomes }\end{array}$ & High risk & $\begin{array}{l}\text { Participants were not blinded; } 2 \text { different types of devices were fitted: hearing } \\
\text { aids or sound generators. Counselling was likely tailored to the device option } \\
\text { that participants received (according to TRT). There is no statement about the } \\
\text { blinding of the personnel. }\end{array}$ \\
\hline
\end{tabular}

Blinding of outcome as- Unclear risk Information not reported in the manuscript

sessment (detection bias)

All outcomes

\begin{tabular}{|c|c|c|}
\hline $\begin{array}{l}\text { Incomplete outcome data } \\
\text { (attrition bias) } \\
\text { All outcomes }\end{array}$ & Unclear risk & $\begin{array}{l}10 \text { participants out of } 101 \text { excluded due to missing recordings (not explained). } \\
\text { Structured interview data were recorded, analysed and reported for the subset } \\
\text { of } 51 \text { out of } 91 \text { participants only. }\end{array}$ \\
\hline
\end{tabular}

\begin{tabular}{lll}
\hline $\begin{array}{l}\text { Selective reporting (re- } \\
\text { porting bias) }\end{array}$ & Low risk & All listed outcomes reported \\
\hline Other bias & Low risk & No prospective protocol available. No other potential biases identified. \\
\hline
\end{tabular}

Stephens 1985

$\begin{array}{ll}\text { Methods } & \text { 3-arm, single-centre, randomised, controlled (parallel) trial with } 6 \text { months duration of treatment and } 6 \\ \text { months duration of follow-up; sub-study as a part of a multi-centre study of tinnitus maskers (Stephens } \\ \text { 1985, Hazell } 1985 \text { paper) }\end{array}$


Stephens 1985 (Continued)

Participants
Setting: patients were screened and treated at the Royal National Throat, Nose and Ear (RNTNE) Hospital, UK

\section{Sample size:}

- Number randomised: 147

- Number completed: 147

147 participants (out of 285; Hazell 1985) took part in the randomised part of the study. Of those 75 reported no hearing disability and 72 complained of hearing disability.

\section{Participant (baseline) characteristics:}

- Age: age distribution in all participants was: (i) < 20 years $(n=2)$; (ii) 20 to 29 years $(n=5)$; (iii) 30 to 39 years ( $n=18$ ); (iv) 40 to 49 years $(n=25)$; (v) 50 to 59 years $(n=54) ;(v i) 60$ to 69 years $(n=39)$; and (vii) 70 to 79 years $(n=10)$

- Gender: the 153 patients included in the study included 77 men and 76 women

- Other characteristics:

Group level data for any of the baseline characteristics were not provided by Stephens 1985 . Tinnitus duration was: 3 to 6 months (3.3\%), 6 to 12 months (21.5\%), 1 to 5 years $(47 \%)$ and > 5 years $(28.2 \%)$. Patients reported tinnitus localised in right ear only (21.5\%), left ear only (23.5\%), equal in both ears $(16.8 \%)$, in both ears, most in left (19.5\%), in both ears most in right $(10.7 \%)$, and in the head $(8.1 \%)$. $34 \%$ of participants reported hearing one sound and $67 \%$ more than one sound. Hearing threshold at $1 \mathrm{kHz}$ was $\leq 20 \mathrm{~dB}$ in 84 participants, 20 to $45 \mathrm{~dB}$ in 34 participants, 50 to $70 \mathrm{~dB}$ in 18 participants, and over $70 \mathrm{~dB}$ in 10 participants.

Inclusion criteria: (1) tinnitus as a main complaint, with or without hearing loss; (2) tinnitus as a major problem (Hazell 1985); (3) tinnitus duration minimum 3 months; (4) English language knowledge enough to fill in the questionnaire; (5) no restrictions on hearing level; (6) no new treatment during the trial period; (7) no severe inter-current illness during trial; (8) no intensive psychiatric treatment

Exclusion criteria: tinnitus as secondary complaint, inability to complete questionnaire, tinnitus duration less than 3 months, being unwell, major psychological treatment, refusing allocation, missing data (Stephens 1985, Hazell 1985 paper)

Intervention group 1: A\&M sound generator $(n=24)$

Intervention group 2: Viennatone sound generator $(n=27)$

Comparator group: limited counselling (no instrument fitting, $n=24$ )

Participants who reported hearing disability:

Intervention group 1: amplification only (hearing aid, $\mathrm{n}=26$ )

Intervention group 2: combination device $(n=23)$

Intervention group 3: A\&M sound generator $(n=23)$

Sound generators and combination devices were fitted unilaterally but hearing aids were fitted unilaterally or bilaterally, according to normal clinical indications. Hearing aids were standard National Health Service behind-the- ear devices. Combination aids fitted were Danavox 775-PP-AGC/masker module combination instruments. Duration of treatment was 6 months. All participants had a month review to ensure adequate management of their devices and counselling advice, repairs, modification of frequency responses, ear-mould changes (if necessary repeated with 1-month intervals).

Use of additional interventions: those fitted with instruments all received a similar counselling in addition to the fitting of appropriate instrumentation 
Stephens 1985 (Continued)

Outcomes

Effectiveness of the interventions was measured using the Masker Effectiveness Questionnaire, changes in the Crown Crisp Experiential Index, changes in the Semantic Differential scores, and for a subset of patients the long pattern of instrument use and needs for other therapy. Stephens 1985 measured anxiety, phobic anxiety, somatic anxiety and depression subscales of the Crown Crisp Experiential Index (data for the randomised and non-randomised group together available in Stephens 1985, Hazell 1985 paper), however data for the randomised part of the study were not reported in the manuscript. Health-related quality of life as measured by a validated instrument was not measured in the included studies.

Outcomes were measured at 6 months

Funding sources The maskers and combination instruments used in this study, together with some of the test equipment, were provided by a grant from the UK Department for Health and Social Security as part of the larger study on tinnitus maskers

Declarations of interest Not reported

Notes -

\section{Risk of bias}

\section{Bias}

Random sequence genera- Unclear risk tion (selection bias)

\section{Authors' judgement Support for judgement}

Manuscript reports use of a randomisation plan but provides no details: "At this time, the patients were allocated to treatment groups. Thus, those reporting no hearing disability were randomly allocated to either a control group with limited counselling but no instrument fitting, to fitting with an A\&M masker or to fitting with Viennatone masker. Those complaining of hearing disability were similarly randomly allocated to a hearing aid fitting with a standard National Health Service behind the ear aid(s), fitting with Danavox 775PP-AGC/masker module combination instrument, or fitting with and A\&M tinnitus masker."

\begin{tabular}{lll}
\hline $\begin{array}{l}\text { Allocation concealment } \\
\text { (selection bias) }\end{array}$ & Unclear risk & No allocation concealment described \\
\hline $\begin{array}{l}\text { Blinding of participants } \\
\text { and personnel (perfor- } \\
\text { mance bias) }\end{array}$ & High risk & $\begin{array}{l}\text { Participants were not blinded as they were fitted with different types of instru- } \\
\text { ments (hearing aid, combination aid, masker) or were in the no device group. }\end{array}$ \\
All outcomes & $\begin{array}{l}\text { Personnel were not blinded; the same therapist was seeing the participant } \\
\text { throughout the study and collected outcome measures. Differences between } \\
\text { therapists regarding the results were reported. }\end{array}$ \\
\hline
\end{tabular}

\begin{tabular}{lll}
$\begin{array}{l}\text { Blinding of outcome as- } \\
\text { sessment (detection bias) } \\
\text { All outcomes }\end{array}$ & High risk & Not blinded; differences between therapists were reported \\
\hline $\begin{array}{l}\text { Incomplete outcome data } \\
\text { (attrition bias) }\end{array}$ & Unclear risk & $\begin{array}{l}\text { Stephens 1985, Hazell } 1985 \text { paper, reports } 153 \text { patients starting the study and } \\
119 \text { reaching the first evaluation. However, data from only 147 participants are } \\
\text { All outcomes }\end{array}$
\end{tabular}

\begin{tabular}{lll}
\hline $\begin{array}{l}\text { Selective reporting (re- } \\
\text { porting bias) }\end{array}$ & Low risk & All listed outcomes reported \\
\hline Other bias & High risk & $\begin{array}{l}\text { Differences between therapists reported. Only some of the patients underwent } \\
\text { full neuro-otological examination. No prospective protocol available. No other } \\
\text { potential biases identified. }\end{array}$ \\
\hline
\end{tabular}


Zhang 2013

Methods

2-arm, single-centre, randomised, controlled (parallel) trial with 12 months duration of treatment and

12 months duration of follow-up

Participants

Setting: patients were screened and tested at the Tianjin Medical University General Hospital Outpatient Clinic, China

\section{Sample size:}

- Number randomised: 154

- Number completed: 154

Participant (baseline) characteristics:

- Age: 154 participants who took part in the study had a mean age of 65.6 years (age range 50 to 79 years).

- Gender: 154 participants who took part in the study included 71 women and 83 men

\section{- Other characteristics:}

Group level data for the baseline characteristics were not reported. 154 participants who took part in the study had a mean duration of tinnitus of 8.8 years (range 1 to 28 years). 33 participants reported their tinnitus to be low-key buzz and 121 reported high-key cicadas. Mean duration of hearing disorder was 10.5 years (SD 7.3; range 1 to 35 years). Report stated that there was no clear difference between the compared groups in baseline measures. Hearing loss degree was not reported, however the inclusion criterion for the study was moderate to severe hearing loss (speech frequency threshold verge from 41 to $90 \mathrm{~dB}$ through pure tone test, according to the WHO, ISO (1980) hearing loss grading standard). Baseline tinnitus severity was not reported, however the inclusion criterion stated long-term, severe tinnitus, affecting work and life (such as affecting sleep and work, anxiety, depression etc.). Baseline tinnitus loudness, laterality and baseline anxiety/depression was not reported.

Inclusion criteria: (1) patients with tinnitus that is affecting work and life, such as affecting sleep and work, causes anxiety or depression, etc; (2) patients with moderate to severe hearing loss (speech frequency threshold verge from 41 to $90 \mathrm{~dB}$ through pure tone test, according to the WHO, ISO (1980) hearing loss grading standard); (3) age $>50$ years

Exclusion criteria: (1) objective tinnitus (such as pulsating tinnitus); (2) patients with acute middle ear discharge or sudden deafness within 3 months before enrolment; (3) patients with severe internal medical conditions, such as not well controlled hypertension, diabetes and cardiovascular disease; (4) patients with definite organic diseases that cause tinnitus, such as diseases of external or middle ear, noise-induced hearing damage, Ménière's disease, acoustic neuroma, etc; (5) patients with severe mental illness or mental disorder; (6) patients with hyperacusis or poor comprehension and expression; or (7) patients who cannot perform routine hearing tests

Interventions

Intervention group: amplification only and relaxation (hearing aid, $\mathrm{n}=84$ )

Comparator group: relaxation only $(n=70)$

Hearing aids fitted were manufactured by GN ReSound, Denmark. Both groups practised relaxation twice daily for 10 to 20 minutes, usually in the morning and before sleeping. Duration of the intervention was 12 months.

Use of additional interventions: both groups had undergone some "counselling" that included: (i) diagnosis of patient's tinnitus symptoms, explaining relevant knowledge, pathophysiological aspects and prognosis about tinnitus; (ii) learning how to adapt to the tinnitus condition (e.g. the patient could compare tinnitus to a roar of a train, the noise of a refrigerator, or snoring); (iii) attention distraction (turning attention to other interesting things, e.g. reading newspaper, watching TV or listening radio); (iv) relaxation training

Outcomes Tinnitus symptom severity, was assessed by criteria for therapeutic effect as follows: (i) complete adaptation: tinnitus symptom disappears or significantly relieves, with normal emotion, sleeping, work and life; (ii) basic adaptation: tinnitus symptom disappears, relieves or still exists, but with normal emotion, sleeping, work and life; (iii) partial adaptation: tinnitus still exists, partial affecting emotion, sleeping, 
The patients had outpatient visits at baseline, 3, 6 and 12 months

\begin{tabular}{|c|c|c|}
\hline Funding sources & \multicolumn{2}{|c|}{ Hearing aids were provided by Disabled Persons' Federation } \\
\hline Declarations of interest & Not reported & \\
\hline Notes & - & \\
\hline \multicolumn{3}{|l|}{ Risk of bias } \\
\hline Bias & Authors' judgement & Support for judgement \\
\hline $\begin{array}{l}\text { Random sequence genera- } \\
\text { tion (selection bias) }\end{array}$ & Unclear risk & $\begin{array}{l}\text { The authors stated that participants were randomly allocated to groups but } \\
\text { did not provide any details on the method }\end{array}$ \\
\hline $\begin{array}{l}\text { Allocation concealment } \\
\text { (selection bias) }\end{array}$ & Unclear risk & Information not reported in the manuscript \\
\hline $\begin{array}{l}\text { Blinding of participants } \\
\text { and personnel (perfor- } \\
\text { mance bias) } \\
\text { All outcomes }\end{array}$ & High risk & $\begin{array}{l}\text { Participants were not blinded; hearing aids were used in only one group and } \\
\text { the other group received only counselling }\end{array}$ \\
\hline $\begin{array}{l}\text { Blinding of outcome as- } \\
\text { sessment (detection bias) } \\
\text { All outcomes }\end{array}$ & Unclear risk & Information not reported in the manuscript \\
\hline $\begin{array}{l}\text { Incomplete outcome data } \\
\text { (attrition bias) } \\
\text { All outcomes }\end{array}$ & Low risk & No missing outcome data \\
\hline $\begin{array}{l}\text { Selective reporting (re- } \\
\text { porting bias) }\end{array}$ & Low risk & All outcomes stated in the methods were reported in the results \\
\hline Other bias & Low risk & No prospective protocol available. No other potential biases identified. \\
\hline
\end{tabular}

EWHA: extended wear hearing aids

HL: hearing level

SD: standard deviation

TFI: Tinnitus Functional Index

THI: Tinnitus Handicap Inventory

TRT: tinnitus retraining therapy

VAS: visual analogue scale

WHO: World Health Organization

Characteristics of excluded studies [ordered by study ID]

\begin{tabular}{ll}
\hline Study & Reason for exclusion \\
\hline Al-Jassim 1988 & ALLOCATION: not randomised; preference study \\
\hline Andersson 2002 & ALLOCATION: not randomised; the study used a $2 \times 3$ mixed experimental design \\
\hline
\end{tabular}




\begin{tabular}{|c|c|}
\hline Study & Reason for exclusion \\
\hline Benton 2016 & ALLOCATION: not randomised; survey study \\
\hline Del Bo 2006 & ALLOCATION: not randomised; before-and-after study; all participants were fitted with hearing aids \\
\hline \multirow[t]{3}{*}{ Durai 2017} & ALLOCATION: randomised cross-over trial \\
\hline & PARTICIPANTS: adults with tinnitus \\
\hline & $\begin{array}{l}\text { INTERVENTION: equivalence study comparing } 2 \text { different sound conditions (broadband noise ver- } \\
\text { sus natural sounds via MP3 player), no control condition included }\end{array}$ \\
\hline Gudex 2009 & ALLOCATION: not randomised; cohort study \\
\hline \multirow[t]{3}{*}{ Henry 2016} & ALLOCATION: randomised controlled trial \\
\hline & PARTICIPANTS: adults with tinnitus \\
\hline & $\begin{array}{l}\text { INTERVENTION: main goal of the study was to compare tinnitus masking (TM) with tinnitus retrain- } \\
\text { ing therapy (TRT). Those were also compared to a tinnitus education (TE) group (where only some } \\
\text { patients were fitted with hearing aids) and a waiting list control. Within the TM and TRT groups par- } \\
\text { ticipants were fitted with a mix of devices: hearing aids, combination aids or sound generators. } \\
\text { Within the TE group only some participants were fitted with hearing aids. }\end{array}$ \\
\hline
\end{tabular}

\begin{tabular}{ll}
\hline Hernández Moñiz 1998 & ALLOCATION: not randomised; cohort study \\
\hline Hiller 2005 & $\begin{array}{l}\text { ALLOCATION: not randomised; although the initial allocation of participants was randomised, par- } \\
\text { ticipants were moved between the study arms after randomisation }\end{array}$
\end{tabular}

ALLOCATION: randomised cross-over trial
PARTICIPANTS: adults with tinnitus
INTERVENTION: equivalence study comparing hearing aids with wide dynamic range compression
with hearing aids with frequency compression; no control condition included

\begin{tabular}{ll}
\hline Lipman 2007 & ALLOCATION: not randomised; all participants started with 2 weeks of control condition followed \\
& by 2 weeks of active treatment
\end{tabular}

ALLOCATION: randomised but not controlled trial. Participants tested 4 different devices in ran-
dom order but no planned comparisons after each device were included.

\begin{tabular}{ll}
\hline Shabana 2018 & ALLOCATION: not randomised; participants were "divided into two equal well-matched groups" \\
\hline Strauss 2015 & ALLOCATION: randomised controlled trial \\
& PARTICIPANTS: adults with tinnitus \\
& INTERVENTION: equivalence study, comparing a hearing aid with standard amplification to the \\
same hearing aid with notched amplification; no control condition included
\end{tabular}

Sweetow $2010 \quad$ ALLOCATION: not randomised; uncontrolled before-and-after study

Tao 2017

ALLOCATION: randomised controlled trial

PARTICIPANTS: adults with tinnitus

INTERVENTION: equivalence study comparing 2 types of masking therapy (multiple-frequency matched masking versus single-frequency masking); no control condition included 


Study Reason for exclusion

Thedoroff 2017

ALLOCATION: randomised controlled trial

PARTICIPANTS: adults with tinnitus

INTERVENTION: equivalence study (3 types of sound therapy devices that differed in the acoustic stimulus used); no control condition included

Characteristics of ongoing studies [ordered by study ID]

\section{ISRCTN15178771}

\begin{tabular}{ll}
\hline Trial name or title & Efficacy of a combination hearing aid and sound generator \\
\hline Methods & 2-arm, randomised, controlled (parallel) trial \\
\hline Participants & $\begin{array}{l}\text { Adults with tinnitus and hearing loss, GAD-7 anxiety screening: score from } 0 \text { to 9, indicating no anx- } \\
\text { iety or minimal to mild anxiety only, PHQ-9 depression screening: score from } 0 \text { to } 9, \text { indicating no } \\
\text { depression or minimal to mild depression only, TFI questionnaire: tinnitus symptoms ranging in } \\
\text { severity rating from } \geq 32 \text { to } \leq 71 \text { points }\end{array}$
\end{tabular}

Interventions

Intervention group 1: combination device

Intervention group 2: amplification only (hearing aid)

\begin{tabular}{ll}
\hline Outcomes & $\begin{array}{l}\text { Tinnitus Functional Index (TFI) to measure tinnitus severity, Tinnitus Acceptance Questionnaire } \\
\text { (TAQ), My Tinnitus document (self-report of symptoms), Hearing Handicap Inventory (HHIA/HHIE) } \\
\text { self-report measure of hearing-related disability, patient interviews at each visit }\end{array}$ \\
\hline Starting date & 1 April 2015 \\
\hline Contact information & $\begin{array}{l}\text { Dr David Baguley, National Institute for Health Research Nottingham Hearing Biomedical Research } \\
\text { Centre, Ropewalk House, 113 The Ropewalk, Nottingham, NG1 5DU }\end{array}$
\end{tabular}

Notes

ISRCTN Registry identifier: ISRCTN15178771. Contacted - trial ongoing.

\section{TCTR20180225002}

\begin{tabular}{ll}
\hline Trial name or title & A randomized controlled trial of music therapy in tinnitus patient \\
\hline Methods & 3-arm, double-blind, randomised, controlled (parallel) trial \\
\hline Participants & $\begin{array}{l}\text { Adults aged } 18 \text { to } 60 \text { years with tinnitus, Tinnitus Handicap Inventory score equal or more than 38, } \\
\text { General Health Questionnaire Score less than } 6\end{array}$ \\
\hline Interventions & $\begin{array}{l}\text { Intervention: Notch-Music (experimental) } \\
\text { Active comparator: conventional music } \\
\text { Control: counselling (counselling patients to ignore the tinnitus and find other activity to distract } \\
\text { themselves from tinnitus) }\end{array}$ \\
\hline Outcomes & Tinnitus Handicap Inventory, Pittsburgh Sleep Quality Index \\
\hline
\end{tabular}


TCTR20180225002 (Continued)

Starting date 23 February 2018

Contact information Chompunut Srisukhumchai, Khon Kaen University, Phone: +66 845105131, Email: csrisukhumchai@gmail.com, Postal Address: 916 Moo.12 Sila Muang Khon Kaen Thailand, State/Province: Khon Kaen, Postal Code: 40000, Country: Thailand

Notes

Thai Clinical Trials Registry identifier: TCTR20180225002

GAD-7: Generalised Anxiety Disorder assessment

PHQ-9: Patient Health Questionnaire-9

TFI: Tinnitus Functional Index

\section{DATA AND ANALYSES}

Comparison 1. Hearing aid only compared to sound generator only for tinnitus

\begin{tabular}{lllll}
\hline Outcome or subgroup title & No. of studies & $\begin{array}{l}\text { No. of partici- } \\
\text { pants }\end{array}$ & Statistical method & Effect size \\
\hline $\begin{array}{l}1 \text { Tinnitus symptom severity at } 3 \\
\text { months }\end{array}$ & 1 & 91 & $\begin{array}{l}\text { Mean Difference (IV, Fixed, 95\% } \\
\text { Cl) }\end{array}$ & $1.30[-5.72,8.32]$ \\
\hline $\begin{array}{l}2 \text { Tinnitus symptom severity at } 6 \\
\text { months }\end{array}$ & 1 & 91 & $\begin{array}{l}\text { Mean Difference (IV, Fixed, 95\% } \\
\text { Cl) }\end{array}$ & $-1.80[-8.82,5.22]$ \\
\hline $\begin{array}{l}3 \text { Tinnitus symptom severity at 12 } \\
\text { months }\end{array}$ & 1 & 91 & $\begin{array}{l}\text { Mean Difference (IV, Fixed, 95\% } \\
\text { Cl) }\end{array}$ & $-0.90[-7.92,6.12]$ \\
\hline
\end{tabular}

Analysis 1.1. Comparison 1 Hearing aid only compared to sound generator only for tinnitus, Outcome 1 Tinnitus symptom severity at $\mathbf{3}$ months.

\begin{tabular}{|c|c|c|c|c|c|c|c|}
\hline \multirow[t]{2}{*}{ Study or subgroup } & \multicolumn{2}{|c|}{ Hearing aid } & \multicolumn{2}{|c|}{ Sound generator } & \multirow{2}{*}{$\begin{array}{c}\text { Mean Difference } \\
\text { Fixed, } 95 \% \mathrm{Cl}\end{array}$} & \multirow[t]{2}{*}{ Weight } & \multirow{2}{*}{$\begin{array}{c}\text { Mean Difference } \\
\text { Fixed, } 95 \% \mathrm{Cl}\end{array}$} \\
\hline & $\mathbf{N}$ & Mean(SD) & $\mathbf{N}$ & $\operatorname{Mean}(S D)$ & & & \\
\hline Parazzini 2011 & 49 & $-18.9(18.4)$ & 42 & $-20.2(15.8)$ & . & $100 \%$ & $1.3[-5.72,8.32]$ \\
\hline 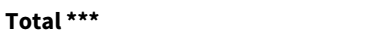 & 49 & & 42 & & & $100 \%$ & $1.3[-5.72,8.32]$ \\
\hline \multicolumn{8}{|l|}{ Heterogeneity: Not applicable } \\
\hline Test for overall effect: $Z=0.36(P=0.72)$ & & & & & & & \\
\hline & & & & Hearing aid & -10 & Sound $g$ & \\
\hline
\end{tabular}

Analysis 1.2. Comparison 1 Hearing aid only compared to sound generator only for tinnitus, Outcome $\mathbf{2}$ Tinnitus symptom severity at $\mathbf{6}$ months.

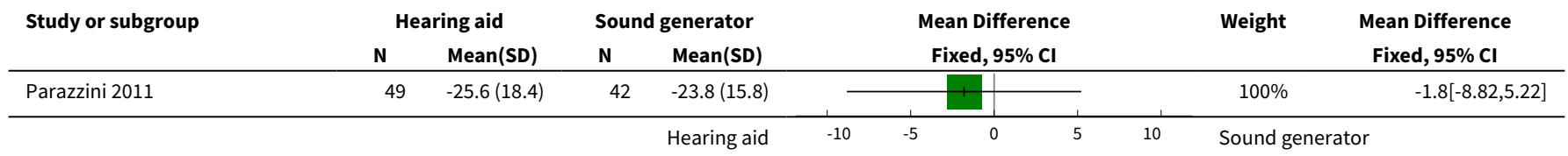




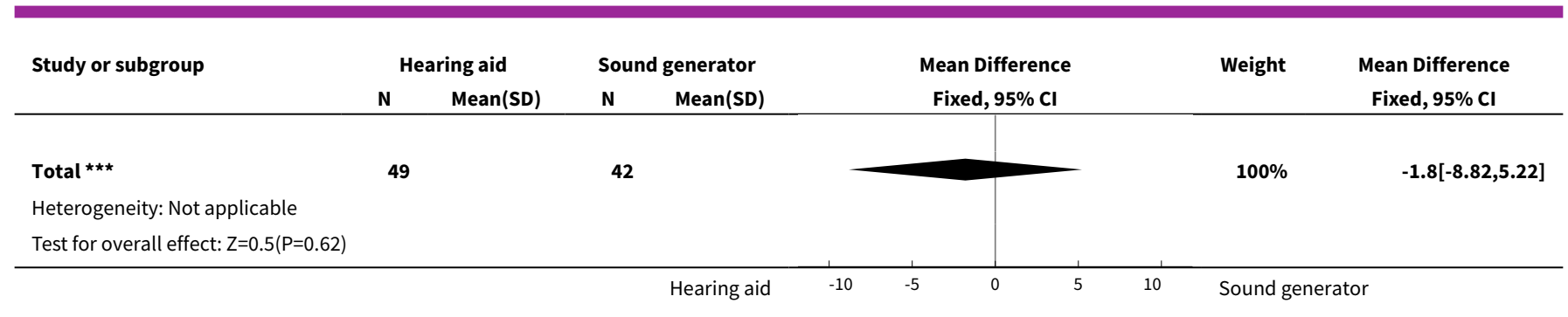

Analysis 1.3. Comparison 1 Hearing aid only compared to sound generator only for tinnitus, Outcome 3 Tinnitus symptom severity at 12 months.

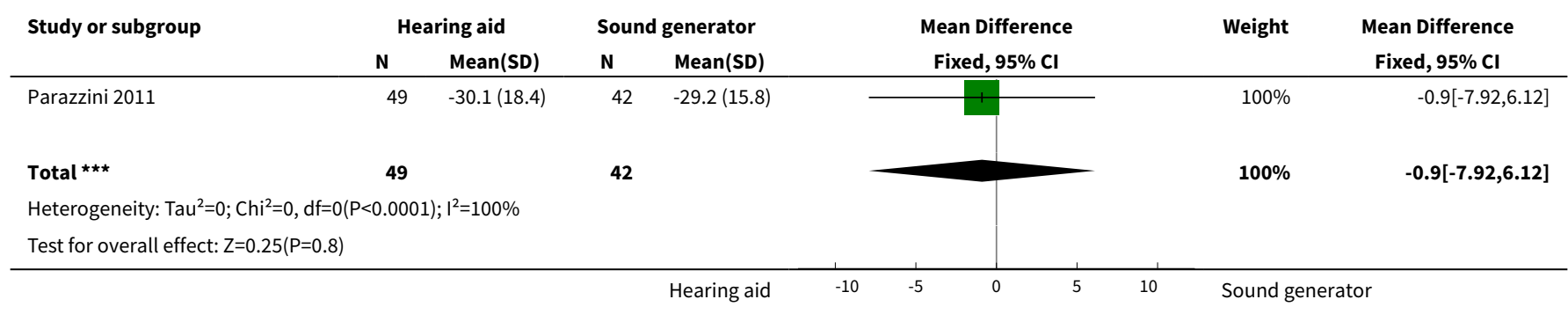

Comparison 2. Combination hearing aids compared to hearing aids for tinnitus

\begin{tabular}{lllll}
\hline Outcome or subgroup title & No. of studies & $\begin{array}{l}\text { No. of partici- } \\
\text { pants }\end{array}$ & Statistical method & Effect size \\
\hline $\begin{array}{l}1 \text { Tinnitus symptom severity at 3 to } 5 \\
\text { months }\end{array}$ & 3 & 114 & $\begin{array}{l}\text { Std. Mean Difference (IV, Fixed, } \\
95 \% \mathrm{Cl})\end{array}$ & $-0.15[-0.52,0.22]$ \\
\hline
\end{tabular}

Analysis 2.1. Comparison 2 Combination hearing aids compared to hearing aids for tinnitus, Outcome 1 Tinnitus symptom severity at 3 to 5 months.

\begin{tabular}{|c|c|c|c|c|c|c|c|}
\hline \multirow[t]{2}{*}{ Study or subgroup } & \multicolumn{2}{|c|}{$\begin{array}{l}\text { Combination } \\
\text { hearing aid }\end{array}$} & \multicolumn{2}{|c|}{ Hearing aid } & \multirow{2}{*}{$\begin{array}{l}\text { Std. Mean Difference } \\
\text { Fixed, } 95 \% \mathrm{Cl} \\
\end{array}$} & \multirow[t]{2}{*}{ Weight } & \multirow{2}{*}{$\begin{array}{l}\text { Std. Mean Difference } \\
\text { Fixed, } 95 \% \mathrm{Cl}\end{array}$} \\
\hline & $\mathbf{N}$ & $\operatorname{Mean}(\mathrm{SD})$ & $\mathbf{N}$ & Mean(SD) & & & \\
\hline dos Santos 2014 & 24 & $-28.2(18.6)$ & 23 & $-33.7(24.2)$ & -1 & $41.73 \%$ & $0.25[-0.33,0.82]$ \\
\hline Henry 2015 & 15 & $-39.3(26.2)$ & 15 & $-32.9(14)$ & & $26.54 \%$ & $-0.3[-1.02,0.42]$ \\
\hline Henry 2017 & 19 & $-33(26.2)$ & 18 & $-20.9(14)$ & - & $31.73 \%$ & $-0.56[-1.22,0.1]$ \\
\hline \multicolumn{8}{|c|}{ Heterogeneity: Tau $^{2}=0 ; \mathrm{Chi}^{2}=3.5, \mathrm{df}=2(\mathrm{P}=0.17) ; \mathrm{I}^{2}=42.78 \%$} \\
\hline \multicolumn{3}{|c|}{ Test for overall effect: $Z=0.8(P=0.42)$} & & & & & \\
\hline
\end{tabular}

\section{ADDITIONAL TABLES}


Table 1. Examples of questionnaires measuring tinnitus symptom severity

\begin{tabular}{llc}
\hline Measurement instrument (author, year) & Number of items and subscales & $\begin{array}{l}\text { Internal consistency } \\
\text { (Cronbach's alpha for } \\
\text { global score) }\end{array}$ \\
\hline Tinnitus Functional Index (Meikle 2012) & 25 items, 8 subscales & $a=07$ \\
\hline Tinnitus Handicap Inventory (Newman 1996) & 25 items, 3 subscales & $a=0.93$ \\
\hline Tinnitus Handicap Questionnaire (Kuk 1990) & 27 items, 3 subscales & $a=0.94$ \\
\hline Tinnitus Questionnaire (Hallam 1996) & 52 items, 5 subscales & $a .94$ \\
\hline Tinnitus Reaction Questionnaire (Wilson 1991) & 26 items, 4 subscales & $a=0.96$ \\
\hline Tinnitus Severity Scale (Sweetow 1990) & 15 items & Not reported
\end{tabular}

\section{APPEN DICES}

\section{Appendix 1. Search strategies}

\begin{tabular}{|c|c|c|}
\hline CENTRAL (CRS) & MEDLINE (Ovid) & Embase (Ovid) \\
\hline $\begin{array}{l}1 \text { MESH DESCRIPTOR Tinnitus EXPLODE ALL } \\
\text { AND CENTRAL:TARGET }\end{array}$ & 1. exp Tinnitus/ & 1. exp tinnitus/ \\
\hline & 2. tinnit*.ab,ti. & 2. tinnit*.ab,ti. \\
\hline $\begin{array}{l}2 \text { (tinnit }^{\star} \text { ):AB,EH,KW,KY,MC,MH,TI,TO AND } \\
\text { CENTRAL:TARGET } 1\end{array}$ & 3. 1 or 2 & 3. 1 or 2 \\
\hline 3 \#1 OR \#2 AND CENTRAL:TARGET & 4. exp Hearing Aids/ & 4. exp hearing aid/ \\
\hline 4 MESH DESCRIPTOR Hearing Aids EXPLODE & 5. exp Perceptual Masking/ & 5. exp auditory stimulation/ \\
\hline ALL AND CENTRAL:TARGET & 6. exp Acoustic Stimulation/ & 6. exp music therapy/ \\
\hline $\begin{array}{l}5 \text { MESH DESCRIPTOR Perceptual Masking EX- } \\
\text { PLODE ALL AND CENTRAL:TARGET }\end{array}$ & 7. Combined Modality Therapy/ & 7. exp auditory masking/ \\
\hline $\begin{array}{l}6 \text { MESH DESCRIPTOR Acoustic Stimulation EX- } \\
\text { PLODE ALL AND CENTRAL:TARGET }\end{array}$ & $\begin{array}{l}\text { 8. exp Music Therapy/ } \\
\text { 9. souND/th, tu [Therapy, Thera- }\end{array}$ & $\begin{array}{l}\text { 8. (((hearing or tinnitus) adj3 aid?) or ear- } \\
\text { mold? or (ear adj3 mold?)).ab,ti. }\end{array}$ \\
\hline 7 MESH DESCRIPTOR Combined Modality & peutic Use] & 9. (mask ${ }^{\star}$ or amplification).ab,ti. \\
\hline $\begin{array}{l}8 \text { MESH DESCRIPTOR Music Therapy EXPLODE } \\
\text { ALL AND CENTRAL:TARGET }\end{array}$ & $\begin{array}{l}\text { 10. (((hearing or tinnitus) adj3 } \\
\text { aid?) or earmold? or (ear adj3 } \\
\text { mold?)).ab,ti. }\end{array}$ & $\begin{array}{l}\text { 10. ("therapeutic sound?" or "therapeutic } \\
\text { noise?" or "white noise?" or "tinnitus instru- } \\
\text { ment?" or "combination instrument?" or } \\
\text { "combination device?" or "static noise?" }\end{array}$ \\
\hline $\begin{array}{l}9 \text { MESH DESCRIPTOR Sound WITH QUALIFIER } \\
\text { TU,TH AND CENTRAL:TARGET }\end{array}$ & $\begin{array}{l}\text { 11. (mask or amplification).ab,ti. } \\
\text { 12. ("therapeutic sound?" or "ther- } \\
\text { apeutic noise?" or "white noise?" }\end{array}$ & $\begin{array}{l}\text { or "tinnitus device?" or "relief product?" or } \\
\text { "puretone device?" or "puretone tinnitus" or } \\
\text { "tinnitus system?").ab,ti. }\end{array}$ \\
\hline $\begin{array}{l}10 \text { (((hearıng or tınnitus) NEAR (aid or aids)) } \\
\left.\left.\text { or earmold* or (ear NEAR mold }{ }^{\star}\right)\right): \text { AB,EH,K- } \\
\text { W,KY,MC,MH,TI,TO AND CENTRAL:TARGET } 657\end{array}$ & $\begin{array}{l}\text { or "tinnitus instrument?" or "com- } \\
\text { bination instrument?" or "combi- } \\
\text { nation device?" or "static noise?" }\end{array}$ & $\begin{array}{l}\text { 11. (tinnitech* or starkey }{ }^{\star} \text { or ultraquiet }{ }^{\star} \text { or } \\
\text { LTWN or MML or TCl or TRD or hisonic }^{\star} \text { or } \\
\text { oticon or phonak or ReSound or widex or }\end{array}$ \\
\hline $\begin{array}{l}11 \text { (mask* or amplification):AB,EH,KW,KY,M- }^{*} \\
\text { C,MH,TI,TO AND CENTRAL:TARGET }\end{array}$ & $\begin{array}{l}\text { or "tinnitus device?" or "relief } \\
\text { product?" or "puretone device?" } \\
\text { or "puretone tinnitus" or "tinnitus } \\
\text { system?").ab,ti }\end{array}$ & $\begin{array}{l}\text { siemens or audeo or alta or zen or danalogic } \\
\text { or audimed or ipod).ab,ti. }\end{array}$ \\
\hline
\end{tabular}


(Continued)

12 ("therapeutic sound*" or "therapeutic noise*" or "white noise" or "tinnitus instrument ${ }^{\star}$ " or "combination instrument ${ }^{\star}$ " or "combination device ${ }^{\star "}$ or "static noise" or "tinnitus device*" or "relief product ${ }^{\star}$ or "puretone device*" or "puretone tinnitus" or "tinnitus system*"):AB,EH,KW,KY,MC,MH,TI,TO AND CENTRAL:TARGET

13 (tinnitech* OR starkey * OR ultraquiet* or LTWN or MML or TCI or TRD or hisonic* or oticon or phonak or ReSound or widex or siemens or audeo or alta or zen or danalogic or audimed or ipod):AB,EH,KW, KY,MC,MH,TI,TO AND CENTRAL:TARGET

14 ((auditory or audio or acoustic or noise* or sound $^{*}$ or music or audio) NEAR (stimulat* or generator? or device? or frequency or stimulus)):AB,EH,KW,KY,MC,MH,TI,TO AND CENTRAL:TARGET

15 ((noise* or sound ${ }^{*}$ or music) near (therap* or training or treatment? or frequency or intervention?)):AB,EH,KW,KY,MC,MH,TI,TO AND CENTRAL:TARGET

16 (tinnitus near pitch ${ }^{\star}$ near match ${ }^{\star}$ ):AB,EH,KW,KY,MC,MH,TI,TO AND CENTRAL:TARGET

17 \#4 OR \#5 OR \#6 OR \#7 OR \#8 OR \#9 OR \#10 OR \#11 OR \#12 OR \#13 OR \#14 OR \#15 OR \#16 AND CENTRAL:TARGET

18 \#17 AND \#3 AND CENTRAL:TARGET 408
13. (tinnitech ${ }^{\star}$ or starkey ${ }^{\star}$ or ultraquiet* or LTWN or MML or TCI or TRD or hisonic* or oticon or phonak or ReSound or widex or siemens or audeo or alta or zen or danalogic or audimed or ipod).ab,ti.

14. ((auditory or audio or acoustic or noise? or sound? or music or audio) adj3 (stimulat* or generator? or device? or frequency or stimulus)).ab,ti.

15. ((noise? or sound? or music) adj3 (therap*or training or treatment? or frequency or intervention?)).ab,ti.

16 (tinnitus adj3 pitch* adj3 match $\left.^{\star}\right) \cdot$ ab,ti.

\section{7. or/4-16}

18. 3 and 17

19. randomized controlled trial.pt.

20. controlled clinical trial.pt.

21. randomized.ab.

22. placebo.ab.

23. drug therapy.fs.

24. randomly.ab.

25. trial.ab.

26. groups.ab.

27.18 or 19 or 20 or 21 or 22 or 23 or 24 or 25

28. exp animals/ not humans.sh.

29. 27 not 28

30. 18 and 98491
12. ((auditory or audio or acoustic or noise? or sound? or music or audio) adj3 (stimulat* or generator? or device? or frequency or stimu(us)).ab,ti.

13. ((noise? or sound? or music) adj3 (thera$\mathrm{p}^{*}$ or training or treatment? or frequency or intervention?)).ab,ti.

14. (tinnitus adj3 pitch* adj3 match*).ab,ti.

15. or/4-14

16. 3 and 15

17. (random* or factorial ${ }^{*}$ or placebo* or assign $^{\star}$ or allocat ${ }^{\star}$ or crossover $\left.^{\star}\right)$.tw.

18. (control* adj group $\left.{ }^{\star}\right)$.tw.

19. (trial ${ }^{\star}$ and (control* or comparative)).tw.

20. ((blind ${ }^{\star}$ or mask ${ }^{\star}$ ) and (single or double or triple or treble)).tw.

21. (treatment adj $\left.\operatorname{arm}^{\star}\right)$.tw.

22. (control ${ }^{\star}$ adj group $\left.{ }^{\star}\right)$.tw.

23. (phase adj (III or three)).tw.

24. (versus or vs).tw.

25. rct.tw.

26. crossover procedure/

27. double blind procedure/

28. single blind procedure/

29. randomization/

30. placebo/

31. exp clinical trial/

32. parallel design/

33. Latin square design/

34. 17 or 18 or 19 or 20 or 21 or 22 or 23 or 24 or 25 or 26 or 27 or 28 or 29 or 30 or 31 or 32 or 33

35. $\exp$ ANIMAL/ or exp NONHUMAN/ or exp ANIMAL EXPERIMENT/ or exp ANIMAL MODEL/

36. exp human/

37.35 not 36

38. $34 \operatorname{not} 37$

39. 16 and 38512 


\section{CONTRIBUTIONS OFAUTHORS}

MS and DJH conceived and all authors contributed to the design of the study.

The Cochrane ENT Information Specialist developed and ran the search strategy.

MS obtained copies of studies with the assistance of the University of Nottingham library.

MS, AER and DAH were responsible for selection of studies.

MS, DJH, AER and JX were responsible for data extraction.

MS, DJH, AER and JX were responsible for assessing risk of bias.

MS entered data into RevMan.

MS conducted the analysis.

MS, DJH and JX interpreted the analysis.

MS, DJH and JX drafted the final review.

MS and DJH will be responsible for updating the review.

All authors agreed on the final draft.

\section{DECLARATIONS OF INTEREST}

Magdalena Sereda: MS is funded through the British Tinnitus Association Senior Research Fellow/Head of Research Fellowship. MS is Chief Investigator on NIHR Research for Patient Benefit grant 'Feasibility of conducting a multi-centre RCT to assess effectiveness and costeffectiveness of digital hearing aids in patients with tinnitus and hearing loss'. MS is a member of the Steering Committee for British Society of Audiology Tinnitus and Hyperacusis Special Interest Group and leading on the development of the BSA recommended procedure for candidacy and fitting of combination hearing aids. MS is a Principal Investigator on the British Society of Audiology Applied Research Grant supporting the development of the recommended procedure.

Jun Xia: none known.

Amr El Refaie: none known.

Deborah A Hall: DAH is an NIHR Senior Investigator and Section Editor for the journal Hearing Research, Elsevier. She leads the Core Outcome Measures in Tinnitus (COMiT) initiative whose work is currently supported by the European Union's Horizon 2020 research and innovation programme under the Marie Skłodowska-Curie grant agreement No 764604 and the NIHR Nottingham Biomedical Research Centre.

Derek J Hoare: DJH is Associate Editor for the International Journal of Audiology and BMC Health Services Research, and Chair of the British Society of Audiology tinnitus and hyperacusis special interest group. He is funded by the NIHR and research lead for tinnitus and hyperacusis at the NIHR Nottingham Biomedical Research Centre. He has received tinnitus research funding from the British Society of Audiology, the British Tinnitus Association and the NIHR.

\section{SOURCES OF SUPPORT}

\section{Internal sources}

- No sources of support supplied

\section{External sources}

- National Institute for Health Research, UK.

Infrastructure funding for Cochrane ENT

- This work was part funded through an NIHR Senior Investigator award, UK.

This is awarded to DAH 


\section{DIFFERENCES BETWEEN PROTOCOL AND REVIEW}

We planned to perform a network meta-analysis, however this was not possible due to limited data from four included studies.

We have included two 'Summary of findings' tables for additional comparisons for which we had data available (i.e. hearing aids versus sound generators and combination devices versus hearing aids).

\section{INDEX TERMS}

\section{Medical Subject Headings (MeSH)}

*Hearing Aids; ${ }^{\star}$ Sound; Acoustic Stimulation [ ${ }^{*}$ methods]; Randomized Controlled Trials as Topic; Tinnitus [ ${ }^{\star}$ therapy]

\section{MeSH check words}

Adult; Humans 